San Jose State University

SJSU ScholarWorks

Master's Theses

Master's Theses and Graduate Research

2003

\title{
Experimental testing of a lateral seismic connection for concrete cladding panels
}

Carter Choi

San Jose State University

Follow this and additional works at: https://scholarworks.sjsu.edu/etd_theses

\section{Recommended Citation}

Choi, Carter, "Experimental testing of a lateral seismic connection for concrete cladding panels" (2003).

Master's Theses. 2514.

DOI: https://doi.org/10.31979/etd.55k2-8bnu

https://scholarworks.sjsu.edu/etd_theses/2514

This Thesis is brought to you for free and open access by the Master's Theses and Graduate Research at SJSU ScholarWorks. It has been accepted for inclusion in Master's Theses by an authorized administrator of SJSU ScholarWorks. For more information, please contact scholarworks@sjsu.edu. 


\title{
EXPERIMENTAL TESTING OF A \\ LATERAL SEISMIC CONNECTION \\ FOR CONCRETE CLADDING PANELS
}

\author{
A Thesis \\ Submitted To \\ The Faculty of the Department of Civil \\ and Environmental Engineering \\ San Jose State University \\ San Jose, California
}

\author{
In Fulfillment \\ Of the Requirements for the Degree \\ Master of Science
}

by

Carter Choi

December 2003 
UMI Number: 1418743

\section{INFORMATION TO USERS}

The quality of this reproduction is dependent upon the quality of the copy submitted. Broken or indistinct print, colored or poor quality illustrations and photographs, print bleed-through, substandard margins, and improper alignment can adversely affect reproduction.

In the unlikely event that the author did not send a complete manuscript and there are missing pages, these will be noted. Also, if unauthorized copyright material had to be removed, a note will indicate the deletion.

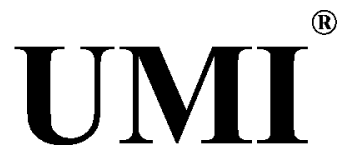

UMI Microform 1418743

Copyright 2004 by ProQuest Information and Learning Company.

All rights reserved. This microform edition is protected against unauthorized copying under Title 17, United States Code.

ProQuest Information and Learning Company 300 North Zeeb Road

P.O. Box 1346

Ann Arbor, MI 48106-1346 
(C) 2003

Carter Choi

ALL RIGHTS RESERVED 
APPROVED FOR THE DEPARTMENT OF CIVIL AND ENVIRONMENTAL ENGINEERING

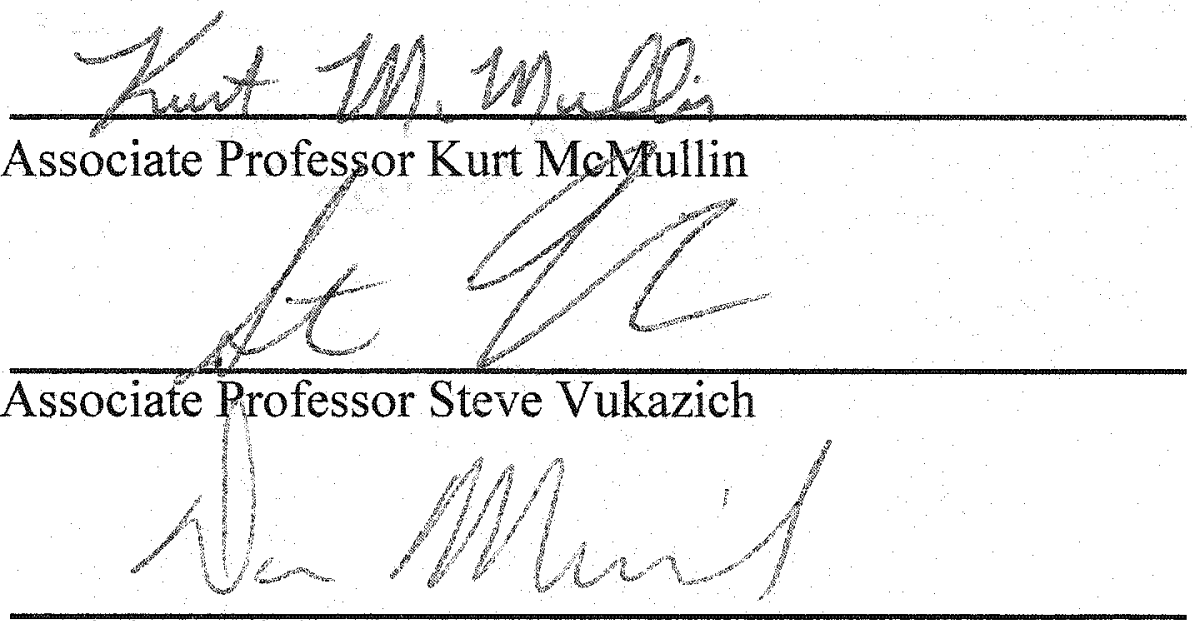

Daniel Merrick

\section{APPROVED FOR THE UNIVERSITY}

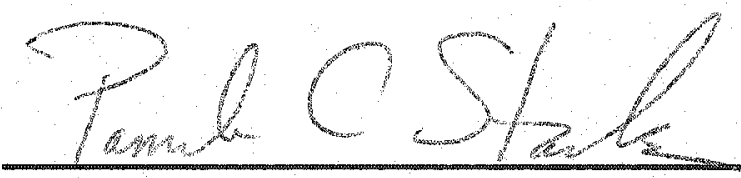




\title{
ABSTRACT \\ EXPERIMENTAL TESTING OF A LATERAL SEISMIC CONNECTION FOR CONCRETE CLADDING PANELS
}

\author{
By Carter Choi
}

Three full-scale specimens tested the components of a lateral seismic connection that supports precast concrete cladding panels. The objective was to investigate the behavior of this cladding connection through in-plane and out-of-plane monotonic panel movement. The first experiment, LSC1, was conducted with pure axial loading, representing in-plane movement of the panel. LSC2 and LPC3 were subjected to out-ofplane movement inducing bending of the specimen away from the column.

Test results compared the strength and displacement of the designed connection and the actual loading that the specimens sustained during testing. Experimental data obtained were compared to predictions based upon various analytical models. LSC1 resulted in a maximum load of $307 \mathrm{kN}$ at $17 \mathrm{~mm}$ of displacement and an energy dissipation of $2829 \mathrm{kN}-\mathrm{mm}$. LSC2 resulted in a maximum load of $154 \mathrm{kN}$ at $8.8 \mathrm{~mm}$ of displacement and an energy dissipation of $1353 \mathrm{kN}-\mathrm{mm}$. Similarly, LPC3 resulted in a maximum load of $326 \mathrm{kN}$ at $67 \mathrm{~mm}$ of displacement along with an energy dissipation of $18289 \mathrm{kN}-\mathrm{mm}$. 
In Dedication and Loving Remembrance Of my Longtime Friend Alexander Brian Chen 


\section{ACKNOWLEDGMENTS}

I would like to express my thanks and gratitude to San Jose State University and the Department of Civil and Environmental Engineering for providing me the opportunity to work on this research. This research provided me hands on opportunity to design, construct, and test an intricate component of cladding connection. I would like to express my gratitude and appreciation to Daniel Merrick and Associate Professor Steve Vukavich for their assistance in reviewing this report.

I wish to thank Willis Construction for providing the drawing of the lateral seismic connection. Without these drawings, accurate representations of the dimensions would not have been duplicated for this study.

I wish to express my utmost gratitude to the University's technicians who helped with fabrication of these specimens. Most notably Dave Hemer and Pat Joice without whose help, especially Pat, I would not have been able to finish my research in time to graduate. I am forever grateful for Pat Joice's expertise in welding and assistance in

assembling the testing arrangement and specimens. I will forever remember my experience working in the lab.

I also wish to thank my fellow student Kevin Chan for his assistance with this research. This past year has been very memorable, working side by side in the lab, checking each other's work, and his aid in fabrication.

In addition, I would like to thank Associate Professor Kurt McMullin for his guidance and wonderful knowledge during this research. I am very grateful for Kurt's assistance in reviewing this report and providing a great experience working on this research.

Finally, I wish to thank my parents and family who have been patient and supportive in reaching my goal: my parents Robert and Linda Choi, grandmother Sui Ying Leung Choi, and siblings Maria, Christopher, and Giselle. 


\section{TABLE OF CONTENTS}

Abstract.......................................................................... iv

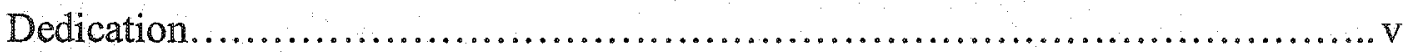

Acknowledgements............................................................

List of Tables ................................................................. ix

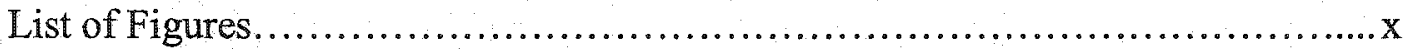

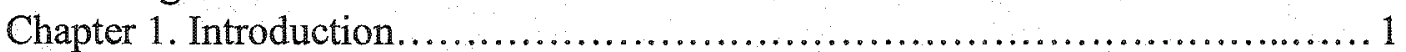

1.0 Introduction ..............................................................

1.1 Problem Statement....................................................... 3

1.2 Project Goals and Objectives.........................................4

1.3 Scope of Work....................................................... 5

Chapter 2. Literature Review.............................................. 6

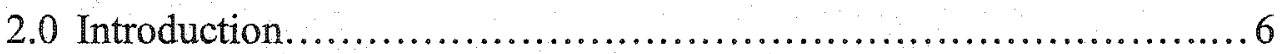

2.1 Research of Connection Behavior................................. 7

2.2 Research on Construction Coordination Issues........................ 9

2.3 Existing Design Code Requirements.................................... 10

2.4 Implementation of Past Research into Current Study.................... 12

Chapter 3. Experimental Design................................................. 13

3.0 Introduction.......................................................... 13

3.1 Failure Modes and Damage Thresholds.............................. 14

3.2 Experimental Specimen............................................... 15

3.3 Testing Arrangement............................................. 16

3.4 Instrumentation................................................... 18

3.5 Testing Procedure................................................ 19

3.6 Predicted Results.................................................... 22

3.6.1 Predicted Results of LSC1 ................................22

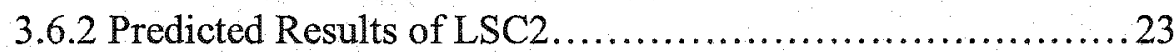

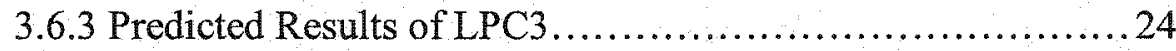

3.7 Variation from Original Testing Program.............................25

Chapter 4. Experimental Results................................................27

4.0 Introduction........................................................ 27

4.1 Behavior of Test Specimens.................................... 27

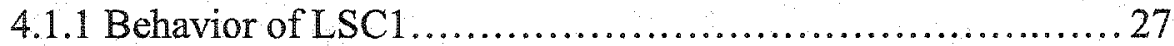

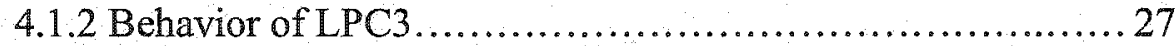

4.1.3 Behavior of LSC2 .........................................29

4.2 Observed Failure Modes............................................ 30

4.3 Results for Individual Tests...................................... 31

4.3.1 Results of LSC1 Test........................................ 32

4.3.2 Results of LPC3 Test.......................................... 33

4.3.3 Results of $\mathrm{LSC} 2$ and $\mathrm{LSC} 2 \mathrm{R}$ Test........................ 35

4.3 .4 Ductility of Test...............................................39

4.4 Variation from Expected Test Specimen and Procedure................. 40 
Chapter 5. Comparison of Test Results........................................ 41

5.1 Secant and Tangent Stiffness of Experiments......................... 41

5.2 Performance Levels................................................ 42

5.3 Comparison of Predicted and Experimental Values..................... 43

5.3.1 Accuracy of Predictive Models................................43

5.3.2 Out-of-Plane Connection Behavior...............................43

5.4 Combined Out-of-Plane Behavior..................................... 44

5.5 Similar Results of All Tests.......................................... 45

5.6 Effect of Change of Test Variables.......................................44

Chapter 6. Conclusions and Recommendations..................................47

6.1 Results of Original Research Objectives............................... 47

6.2 Conclusions..........................................................47

6.3 Recommendations for Engineering Practice............................49

6.4 Recommendations for Continuation of Research...................... 50

References................................................................. 51

Appendix A. Notations......................................................... 53

Appendix B. Glossary ...................................................... 55

Appendix C. Tables.......................................................... 57

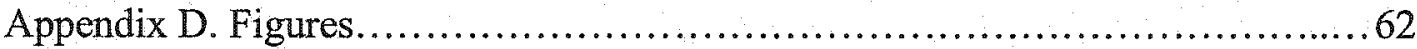

Appendix E. Test Summaries and Material Tests................................ 99

Appendix F. Calibration Charts of Instrumentation............................. 115

Appendix G. Supporting Calculations......................................... 120 


\section{LIST OF TABLES}

Table 1

Table 2

Table 3

Table 4

Table 5

Table 6

Table 7

Table 8

Table 9

Table 10

Table 11

Table 12
FEMA-273 Cladding Component

Performance Levels (1997) ...............................557

Experimental Test Matrix................................ 57

Predicted Results of Experiment: LSC1 ................... 57

Predicted Results of Experiment: LSC2/LSC2R ............58

Predicted Results of Experiment: LPC3 .................... 58

Instrumentation of Experiment: LSC1 ...................58

Instrumentation of Experiment: LSC2/LSC2R...............59

Instrumentation of Experiment: LPC3 .....................59

Comparison of Predicted and Actual Strength................559

Ductility and Energy of Test Specimens...................6 60

Stiffness Method for Defining Yield....................... 60

Displacement Damage Thresholds for

Performance Based Design...............................6 61 


\section{LIST OF FIGURES}

Fig. $1 \quad$ Lateral Seismic Connection based upon Detail

Drawings provided by Willis Construction........................6 62

Fig. 2 Intended Designed Loading of Lateral Seismic Connection......... 63

Fig. 3 Three Main Components in an Advanced Cladding

Connection (Pinelli et al, 1992) ....................................6 63

Fig. $4 \quad$ Slotted Bolted Connection (Pinelli et al, 1996).....................64

Fig. 5 Tapered Connection Geometry of

Slotted Bolted Connection (Pinelli et al, 1996).....................65

Fig. 6

Fig. 7

LSC 1 Test Specimen............................................66 66

Fig. 8

LSC1 Force Loading Diagram..................................66

Fig. 9

LSC2 Test Specimen.........................................67

Fig. 10

LSC2 Force Loading Diagram...................................67 67

Fig. 11

LPC3 Test Specimen.............................................66

Fig. 12

Fig. 13

Fig. 14

Enlarged Section of Rod Region of LPC3 ........................69

LPC3 Force Loading Diagram..................................... 70

Fig. 15

Whitewashed Side B of LPC3 before Loading......................70

Fig. 16

Photograph of LSC1 Test Arrangement........................... 71

Reaction Blocks for LSC2 and LPC3 ............................... 71

Fig. 17

Fig. 18

Fig. 19

Reaction Frame with W16x40 Beam Attached................... 72

Test Arrangement of LSC2 ......................................... 73

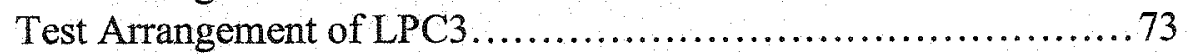

Fig. 20

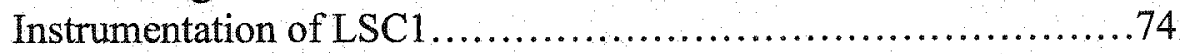

Fig. 21

Fig. 22

Wire Potentiometer on the Plate of LSC2 and LSC2R..............74

Diagram of Instrumentation used in Testing, LSC2.................75

Fig. 23

Fig. 24

Diagram of Instrumentation used in Testing, LPC3 ................ 76

Instrumentation on Side A of the Tube of LPC $3 \ldots \ldots \ldots \ldots \ldots \ldots \ldots . \ldots 77$

Fig. 25

Fig. 26

Fig. 27

Eccentric Loading of LSC1 ...................................... 78

Cantilever Displacement of the Tube and Plate.................... 78

Weld Dimension of LSC1 ........................................79

Weld Dimension of LSC2 .......................................8 80

Fig. 28 Plate Deformation on Side B of LSC2 Prior to Retest................81

Fig. 29a Weld Dimension of LPC3 Side A................................ 82

Fig. 29b Weld Dimension of LPC3 Side B............................. 83

Fig. $30 \quad$ Lime-Coated Side B of LPC3 Specimen............................8 84

Fig. 31 Flaking and Initial Yielding Detected at $1 / 2$ in. of Movement.......... 84

Fig. 32 Local Bending of the Tube Wall at 1 in. of Movement................ 85

Fig. 33 Local Bending of the Tube Wall at 2.7in. of Movement............. 85

Fig. 34 Local Bending of the Tube Wall on Side B

of Column for Test LPC3........................................ 86

Fig. $35 \quad$ Bowing of the Tube for LPC3 ................................ 86

Fig. $36 \quad$ Initial Crack on the Weld Return on Side B of LPC3 ................87 
Fig. 37

Fig. 38

Fig. 39

Fig. 40

Fig. 41

Fig. 42

Fig. 43

Fig. 44

Fig. 45

Fig. 46

Fig. 47

Fig. 48

Fig. 49

Fig. 50

Fig. 51

Fig. 52

Fig. 53

Fig. 54

Fig. 55

Fig. 56
Complete Weld Fracture of LPC3 Specimen......................87

Lime-Coated Side B of LSC2 ..................................... 88

Flaking of Lime-Coat on Side B of LSC2 ....................... 88

Weld Fracture on Side A of LSC2R .............................. 89

Weld Fracture at the Bottom Plate of LSC1 .........................90

LSC1 In-Plane Force Displacement Graph....................... 91

LSC1 Force-Displacement Graph Measuring Twist of the Angle....91

LPC3 Force-Displacement Graph at the Connection................92

LPC3 Force Versus Displacement of the Rod

Stretching, Dishing, and Bending of the Tube.....................92

LPC3 Force versus Displacement of the Tube

Bending (Ch 5) and Dishing of the Tube........................... 93

LSC2 Force-Displacement Graph at the Connection.................93

LSC2 Comparison of Tip and Mid-length Displacement per Angle. 94

LSC2 Torque versus Twist at the Tip of the Plate (Side A).........94

LSC2R Force-Displacement Graph at the Connection...............95

LSC2R Comparison of Tip and Mid-Length

Displacement per Angle...........................................995

LSC2R Torque versus Twist at the Tip of the Plate (Side A)....... 96

Procedure for Determining the Offset Yield Displacement...........96

Illustrates the Original Tangent Stiffness Graph of LPC3 ............97

Tangent Stiffness Curve after Smoothing of LPC3 .................97

Total Force of LSC2 and LPC3 versus Displacement

of the Lateral Seismic Connection. 98 


\section{CHAPTER 1. \\ INTRODUCTION}

\subsection{Introduction}

With the advancement of technology and construction practices, current exteriors of modern buildings are covered with architectural precast concrete cladding systems. Precast concrete cladding panels were once viewed as dead weights that carry little structural load or offer minimal seismic response towards a building. In other words, cladding was expected to survive an earthquake, but with little definition as to the expected performance. Currently, precast concrete cladding not only provides a distinct architectural purpose but also serves as an enclosure for a building's function, and ultimately the ability to transfer lateral forces such as wind and temperature variations from the cladding to the supporting frame.

Potential structural uses of cladding began to gain ground in the late eighties and nineties when extensive research aimed to determine whether cladding could increase ductility and lateral stiffness towards a structure during a seismic event. Results of recent studies confirmed that the connection between the concrete panel and steel frame is vital in accurately evaluating the role that precast concrete cladding connections attains under seismic influence. According to publications by Rihal, precast concrete claddings are especially important towards a structure's seismic damage level (Rihal, 1988).

The failure of cladding connections and concrete panels can pose a potential life hazard as characterized in Table 1 , based upon nonstructural performance levels. (FEMA-273, 1997) Through additional research, precast concrete cladding has been noted to significantly influence the behavior and response of a building's structure system. Cladding connections are important in buildings with lateral force resisting steel frame systems or concrete rigid frames used in moment resisting systems (Rihal, 1988). According to previous authors, hysteretic damping augmentation using ductile cladding connections have been shown to reduce seismic response and improve a buildings performance by having inelastic deformation of cladding panels dissipate seismic energy. 
(Weston et al, 2000). However, the potential to use ductile cladding connections as a control mechanism to dissipate seismic energy under severe earthquakes has not been incorporated within current standards nor was this method found to be economically feasible (Weston et al, 2000).

There are numerous precast concrete cladding connections that are utilized in the construction industry today, such as a push-pull connection, tie-back connection, bearing connection, and alignment connection. (PCI, 1999) There have been studies conducted by previous scholars on push-pull connection and more advanced cladding connections. This study will primarily focus on the lateral seismic connection. One style of a lateral seismic connection was used during the construction of the new San Jose State University Martin Luther King library, a joint facility with the City of San Jose. Push-pull and lateral seismic connections were two types of cladding connections that were used to connect the precast cladding to the moment frame structure. Willis Construction Company, a specialist in pre-cast concrete products, provided details of this connection for this study as shown in Figure 1. Lateral seismic connection is a connection that consists of many components, such as a TS section, L-shape, a leveling bolt, a $25 \mathrm{~mm} \mathrm{x}$ $125 \mathrm{~mm} \times 685 \mathrm{~mm}(1 \times 5 \times 27)$ plate, and various $8 \mathrm{~mm}\left(5 / 16^{\prime \prime}\right)$ fillet welds that connect the components together. Due to the connections many components, this connection was separated and tested in three specimens.

Lateral seismic connection, LSC, has two important components, the plate that connects the connection to the column and the push-pull connection assembled from a rod and tube that connects the precast panel to the structure. The intent of the $25 \mathrm{~mm}$ (1in) plate is to resist any loading that is parallel to the plane of the panel. The plate is field welded to the angle and column. Under pure seismic loading the plate restricts the panel from moving horizontally (in-plane to the panel). The plate is intended to resist all horizontal loading that is parallel to the plane of the panel. The tube and rod connection, otherwise known as push-pull, resists out-of-plane movement of the panel due to wind or seismic loading. Another loading that the push-pull of the lateral seismic connection 
resists is the moment from the panel due to gravity loading. LSC was designed to combine both components to act as one unit to resist gravity, wind, and seismic loading.

\subsection{Problem Statement}

Pushover analysis of a cladding panel was initially performed by Kwong and McMullin (2002). Detailed force displacement relationships for Kwong and McMullin's model connection were missing for this research and thus the model assumed a push-pull connection in pure tension or compression for all analysis based on simple mechanics. Accurate information was necessary because Kwong had to make simplistic assumptions about deflections and forces of the connection for her research. The current studies on lateral seismic connection was initiated in order to fulfill the assumptions that were made in Kwong's non-linear analysis of all four connections in the pushover analysis.

The sequence of failure modes will be evaluated through monotonic experiments, the intended loading direction, and out-of-plane loading of the lateral seismic connection. This investigation will explore the characteristics of this one connection, in hopes that a better understanding of cladding connections can be obtained and further developed in terms of maintaining a reflective model of this connection.

This study compares the intended loading of the designed connection versus the actual loading that the specimens sustain during testing. Figure 2 reveals the intended loading for the designed connection. The design of the lateral seismic connection was intended to restrict lateral movement of the panels in-plane and out-of-plane movement. The plate of the lateral seismic connection is expected to be loaded in pure tension or compression, thereby restricting horizontal in-plane movement of the panel. The push-

pull rod is expected to be loaded in tension or compression, which will eventually bend the tube. The push-pull restricts movement of the panel in and out-of-plane.

In this study, LSC1 (plate) and LPC3 (push-pull) were loaded in their intended design mode. On the other hand, LSC2 was loaded through bending of the plate, which represents an unintended response. The design of this component was not expected to resist loading of the panel moving out-of-plane. In this case, the plate is loaded outwards, 
away from the W12 column. Based on time and financial constraints, this study focused solely on the monotonic force deflection and stiffness values of the intended loading of in-plane testing of LSC1, intended out-of-plane loading of LPC3, and the unintended outof-plane loading of LSC2.

Preliminary calculations and initial predictions were based upon a nominal strength that was compared to actual strengths of the test specimens. The analyzed data of the three studies should allow designers and engineers to accurately estimate the strength, ductility, stiffness, and predictive model of this connection. New information can hopefully be concluded from this study of the lateral seismic connection, leading to an efficient and effective design based on the behavior of this connection.

\subsection{Project Goals and Objectives}

The goal of this research was to gain insight into the sequence of seismic failure modes of the lateral seismic connection design. This study defines the strength and stiffness of this connection in response to resisting intended and unintended modes of loading.

There are four objectives to this research:

- To measure the force-deflection relationship of each specimen

- To develop an analytical and predictive model of this connection

- To determine the accuracy of the predictive model in respect to the failure modes

- To define deflections representing the threshold for potential damage levels associated with FEMA performance levels

Failure modes of the three specimens were sequenced from the lowest strength to the highest to define the expected order of failure. All experiments were monotonically loaded and the strength, stiffness, and deflection values for each specimen were measured. 


\subsection{Scope of Work}

This experiment was proposed after considering past studies of various cladding connections by previous scholars. The lack of published research for this specific connection and the need to supplement Kwong and McMullin's (2002) model spurred the investigation. The majority of fabrication work of the testing arrangement and the experimental specimens for this connection were conducted in the Engineering building of San Jose State University.

This report represents the conclusion of a six-credit independent study project. Three full-scale specimens were constructed with various steel geometric parameters that varied with each experiment. This study began in January of 2002, with a projected completion within a year. However, due to the complexity of fabricating the test arrangement, the actual duration of the study lasted a year and a half to completion of the final report. Initial calculations, test setup, and design of testing arrangement occurred over the duration of eight months. Fabrication of the specimens took place during the late summer months and into the winter of 2002. Fabrication of these specimens and especially the testing arrangement were found to be time consuming. The machinery in the central shop of the engineering facility was used to cut and drill bolt holes in the specimens and testing arrangement. The geometry of specimens in this research were cut and welded to replicate the exact lengths based on Willis Construction's drawings.

The location of the test setup of the later two specimens played a major role in the design of the testing arrangement. Room 106 was chosen over other laboratories because this room contained an open floor large enough to support the many pieces of the test arrangement. Plate stiffeners were fabricated and welded to the W24 support beams and bolted to the reaction floor with hold down bars (fabricated in house). Fabrication, moving, and assembly of the test arrangement required the use of both a 2500 and 3500 $\mathrm{lb}$ forklifts. The forklifts aided in the placement of the $1800-1 \mathrm{~b}$ W12 column beam as well as both W24 reaction blocks. Testing of the specimens began in November 2002 for LSC1 and continued in February of 2003 for LSC2 and LPC3. 


\section{CHAPTER 2. \\ LITERATURE REVIEW}

\subsection{Introduction}

Locating published information discussing the lateral seismic connection proved difficult. Initial research on precast cladding and lateral seismic connection started on the Internet. Beginning with the largest search engine on the Internet, Yahoo contained links to sites containing information regarding other connections, but there was no information specifically regarding lateral seismic connection. Other search engines utilized included Google and AltaVista. Such key words used for this search were:

- Precast Concrete Cladding

- Cladding Connections

- Lateral Seismic Connections

- Lateral Connections

- Seismic Connections

- Seismic Connection and Precast

However, none of the search engines gathered any substantial information on the lateral seismic connection of interest. The Compendex, an online library catalog, also yielded no substantial information regarding the lateral seismic connection.

The PCI Handbook (1999) did not provide a connection that closely resembled the lateral seismic connection shown in Figure 1. The design of connections of non-load bearing wall panels follows similar principles as structural connections, except that the loads are designed for self-weight of the panel and for lateral loads. The PCI handbook illustrates the categories of connections, namely bearing, tie-back, and alignment connections.

Studies and publications of various precast cladding connections were found in the Earthquake Engineering Research Center's library in Richmond, California. However, specific testing and experimental data pertaining to the lateral seismic connections proved to be non-existent in all publications reviewed. The majority of the 
papers published referred to the push-pull connection or typical precast cladding connections. Previous research projects were based upon dynamic modeling rather than experimental testing.

\subsection{Research of Connection Behavior}

In general, a small group of scholars and institutes have performed most of the studies of precast cladding connections. Pinelli et al, (1992) conducted experimental testing showing the advantages of an advanced cladding connection where energy is dissipated through the connector body of the connection, therefore reducing the response on the main structure. The models included connector elements with optional inserts or anchors at both ends. Generally, there are three main components in a cladding connection as shown in Figure 3. The first element, which provides the panel anchorage, is the attachment point that consists of steel inserts imbedded in the panel concrete. Second is the connector body that attaches the connection between the main structure and cladding panel. Lastly, the third element is the attachment to the building's frame structure. The main goal of Pinelli et al (1992) was to use a special testing machine to test the behavior of an advanced cladding connection. The main characteristics of the experiment were to achieve shear loading of the advanced cladding connection without inducing axial stress or torsional effects of the specimen. The advanced connection or bearing connection was loaded cyclically and exhibited good low-cycle fatigue behavior and the specimen sustained gravity loads without losing energy dissipation capabilities. Craig et al (1992) had similar findings to Pinelli; both research experiments involved advanced connections. However, designs from their testing did not resemble those of the lateral seismic connection. Hence experimental data was not collected.

Pinelli et al (1996) reports on a continuation of their earlier work of advanced connection testing. As stated earlier, an advanced connection exhibits properties of ductility and damping and often results in high-energy dissipation without failure during moderate to strong earthquakes. This type of connection provides stiffness and damping to the structural system while remaining a simple, replaceable, and cost effective 
connection. Pinelli's report discusses the slotted bolted connection shown in Figure 4. Different variations of this connection were tested ranging from geometric alterations of tube size and thickness, tapered connections, and whether or not the attachment was welded or bolted. Figure 5 illustrates the tapered connection geometry of the slotted bolted connection. The objective behind the development of the test apparatus was to simulate the behavior of the connection subjected to interstory drift. An energy dissipation mechanism will be triggered by the interstory drift during an earthquake, and often damping results from a hysteretic process. The tapered advanced connections performed adequately in the tests as the connectors exhibited a hysteretic behavior of large energy dissipation with stable loops and no stiffness or strength degradation. The specimen exhibited good low cycle fatigue behavior and the failed tapered section was shown to be ductile. The specimen was able to sustain vertical loading without losing energy dissipation capabilities, thereby, indicating that the specimen would perform adequately in an event of combined high vertical and horizontal accelerations of an earthquake.

Goodno et al (1988) reports on a study to develop a refined model for a portion of a heavy cladding system to determine forces on the cladding panel, panel insert, and connection due to interstory drift motions. Models were based upon clip angle connections and ductile rod (push-pull) connection. Clip angle connection resulted in an interstory shear stiffness value per bay ( 1 bay has 4 connection points) of $11.07 \mathrm{kN} / \mathrm{mm}$ $(63.19 \mathrm{k} / \mathrm{in})$ verses a ductile rod stiffness of $2.26 \mathrm{kN} / \mathrm{mm}(12.89 \mathrm{k} / \mathrm{in})$. The ductile rod connection was effective in reducing the overall panel forces and interstory shear stiffness by a factor of five.

Craig et al (1988) reports on push-pull connections that are designed to isolate the cladding and provide some stiffness augmentation. Craig et al test matrix involved the studies of bolt-insert and ductile rod push-pull connections under cyclic loading. Craig et al's model accurately predicted the onset of inelastic behavior at large levels of displacement. Measured stresses and deflections were accurately predicted and the potential of low-cycle fatigue failure of the ductile rod was observed experimentally. 
Similarly, results from their testing did not resemble those of the lateral seismic connection. Hence experimental data was not compared to those of this research.

Pinelli et al (1990) tested weld plate type inserts with certain variations. The experiments determined shear and moment capacities, linear and nonlinear characteristics of hysteretic behavior, energy dissipation properties, and ductility. Variations included different sizes of steel inserts, rebar lengths, and various orientation of each specimen. The inserts exhibited a nonlinear hysteretic behavior with pinching. Under shear testing, the interaction between the steel insert and concrete cladding showed a special bilinear behavior with a low stiffness at low load levels due to the displacement of the insert corresponding to the concrete. Concrete failure often was sudden and brittle as the magnitude of the loading increased. Once the concrete failed the specimen acted similar to a hinge; thereby causing the steel inserts to experience large displacements and stiffness. Ductility and damping of the connection increased dramatically once the concrete failed.

\subsection{Research on Construction Coordination Issues}

Cohen (1995) discussed the consequences pertaining to cladding damage that occurred during the January $17^{\text {th }} 1994$ Northridge earthquake. Cohen recommends the development and implementation of a plan for not only engineering all claddings that could pose life-safety hazards but also to design heavy cladding to be an integral part of the structure of three-dimensional building systems. Cohen's paper discusses the various factors of cladding design, code requirements, and analyzing the cladding panels for predictable, reliable, and safe seismic performance. Since the upper one-third or onefourth of the building generally experiences the strongest motions during a seismic event, inspections beginning here are advised, as well as areas that experienced large drifts. Suggestions for the examinations of damage to the panels are listed below: (Cohen 1995)

- Binoculars are useful for inspecting panels from the ground.

- Examinations from the roof can help detect dislodged panels. 
- Examining the edges of the panels for caulking, glazing, exterior surfaces, and interior panel surfaces may reveal possible damage to the panels.

Pietroforte (1995) reports on the challenges of thin stone veneered cladding system technology. Pietroforte addresses the characteristics of this system and the claddings related industry and availability of engineering capabilities. The writer discusses the three main tasks in the design and engineering process of this type of cladding system; design definition, design finalization, and design realization. Pietroforte focuses on design coordination between subcontractors and manufacturers. Lack of proper definition of design activities, and responsibilities of the specialty subcontractors creates inefficiencies and ultimately diminishes the quality of the final product leading to performance at a level lower than its potential.

Both authors stress similar beliefs in making cladding connections safer through better designs and engineering. Cohen focuses on code requirements and seismic performance of cladding, whereas Pietroforte stresses the importance of coordination between subcontractors and manufacturers to construct a viable product.

\subsection{Existing Design Code Requirements}

Drake et al (1996) discusses seismic-force and displacement equations that are incorporated into the 1994 (NEHRP) National Earthquake Hazards Reduction Program for nonstructural components. NEHRP included new provisions for the seismic designs of not only nonstructural components but also architectural, mechanical and electrical components. This provision requires consideration of the effect of structural displacements on nonstructural components. For example, Equation 1 is prescribed for nonstructural components:

$$
\begin{gathered}
\mathrm{F}_{\mathrm{p}}=\mathrm{a}_{\mathrm{p}} \mathrm{A}_{\mathrm{p}} \mathrm{I}_{\mathrm{p}} \mathrm{W}_{\mathrm{p}} / \mathrm{R}_{\mathrm{p}} \quad \text { Equation } 1 \\
\mathrm{a}_{\mathrm{p}}=\text { component amplification factor, varies from } 1.00 \text { to } 1.50 \\
\mathrm{~A}_{\mathrm{p}}=\text { component acceleration factor, varies from } 1.00 \text { to } 1.50 \\
\mathrm{R}_{\mathrm{p}}=\text { component-response modification factor, varies from } 1.50-6.0
\end{gathered}
$$




$$
\begin{aligned}
& \mathrm{I}_{\mathrm{p}}=\text { component importance factor, varies from } 1.00 \text { to } 1.50 \\
& \mathrm{~W}_{\mathrm{p}}=\text { component operating weight }
\end{aligned}
$$

Based on typical values shown by Drake (1996) a value of $a_{p}=1.0, I_{p}=1.0$, and $R_{p}$ $=3.0$ are provided for exterior wall panels. Equation 1 is less conservative, more detailed, and more closely represents realistic seismic loading than other seismic design force equations. Equation 1 addresses the location of the structure within a regional seismic zone, and location of the component within the primary supporting structure.

Section 1632 of the Uniform Building Code (1997) states, "Elements of structures and their attachments, permanent nonstructural components and their attachments, and the attachments for permanent equipment supported by a structure shall be designed to resist the total design seismic forces." Similar to Drake et al (1996) the total design lateral seismic force $F_{p}$ is determined from the formula:

$$
\mathrm{F}_{\mathrm{p}}=4.0 \mathrm{C}_{\mathrm{a}} \mathrm{I}_{\mathrm{p}} \mathrm{W}_{\mathrm{p}} \quad \text { Equation } 2
$$

Forces determined from Equation 2 is used to design members and connections that transfer forces to the seismic-resisting systems. Sections 1633.2.4.2 requires the connections and panel joints to allow relative movement between stories of not less than twice the story drift caused by wind. This section also states "bodies of connections shall have sufficient ductility and rotation capacity to preclude fracture of concrete or brittle failure at or near welds."

FEMA 273 (1997) defines the nonstructural performance level of cladding components. Cladding components are separated into four major categories, Hazard Reduced (N-D), Life Safety (N-C), Immediate Occupancy (N-B), and Operational (N-A). Table 1 lists the description pertaining to each performance level with Hazard Reduced being the most damaging and dangerous and Operational as the lowest. 


\subsection{Implementation of Past Research into Current Study}

Based on the publications, Pinelli et al $(1990,1992,1996)$ were the closest publications located that had a resemblance to those of the lateral seismic connection in this study. Both advanced and lateral seismic connections involved complicated and multiple components. The publications discussed provided an overall picture of cladding connection's behavior and characteristics. Most studies were based upon push-pull connections and advanced cladding connections subjected to cyclic loading. Research experiments elaborated on the cladding performances and how they reflected the overall structure characteristics. However, no previous experimental results were found based upon the lateral seismic connection in this study. Therefore, comparisons of past experimental data were not used and compared to the experimental data of this research. 


\section{CHAPTER 3. EXPERIMENTAL DESIGN}

\subsection{Introduction}

Three monotonic experiments were designed and tested to quantify their failure modes. Shearing of the welds, bending of the plate, angle, and/or tube were tested to resemble an actual cladding connection system loaded during a seismic event. Due to the size and complexity of the lateral seismic connection, each test focused on a different component of the connection. These tests provide qualitative and quantitative information on the sequence of failure modes for each of the specimens. This chapter explains the failure modes and damage thresholds, test arrangement, specimen, instrumentation, and predicted results for each specimen. Experimental results are provided in Chapter Four.

Figure 2 illustrates the intended design loading of this connection. LSC1 experiment was an axial test of the strength of the welded connection between the angle and plate. LSC2 experiment was bending of the $25 \mathrm{~mm}$ plate welded to the W12 column and L8x8x1 angle. LPC3 experiment measured the bending strength and displacement of the tube relative to the $\mathrm{W} 12$ column. $\mathrm{LSC} 2$ and LPC3 simulated the lateral seismic connection due to out-of-plane (movement of the panel relative to the structure). Referring to the intended design of the overall connection in Figure 2, in-plane movement was tested in LSC1. Out-of-plane movement tested away from the column was specifically for LSC2 and LPC3. Table 2 lists the experimental test matrix and variation in direction loading of these specimens.

The order of testing was: LSC1, LPC3, and then LSC2. LPC3 was tested before LSC2 because this experiment required the welding of the angle onto the $400 \mathrm{~mm} \mathrm{x}$ $480 \mathrm{~mm} \times 13 \mathrm{~mm}\left(16 \times 19 \mathrm{x}^{1 / 2}\right)$ plate of the testing arrangement. Had LSC2 been built first, grinding of the welds and removal of the angles would have been required to allow assembly of the push-pull connection for LPC3. 


\subsection{Failure Modes and Damage Thresholds}

One of the objectives of this study was to investigate the failure modes of the lateral seismic connection under simulated seismic loading by way of in-plane and outof-plane loading. Each of the failure modes were analyzed and a list was compiled in Tables 3 through 5 for each specimen beginning from the lowest nominal calculated strength to the highest. One criteria for the three experiments were to simulate the behavior of the lateral seismic connection to possible lateral movements and displacements during simulated loading.

Potential failure modes are characterized below:

Weld failure:

- Fracture of the welds in shear, tension or compression and this failure mode was confirmed through visual cracks in the weld return.

Specimen yielding:

- Yielding of the plate was detected through the aid of white washing the specimen with lime. Flaking of the mill scale and/ or lime whitewash was visually observed.

Hot-rolled section yielding:

- Yielding of the angle and/ or tube would also be seen through the aid of white washing; severe plastic deformation of the specimen can be visually detected.

Rod yielding:

- Fracture of the $25 \mathrm{~mm}$ diameter coil rod.

Excessive deformation:

- Visual observations of the deformations of the plate, angle, and/ or tube.

The related failure modes from each specimen were compared with the nonstructural performance levels for architectural components (FEMA, 1997) of Table 1. The definition of performance levels according to FEMA-273 should allow for an industry-wide standard to base engineering performance of each failure mode. Predicted failure modes and calculations are discussed in Section 3.6. 


\subsection{Experimental Specimen}

Figure 6 illustrates the layout of the $\mathrm{LSC} 1$ test specimen. The main components of Experiment 1, LSC1, were two identical $25 \mathrm{~mm} \times 125 \mathrm{~mm} \times 685 \mathrm{~mm}(1 \times 5 \times 27)$ plates and one $L 8 \times 8 \times 1$. The ends of the $25 \mathrm{~mm}$ plate were tapered from a width of $125 \mathrm{~mm}$ to $75 \mathrm{~mm}$ to enable the test specimen to slide into the jaws of the testing machine. Approximately, $178 \mathrm{~mm}$ (7in) in length was tapered to provide adequate grip in the jaws of the testing machine. Note that the tapered ends are not illustrated in Figure 6. An L8x8x1 was welded to connect the two plates using a single-fillet $8 \mathrm{~mm}\left(5 / 16^{\prime \prime}\right)$ weld 125 $\mathrm{mm}$ (5") long using DC stick welded E-70XX electrodes. The testing machine provided axial force to both the angle and plates. Figure 7 illustrates the direction of the applied loading of this specimen. The intent of the laboratory test was to measure the shear strength of the longitudinal weld and simulate the complex stress distribution of the plate.

Figure 8 shows the components of LSC2, a $25 \mathrm{~mm} \times 125 \mathrm{~mm} \times 864 \mathrm{~mm}(1 \times 5 \times 34)$ plate, two L8x8x1, and four $125 \mathrm{~mm}$ (5") long $8 \mathrm{~mm}(5 / 16$ ") stick welded E70XX welds. As discussed in Section 1.1, the intent of this experiment was to simulate bending of the plate due to out-of-plane panel movement away from the W12 column beam. This movement may lead to weld fracture due to shear force and torque along the plate. It should be noted that this is not the intended design loading of the plate component of the lateral seismic connection. Figure 9 illustrates the applied loading on LSC2.

The two angles were welded on all four sides to the top of a $400 \mathrm{~mm} \times 480 \mathrm{~mm} \times$ $13 \mathrm{~mm}\left(16 \times 19 \mathrm{x}^{1 / 2}\right)$ reaction plate to ensure that the angle remained stationary to simulate the angle embedded into an actual concrete panel. The welds surrounding the angles were not an intended failure mode. In addition, the angle was found to not be a major parameter in terms of failure mode.

Figure 10 shows the components and layout of the LPC 3 specimen: a TS $8 \times 3 \times$ $3 / 8$, two $25 \mathrm{~mm}$ (1") diameter coil rods, two $300 \mathrm{~mm} \times 330 \mathrm{~mm}(12 \times 13)$ column plates with a $180 \mathrm{~mm} \times 75 \mathrm{~mm}(7 \times 3)$ notched seat for the tube. These components are connected with DC weld by stick electrode with E-70XX electrodes. The tube was welded to the column plates with a single $8 \mathrm{~mm}\left(5 / 16^{\prime \prime}\right)$ fillet weld $180 \mathrm{~mm}$ (7') long E-70XX stick 
electrodes, and an $8 \mathrm{~mm}\left(5 / 16^{\prime \prime}\right)$ by $75 \mathrm{~mm}$ (3") long double fillet weld. The $180 \mathrm{~mm}$ (7") long weld was subjected to tension loading whereas the $75 \mathrm{~mm}$ (3") long double fillet weld was subjected primarily to shear loading. The dimensions of the coil rod for this experiment are illustrated in detail in Figure 11. A $250 \mathrm{~mm}$ length of the $25 \mathrm{~mm}$ diameter rod was tested in axial loading. This length was measured from the bottom nut to the top nut of the rod. The dimension was measured from Side $A$ of the test specimen. Based on Willis constructions details, the actual length of the coil rod for the lateral seismic connection was $203 \mathrm{~mm}$ ( $8 \mathrm{in})$.

This specimen was then welded onto the W12 column by two nominal $8 \mathrm{~mm}$ (5/16") weld $165 \mathrm{~mm}$ (6.5") long on both sides of the column. Each side of the column plates was denoted with a letter (either A or B) to distinguish the sides of both LSC2 and LPC3.

The intent of the laboratory test was to simulate the failure mode of coil rod fracture, tube bending about the column, and weld fracture due to tensile strength. Figure 12 shows the applied loading for this experiment where the coil rods carry the force throughout this experiment and Figure 13 is a photograph of the whitewashed Side B of this experiment prior to loading.

Full size specimens for testing were designed with specific geometric parameters that varied from the original lateral seismic connection shown in Figure 1. The actual lateral seismic connection has neither symmetric properties nor configurations. The three experiments were designed symmetrically to ease testing and experimental setup. Hence all specimens were designed as a mirror image of the column centerline.

\subsection{Testing Arrangement}

LSC1 was the simplest testing arrangement of the three experiments. LSC1 was loaded using a $900 \mathrm{kN}$ (200-kip) testing machine. The lone difficulty of this arrangement

involved setting the specimen into the jaws of the machine. Figure 14 shows a photograph of this specimen installed in the testing machine. 
LSC2 and LPC3 were more complicated in terms of preparation and testing. As stated at the end of Chapter 1, due to the large predicted forces in both experiments, Room 106's strong floor was chosen to test these two specimens. Both specimens (LSC2 and LPC3) used two W24x68 beams as the reaction blocks to simulate the precast concrete cladding. Figure 15 shows the reaction blocks before the specimens were attached. These two beams were held to the floor by twelve $25 \mathrm{~mm} \times 125 \mathrm{~mm} \times 200 \mathrm{~mm}$ ( $1 \times 5 \times 8)$ steel bars bolted with $38 \mathrm{~mm}\left(1.5^{\prime \prime}\right)$ diameter bolts into the concrete floor. Steel stiffeners were installed to support the W24's beam flanges to prevent local bending. Possible twisting of the beams was resisted by bolting a $400 \mathrm{~mm} \times 480 \mathrm{~mm} \times 13 \mathrm{~mm}$ $(16 \times 19 \times 1 / 2)$ steel plate connecting the top of both W24 beams. This plate was connected with eight $A 325$ bolts per plate. This $13 \mathrm{~mm}(1 / 2 ")$ plate also simulated the steel embed that would be installed in the concrete panel.

Both experiments required the use of a W12x120 column beam to simulate the column of the structure. The placement of the plate, tube, reaction blocks, and $300 \mathrm{~mm}$ (12") diameter hydraulic pistons was partially governed by the existing condition of the W12 column beam. Due to previous experimental uses of the W12 column beam, one piston was positioned further from the test specimen than the other. The use of a long column beam in this experiment increases the potential energy. Hence, a restraining track was assembled at each end to protect against out-of-plane movement of the column during the test. A reaction frame and W16 $\times 40$ beam restrained each end of the W12 from moving horizontally or laterally as shown in Figure 16. The W16 beams enabled the load beam to move vertically without touching the flanges, while still preventing the column beam from falling off the setup during testing. For safety purposes the load beam was chained loosely to dead weights to prevent the beam from jumping vertically at the time of fracture due to internal elastic strain. Figures 17 and 18 illustrate the test arrangement of LSC2 and LPC3 experiments. The column beam and reaction blocks were selected to ensure that they would remain elastic during the experiment and would not affect the result of the experiment. 
LPC3 included two $480 \mathrm{~mm} \times 230 \mathrm{~mm} \times 25 \mathrm{~mm}(19 \times 9 \times 1)$ plates with a $38 \mathrm{~mm}$ (1.5") diameter hole for the rod. A nut and plate washer was tack welded below the plate to support the coil rod. This plate was placed between the two W24's and directly beneath their flanges. The use of this $480 \mathrm{~mm} \times 230 \mathrm{~mm}$ plate was to connect the rod as though the rod was embedded in the concrete panel. Figure 10 shows the placement of this plate. All loading and reaction members were fabricated in the laboratory.

\subsection{Instrumentation}

Photographs and notes were logged at critical phases of both LSC2 and LPC3. Tables 6 through 8 list the instrumentation for each test.

LSC1: Figure 19 shows the instrumentation setup for this experiment. The instrumentation consisted of the testing machine's internal load cell that measured the axial force. An internal pressure gauge calibrated to force measured the applied load from the testing machine. Dial gage 1 was installed vertically to log the overall vertical displacement of the specimen. This dial gage measured the movement between the upper and lower heads of the actuator. Since the area surrounding the welded plates to the angle was subjected to twist and rotation due to eccentric loading, dial gage 2 was installed to measure the twisting of the angle. All readings were recorded manually.

LSC2: The instrumentation consisted of two dial gages, 5 wire potentiometers and two load cells as shown in Figure 17. Each load cell, left (Ch 1) and right (Ch 8), measured the force supplied by one of the pistons. These pistons provided the vertical movement of the load beam. Seven channels of electronic data were monitored at a rate of $1 \mathrm{~Hz}$ and stored through a PC-based data acquisition system to log the voltage of each channel. Two wire potentiometers ( $\mathrm{Ch} 3$ and 6) measured the displacement of the column beam, right and left respectively. Additional wire potentiometer ( $\mathrm{Ch} 2,4$, and 5 ) was placed on the flat section of the plate to measure the displacement and possible twist at the tip of the plate. Specifically, wire potentiometer Ch 4 was placed in the center of the plate, and wire potentiometer $\mathrm{Ch} 2$ and 5 are the front left and right respectively. The dial gages as noted in this figure were used as a visual indicator of the beam movement 
applied by the lift of the W12 column beam. The column beam was pumped every 0.025 of an inch until failure. At a tenth of an inch observations, notes, and pictures were logged. Figure 20 is a photograph of the wire potentiometers on the plate of LSC2 and LSC2R and Figure 21 provide the dimensions for the exact placement of these instruments. LSC2R utilized the same setup for instrumentation.

LPC3: The number of instruments, total channels, data acquisition, and instrumentation setup was similar to LSC2 as shown in Figure 18. Figure 22 illustrates the exact placements of the instrumentation. Similar to LSC2, two wire potentiometers (Ch 3 and 6) measured the displacement of the column beam, right and left respectively. The primary difference in instrumentation between LSC2 and LPC 3 was the placement of the wire potentiometers for Channels 2, 4, and 5. One wire potentiometer (Ch 2) measured the vertical deflection on the tube along the line passing through the coil rod, while another wire potentiometer ( $\mathrm{Ch}$ 5) measured the vertical deflection of the tube halfway between $\mathrm{Ch} 2$ and the face of the column plate. A third wire potentiometer (Ch 4) measured the displacement of the tube at the location of the rod. Similar to LSC2, dial gages were utilized to monitor the distance traveled by the load beam. Figure 23 is a photograph of the instrumentation on side $A$ of the tube.

\subsection{Test Procedures}

The following is the test procedure for each specimen:

\section{Experiment LSC1:}

1.) The specimen was fabricated and assembled in the laboratory.

2.) Certified welder welded the plates to the angle.

3.) The specimen was hoisted into the testing machine and attached by the grips of the heads.

4.) Two dial gages were placed for manual reading of data.

5.) The specimen was coated with a lime whitewash to visibly document the first sign of weld or plate yielding. 
6.) A small load of $10 \%$ of the expected failure load was applied to the specimen to confirm that the instrumentation was correctly set up.

7.) Monotonic tension loading was applied until the specimen failed.

8.) A test summary was written from the data gathered.

9.) Graphs of force vs. displacement were plotted.

Experiment LSC2:

1.) The specimen was fabricated and assembled in the laboratory (Engr. Bldg, Room 106).

2.) The Civil Engineering department technician welded the plate to the angles, reaction plate, and W12 column beam. Reaction blocks, frames, and load beam were already set in place in experiment LPC3.

3.) Wire potentiometers and load cells were placed and connected to a PC for data acquisition.

4.) The specimen was coated with a lime whitewash (Side B) to visibly document the first sign of plate yielding or fracture.

5.) Hydraulic jacks were pumped manually every 0.025 of an inch, alternating between jack 1 and 2 (raise 1, then 2, then 1, etc.) to lift the W12 column. Observations and pictures were taken at a tenth of an inch of column movement.

6.) The pistons applied loading until the specimen failed. The test concluded with complete loss of load resistance, specimen instability, or maximum extensions of the actuators.

7.) A test summary was written from the data gathered.

8.) Data was converted to engineering units and reduce to suitable engineering terms. 


\section{Experiment LSC2R:}

1.) The Civil Engineering department technician ground and re-welded the fractured weld on Side B of the column.

2.) Follow steps 3-8 as stated for LSC2.

Experiment LPC3:

1.) The specimen was fabricated and assembled in the laboratory (Engr. Bldg, Room 106).

2.) Reaction block, plates, and rods were bolted and set in place.

3.) The Civil Engineering department technician welded the specimens for this experiment.

4.) Column beam and specimen were hoisted into the W16x40 vertical tracts and attached onto the W24 reaction blocks.

5.) Wire potentiometers and load cells were placed and connected to a PC for data acquisition.

6.) The specimen was coated with a lime whitewash (Side B) to visibly document yielding or slipping.

7.) Hydraulic jacks were pumped manually every 0.025 of an inch, alternating between jack 1 and 2 (raise 1 , then 2 , then 1 , etc.) to lift the W12 column. Observations and pictures were taken at a tenth of an inch of column movement.

7.) The pistons applied a loading on this specimen until the specimen failed. The test concluded with complete loss of load resistance, specimen instability, or maximum extensions of the actuators.

8.) A test summary was written from the data gathered.

9.) Data was converted to engineering units and reduce to suitable engineering terms. 


\subsection{Predicted Results}

Strengths of various failure modes are listed in Tables 3 through 5 for each experiment. However, not all possible means of failure for an actual connection were included in testing of prototype specimens. These tables list the nominal force of failure mode for each specimen. Lower bound, mean, and upper bound values were calculated for each failure mode. Lower bound values included the safety factor for that failure mode whereas the mean value was calculated without. Upper bound value was the addition of the difference between the lower bound and mean to the mean value. Calculations were based upon standard steel design strength equations as provided by AISC formulas.

\subsubsection{Predicted Results of LSC1}

Figure 24 is the structural model for LSC1 experiment. Based on Table J2.5 of the LRFD specification, Equation 3 indicates that weld fracture was the lowest strength failure mode to occur as a result of axial loading. A nominal design strength of $207 \mathrm{kN}$ (46.46 kips) and an as-built strength of $308 \mathrm{kN}$ (69.34 kips) were calculated to be the maximum force needed to fail the weld. Nominal design and as-built strength values differ in that as-built strength uses the actual dimensions of the welds in the calculation. Nominal design strength was calculated using the dimensions specified by the standard layout provided by Willis construction. The LRFD formula used to predict the weld strength was:

$$
\begin{aligned}
\mathrm{R}_{\mathrm{nw}}=\mathrm{t}_{\mathrm{e}}(0.60)\left(\mathrm{F}_{\mathrm{exx}}\right) & \text { Equation } 3 \\
\mathrm{t}_{\mathrm{e}} & =\text { effective throat dimension } \\
\mathrm{F}_{\mathrm{exx}} & =\text { tensile strength of electrode material }
\end{aligned}
$$

The specified or actual weld length was multiplied by Equation 3 to get a value of force. Weld fracture due to eccentric loading was calculated to occur at a force of $255 \mathrm{kN}$ 
(57.33 kips) just 19\% higher than pure shear fracture of the weld. Figure 24 illustrates the eccentric loading for this experiment.

The predicted force-displacement model for LSC1 was calculated using the structural model in Figure 24. Equation 4 is the linear elastic deflection of the plate and angle. Since the angle's cross sectional area was three times the area of the plate the angle's deflection is a third of the total deflection. Thus, $\Delta_{\mathrm{L}}$ was assumed to be zero because of the larger area and shorter length. Equation 4 predicted small displacements for LSC1 specimen.

$$
\begin{aligned}
\Delta_{\mathrm{LSCl}}=\Delta_{\mathrm{PL}} & +\Delta_{\mathrm{L}}=\mathrm{PL} / \mathrm{AE} \\
\mathrm{P} & =\text { load } \\
\mathrm{L} & =\text { length } \\
\mathrm{A} & =\text { cross-sectional area } \\
\mathrm{E} & =\text { modulus of Elasticity of steel }(29,000 \mathrm{ksi}) \\
\Delta_{\mathrm{PL}} & =\text { deflection of the plate } \\
\Delta_{\mathrm{L}} & =\text { deflection of the angle }
\end{aligned}
$$

\subsubsection{Predicted Results of LSC2}

Two failure modes may govern LSC2 experiment. The lowest strength failure was fracture of the weld joining the W12 column beam and $25 \mathrm{~mm}$ plate shown in Figure 8. The nominal design strength of LSC2 was $177 \mathrm{kN}$ (39.78 kips) and an as-built strength of $249 \mathrm{kN}$ (55.96 kips). As illustrated in Figure 8, the test is concentric and is assumed to have cantilevers supported by each column face. The strength of a single side of the cantilever will be half of the total force applied to the specimen. The summation of the forces in the vertical direction shows that the strength of the applied load will be twice the strength of the individual components. The design strength formula based on tension or compression parallel to the axis of a fillet weld is based on Equation 5 . (Salmon and Johnson, 1996) 


$$
\begin{aligned}
R_{n}=t_{e} F_{y} & \\
t_{e} & =\text { effective throat dimension } \\
F_{y} & =\text { yield stress of the steel }
\end{aligned}
$$

The actual and/or specified weld length was multiplied by Equation 5 to get a value of force. The second lowest failure strength was weld fracture at the angle due to eccentric loading of the weld. This was expected to occur at a nominal design strength of $255 \mathrm{kN}$ (57.33 kips). Table 4 lists the lower and upper bound failure limits for this experiment. The weld fracture formula based on Equation 6 is (LRFD, 1998):

$$
\begin{aligned}
\mathrm{R}_{\mathrm{n}}=\mathrm{CC}_{1} \mathrm{DL}_{\mathrm{w}} & \text { Equation } 6 \\
\mathrm{C} & =\text { coefficient tabulated below, a function of a and } \mathrm{k} \\
\mathrm{C}_{1} & =\text { electrode strength coefficient from, use } 1.0 \text { for } \mathrm{E} 70 \mathrm{XX} \\
\mathrm{D} & =\text { number of sixteenth of an inch in the fillet weld size } \\
\mathrm{L}_{\mathrm{w}} & =\text { characteristic length of weld group } \\
\mathrm{e}_{\mathrm{x}} & =\text { horizontal component of eccentricity with respect to centroid } \\
& \text { of weld group }
\end{aligned}
$$

\subsubsection{Predicted Results of LPC3}

For the LPC3 experiment, tension failure of the rod was predicted to occur at 92 kN (20.7 kips). Based on the Equation 7 (Salmon and Johnson, 1996) the predicted failure was:

$$
\begin{aligned}
\mathrm{R}_{\mathrm{n}}=\mathrm{F}_{\mathrm{u}} \mathrm{A} & \text { Equation } 7 \\
\mathrm{~F}_{\mathrm{u}} & =\text { tensile strength of rod } \\
\mathrm{A} & =\text { cross sectional area of rod based on } \mathrm{d}_{\mathrm{rms}}
\end{aligned}
$$

A second failure mode, with strength just higher than $92 \mathrm{kN}$, was weld fracture at the tube and column plate. The weld between the column plate and tube would be 
subjected to downward bending force from the cantilevered portion of the tube. This section of the connection will be subjected to high stresses and possible failure. The combined weld fracture strength of the $76 \mathrm{~mm}$ and $178 \mathrm{~mm}$ long welds at the tube and column plate was calculated to occur at a total force of $545 \mathrm{kN}$ (123 kip). As before, Equations 3 and 5 were used to calculate the governing weld fracture. Table 5 lists the sequence of failure modes for LPC 3 based upon the total force applied to the specimen.

The structural model for both experiments LSC2 and LPC3 were calculated assuming the plate or the tube was a cantilever beam with the W12 column being the fixed end and a load concentrated along its length as shown in Figure 25. Details of all calculation are listed in Appendix G. The displacement formula for this assumption was:

$$
\begin{aligned}
\Delta_{\max }= & \mathrm{P}_{\mathrm{p}} \mathrm{b}^{3} / 3 \mathrm{EI} \\
\mathrm{P}_{\mathrm{p}} & =\text { predicted load } \\
\mathrm{b} & =\text { length dimension } \\
\mathrm{E} & =\text { modulus of Elasticity of steel }(29,000 \mathrm{ksi}) \\
\mathrm{I}_{\mathrm{y}} & =\text { moment of inertia about } Y \text {-axis }
\end{aligned}
$$

An expected maximum displacement of $0.47 \mathrm{~mm}$ was calculated for a loading of $248 \mathrm{kN}$ in LPC3 and $2.57 \mathrm{~mm}$ for a loading of $255 \mathrm{kN}$ for LSC2. As noted in Figure 25, dimension ' $b$ ' for LSC2 was measured from the outside face of the flange of the W12 column to the beginning of the weld on the angle and plate whereas ' $b$ ' for the LPC3 test was measured from the face of the column plate to the centerline of the rod.

\subsection{Variations from Original Testing Program}

For LSC1, the original industry design was for a $25 \mathrm{~mm}$ (1") clearance from the edge of the angle leg to the plate. However during fabrication of the specimen, this weld was made with a $51 \mathrm{~mm}$ (2") clearance as illustrated in Figure 6. The extra $26 \mathrm{~mm}$ did not seem to alter the experiment significantly however this did decrease the eccentricity of the weld and reduced twist on the specimen. Figure 26 compares the actual welded 
dimension size for experiment LSC1 to the dimensions stated in the design plans of Willis Construction. The actual weld size was wider and longer than the specified dimension.

Trouble with instrumentation occurred during the testing of LSC2. The test was interrupted in the early stages of the loading process when it was found that the left load cell, Ch 1, was not transmitting data to the PC data acquisition system. The test was immediately ceased, and the test setup was unloaded back to zero displacement. At this point, there was minimal permanent deformation in the plate. The test continued with reloading until weld fracture occurred. At the point of fracture the specimen showed limited permanent deformation and the weld that fractured appeared to be relatively easy to repair. The fractured weld was replaced. As stated in Section 3.0, LPC3 was tested before LSC2 and LSC2R. Therefore, any instrumentation error only occurred in LSC2 and did not affect any of the other experiments.

Figure 27 shows the actual weld dimension for LSC2 experiment. The existing inelastic plate deformation on Side B of the specimen was not removed. Figure 28 illustrates the pre-existing deformation of the $25 \mathrm{~mm} \times 125 \mathrm{~mm}(1 \times 5)$ plate relative to the angle. This figure shows the plate prior to retesting. LSC2R, the retest, was a repeat of the procedure for LSC2; actual weld dimensions for the re-weld are shown in Figure 27.

Figures $29 \mathrm{a}$ and $29 \mathrm{~b}$ show the actual weld size dimensions for the LPC3 experiment at Side A and Side B of the specimen. Most welds were of lengths and widths greater than specified. Calculations using the actual larger weld size equaled greater expected strength for this test. Thereby allowing the specimen to fail at a larger strength. 


\section{CHAPTER 4. EXPERIMENTAL RESULTS}

\subsection{Introduction}

The procedures used in the design of the plate and tube connections were strength-based calculations that were aimed to predict the occurrence of failure modes such as fracture of welds. As discussed in Chapter One, the objectives of these experiments were to determine the force-deflection relationship for each specimen, develop an analytical and predictive model of this connection, determine the accuracy of the predictive model in respect to the failure modes, and document displacements of potential damage thresholds associated with FEMA performance levels.

\subsection{Behavior of Test Specimens}

\subsubsection{Behavior of LSC1}

Initial cracking of the weld return was observed at $138 \mathrm{kN}$ (31 kips) of load during the axial loading of LSC1. The welds on the plate were subjected to twisting of the angle relative to the plates. Visual observations noted that the angle bowed slightly out-of-plane along the angle leg. However, the amount of bowing was not significant. The weld on the bottom plate completely fractured at $307 \mathrm{kN}$ (69 kips) resulting in complete loss of load resistance.

\subsubsection{Behavior of LPC3}

The next experiment was the lateral push-pull connection (LPC3) where bending of the side of the tube initially began under the plate washer in the weak direction of the tube. Due to high punching stresses exerted by the rod, the plate washer was severely cupped and subjected to local bending to the wall of the $8 \times 8 \times 3 / 8$ tube. Figures 30 through 33 illustrate the sequence of local dishing of the side of the tube. Figure 30 shows Side B of the connection prior to loading, followed by Figure 31 where flaking and initial yielding of the whitewash are visually detectable on the plate washer at $13 \mathrm{~mm}$ 
(0.5in) of displacement. Figures 32 and 33 show the growth of the dishing of the tube wall at $25 \mathrm{~mm}$ and $69 \mathrm{~mm}$ ( 1 and $2.7 \mathrm{in}$ ) of loading respectively. Figure 34 , shows the specimen after load was removed. The $100 \mathrm{~mm} \times 100 \mathrm{~mm} \times 13 \mathrm{~mm}\left(4 \times 4 x^{1 / 2}{ }^{\prime 9}\right)$ washer severely yielded due to punching stress as depicted in this figure. The plate washer folded into a bowl shape displacing upwards a distance of $19 \mathrm{~mm}-23 \mathrm{~mm}(0.778-0.902 \mathrm{in})$.

Once the rod and plate washer folded the top wall of the tube to contact the other face, beam bending of the tube became visible. Bearing stress on the tube increased in the region under the plate washers. However, the region plastified and the tube continued to deform and bow until the load approached weld fracture. Figure 35 shows the permanent bending of the tube. This photo was taken after the specimen was removed from the test arrangement.

The weld connecting the column plate and tube initially cracked on Side B of the specimen, as can be seen in Figure 36. Dishing of the tube wall can also be seen in this figure. The first crack of the weld was recorded at approximately $48 \mathrm{~mm}$ (1.90 in) of deflection. As the tube continued to bow, the weld on both sides of the column plate cracked and continued to tear away from the tube. The welds were subjected to shear stresses as a result of the tube bending. Deformation of the tube appeared nearly symmetrical, however Side B did have a slightly larger deformation. The displacement of the tube displayed a single curvature bend similarly to the assumed cantilever behavior shown in Figure 25.

In this test, the tension strengths of the rods was calculated to be the lowest failure strength and first failure mode, however, the rods did not slip nor did they show any signs of yielding throughout the experiment. The rod strength surpassed the predicted failure strength of $92 \mathrm{kN}$ ( $20.76 \mathrm{kip}$ ), partly due to the loading being transferred to the dishing of the tube wall. Dishing of the tube allowed large displacements at lower forces. Displacements provided by dishing of the tube wall reduced the concentrated load needed for rod yielding. The rods, specifically the top $50-75 \mathrm{~mm}(2-3 \mathrm{in})$, bent slightly at the region near the top nut and washer plate as seen in Figure 34. 
The test concluded when the welds between the column plates and tube suddenly separated. Figure 37 shows the complete weld fracture of the specimen after the specimen was unloaded. The welds fractured cleanly and cracked throughout their entire length on both Side A and B. Ultimate failure occurred at $326 \mathrm{kN}$ (73.21 kips).

\subsubsection{Behavior of LSC2}

Figure 38 is a photograph of the lime-coated Side B of LSC2 experiment prior to loading. The behavior of LSC2 was dominated by bending of the $25 \mathrm{~mm} \times 125 \mathrm{~mm}$ ( $1 \times 5$ ) plate. In the first portion of the experiment, as the load was applied to the specimen, visual flaking of the lime coat and bending of the plate was noticed, seen as the ripples in the lime coating of Figure 39. The plate on Side B of the column, bent and deformed at a greater angle compared to Side A according to visual inspection. Figure 28 shows the permanent deformation on the plate after it was subjected to loading. The plate was bent vertically approximately $25 \mathrm{~mm}(\mathrm{in})$ measured at the tip of the plate. The plate on Side $\mathrm{B}$ of the specimen bent more than Side A, possibly due to the misalignment of the hydraulic pistons under the web of the W12 column beam. Upon closer inspection, it was found that the right piston was off center from the web of the W12 about $25-50 \mathrm{~mm}$ (1-2in). Readjustment of the actuator location took place prior to the retest of LSC2R.

Following the bending of the plate, the weld at the angle and plate (Side B) fractured as a result of the forces exerted by the bending of the plate. Complete loss of the connection strength did not occur immediately after the weld return cracked. With continued displacement the load did not increase, but the specimen continued to resist the full loading for some time. The weld fractured between the plate and angle at $154 \mathrm{kN}$ (34.6 kips).

As discussed in Section 3.7, the plate in LSC2 was repaired by grinding out the previous weld and re-welded with the existing plate deformation and tested under experiment named LSC2R. Side A of the plate deformed inelastically leading to twisting of the plate. The experiment concluded when the weld connecting the W12 column and plate (Side A) fractured at a maximum force of $147 \mathrm{kN}$ ( $33 \mathrm{kips}$ ). Figure 40 shows the 
weld fracture on Side A of experiment LSC2R. The stress distribution was indicated by the contours of the flaking of the mill scale on the upper left side of the plate as a result of twisting and yielding of the plate between the two welds (angle to plate, and plate to the W12 column beam). The strength of the plate may have been altered as a result of the unloading and reloading of the specimen in experiment LSC2. The plate and welds were subjected to plastic deformation and stress due to the process of unloading and reloading. Hence, a lower force of $147 \mathrm{kN}$ resulted in weld fracture for LSC2R than the $154 \mathrm{kN}$ force required for $\mathrm{LSC} 2$.

\subsection{Observed Failure Modes}

Failure modes of the lateral seismic connection were predicted to occur as a combination of plastic deformation of the plate or tube followed by weld fracture. Test summaries in Appendix E outline the behavior of each test. The LSC1 specimen behaved in the following sequence:

1. Angle showed visible signs of bending

2. Weld fracture due to shearing forces

3. Weld fracture due to eccentric load on weld

It was likely that more than one failure sequence would be observed for these experiments. However, the test would be halted once weld fracture was achieved. In respect to the actual connection shown in Figure 1, had in-plane failure of the plate occurred, the lateral load on the connection would be carried by the push-pull of the rod and tube. The plate resists the majority of in-plane loading when the panel is subjected to in-plane seismic forces.

The LPC3 specimen behaved in the following sequence:

1. The tube wall of the TS $8 \times 8 \times 3 / 8$ begins to locally distort

2. One side of the tube wall deforms until it bears against the other side of the tube

3. The tube begins to visibly bend 
4. Weld cracking at the return initiated on Side B, specifically the $178 \mathrm{~mm}$ (7in) long weld connecting the column plate and tube

5. As additional load was applied, a weld crack developed on the $178 \mathrm{~mm}$ (7in) long weld on Side A.

6. Continued bending of the tube concave downwards propagated the cracks along both sides

7. At the same time, strains in both of the $178 \mathrm{~mm}$ long welds cause a crack to develop in the $75 \mathrm{~mm}$ length vertical welds (weld along the shorter end of the tube and column plate), leading to complete sudden fracture of both sides.

For LSC2, the observed behavior was:

1. Yielding and flaking of the plate and lime-coating

2. Plate bends in single curvature

3. Cracking of the weld return between the plate and angle of Side B

4. Complete fracture of the weld on Side B of the specimen

For LSC2R, the observed behavior is similar:

1. Slight yielding of the plate

2. Plate also bends in single curvature

3. Fracture of the weld occurred between the plate and W12 column of Side A

4. Complete fracture of the weld on Side A of the specimen

\subsection{Results for Individual Tests}

At the conclusion of each test, a test summary was written of qualitative information. Tension test coupons were fabricated from the material used for the specimens and tested to obtain uniaxial mechanical properties of the steel. These results and test summaries are provided in Appendix E. 


\subsubsection{Results of LSC1 Test}

Table 9 is a comparison between actual, design, and as-built strength of each experiment. Recalling that calculations for as-built strength of each experiment were determined based upon the actual dimensions of the specimen and the design strength were determined using the specified dimensions. LSC1 was two plates welded to an angle by two- $8 \mathrm{~mm}$ (5/16") $125 \mathrm{~mm}$ ( $\left.5^{\prime \prime}\right)$ long welds and subjected to axial loading. This test was loaded corresponding to the intended design loading of the lateral seismic connection for in-plane panel movement. The weld was thicker and longer than the nominal size of $8 \mathrm{~mm}\left(5 / 16^{\prime \prime}\right)$ by $125 \mathrm{~mm}\left(5^{\prime \prime}\right)$ as shown in Figure 26. The test resulted in weld fracture occurring at the angle and the bottom plate as shown in Figure 41 . The weld appeared to be of good quality having adequate penetration into the base metal. Good weld quality and larger weld size appeared to have contributed to higher strength. The peak force at failure was $307.4 \mathrm{kN}$ (69.12 kips) corresponding to a vertical displacement of $17 \mathrm{~mm}(0.67 \mathrm{in})$. The experimental force exceeded the design strength capacity of $206 \mathrm{kN}$ ( $46.46 \mathrm{kips}$ ) by $49 \%$. When using actual weld size dimensions, this experiment failed near the as-built strength. Maximum displacement of this experiment was $21 \mathrm{~mm}(0.83 \mathrm{in})$.

Figure 42 is the force-displacement relationship of LSC1. The strength was reasonably predicted, however the experimental deflection far exceeded the predicted force-displacement curve. Since the specimen was loaded only in tension, the test provides no verification if compression buckling might occur. The displacement measurement also included slip of the testing machine jaws. From Figure 42, it appears that significant slip occurred over the first $3.2 \mathrm{~mm}$ of displacement and gradual engagement of the jaws continued up to $12 \mathrm{~mm}$ of displacement. Slip is noted in this figure according to the small spike in the force-displacement graph. (McMullin et al, 2003a)

Due to the axial force exerted by the plates on the angle, slight bending of the angle occurred because the centerlines of the angles and plate were not in alignment with each other. Though visible bending of the angle was observed this did not appear to 
adversely affect the overall behavior of the connection. Once weld fracture initiated, Figure 42 shows that fracture was not sudden, that the connection slowly loses strength after the peak force has been recorded, thereby allowing additional deflection. (McMullin et al, 2003) The energy dissipated during this test was $2829 \mathrm{kN}-\mathrm{mm}$. Table 10 lists the energy dissipated and ductility for each test specimen. LSC1 was not very ductile as the ultimate, maximum, and energy ductility values were $1.4,1.6$, and 1.9 respectively. However, the connection displaced $10 \mathrm{~mm}(0.40 \mathrm{in})$ before yielding. Ductility values were derived based on these formulas:

\section{Ultimate Ductility}

$$
\mu_{\text {ult }}=\Delta_{\text {ult }} / \Delta_{\text {yield }}
$$

Equation 9

Maximum Ductility

$$
\mu_{\max }=\Delta_{\max } / \Delta_{\text {yield }}
$$

Equation 10

Energy Ductility

$$
\mu_{\mathrm{E}}=\mathrm{E}_{\text {total }} / 1 / 2 \mathrm{~F}_{\mathrm{y}} \Delta_{\text {yield }} \quad \text { Equation } 11
$$

Total Energy Dissipated

Area under force-displacement curve Equation 12

Figure 43 shows the force versus transverse displacement. This displacement indicates the twist of the angle. The graph shows an elastic relationship at the beginning of the experiment and once fracture begins the angle returns to its original position. The angle was subjected to bending and tension forces prior to weld fracture as was observed with the angle bending concave downward. Once weld fracture begins, the connection loses strength and the angle unloads in an elastic state.

\subsubsection{Results of LPC3 Test}

As discussed in Section 4.1 the initial predicted failure mode for LPC3 was yielding of the rod. However, the final failure was in the weld region connecting the column plate to the tube. As the tube bends concave downward, the strains induced in 
the weld return grew until large enough to cause the $178 \mathrm{~mm}$ long weld (along column plate and tube) to crack. The peak force in this test was $325.6 \mathrm{kN}$ (73.21 kips) at $66.9 \mathrm{~mm}$ (2.64in) of displacement, the test continued and failed abruptly at a maximum displacement of $69 \mathrm{~mm}$ (2.72in). The experimental force exceeded the design strength of $297 \mathrm{kN}$ ( $67 \mathrm{kips}$ ) by $9.6 \%$. The failure strength was based on the $178 \mathrm{~mm}$ ( $7 \mathrm{in}$ ) long weld connecting the tube and column plate.

Of the three components tested, LPC3 resulted in the greatest energy dissipated at $18,289 \mathrm{kN}-\mathrm{mm}$. This experiment was the most ductile component of the lateral seismic connection. The ductility values were 13,14 , and 41 for ultimate, maximum, and energy dissipated respectively.

Figure 44 shows the force-displacement relationship of the experiment. Instrumentation showed no indication of slippage between the welded specimen and W12 column beam or at the coil rod and tube connection. Dishing and local bending of the tube were visibly observed. The connection's behavior and deflection were dominated by dishing of the tube. The specimen loads plastically once weld fracture begins at the tip of the weld return on the column plate and tube. Significant deflection was recorded prior to weld fracture. The graph illustrates that fracture was sudden and the connection loses strength shortly after peak force was recorded. In addition, the prediction model was poor when compared to the experimental data as shown in this figure.

Figure 45 shows a breakdown of the total displacement for one side of the connection. The total displacement of Equation 13 for this specimen was the summation of rod displacement, dishing of the tube, and the displacement of the tube due to bending. Equations 14-17 were used to convert readings from wire potentiometers.

$\Delta_{\mathrm{T}}=\Delta_{\mathrm{rod}}+\Delta_{\mathrm{dish}}+\Delta_{\mathrm{TS}}$

Rod elongation

$$
\Delta_{\mathrm{rod}}=\Delta_{\text {connection }}-\Delta_{\mathrm{CH} 4}-\Delta_{\mathrm{CH} 2}
$$

Tube Dishing

$$
\Delta_{\text {dish }}=\Delta_{\mathrm{CH} 4}-\Delta_{\mathrm{CH} 2}
$$

Equation 13

Equation 14

Equation 15 
Tube Bending

$$
\begin{aligned}
& \Delta_{\mathrm{TS}}=\Delta_{\mathrm{CH} 5} \quad \text { Equation } 16 \\
& \Delta_{\mathrm{TS}}=\Delta_{\mathrm{CH} 2} \quad \text { Equation } 17 \\
& \text { where: } \\
& \Delta_{\text {connection }} \text { is the displacement at the centerline of specimen } \\
& \Delta_{\mathrm{CH} 4} \text { measured the displacement on the rod } \\
& \Delta_{\mathrm{CH} 2} \text { measured the displacement along the rod bolt line } \\
& \Delta_{\mathrm{CH} 5} \text { measured the displacement on the tube, placed } \\
& \text { between the column plate and } \Delta_{\mathrm{CH} 2}
\end{aligned}
$$

Figure 22 and Table 8 illustrate the placement of the wire potentiometers and corresponding channels. As shown in Figure 45 , tube dishing provided the most deformation, occurring at a constant stiffness over the last $50 \mathrm{~mm}$ of displacement whereas tube bending and rod elongation experienced minimal displacements, remaining under $3 \mathrm{~mm}$ throughout the test. The rod stretches oddly due to the movement of the W12 column beam. Rocking and an uneven tilt of the column beam may have resulted in the rod stretching in a shape similar to an S-pattern.

During testing no slip occurred between the coil rod and the $75 \mathrm{~mm}$ ( $3 \mathrm{in}$ ) diameter hole in the tube. Slip was expected to occur between the plate washer and tube as a result of the existing $75 \mathrm{~mm}$ diameter hole, which was designed to allow placement of the pushpull connection. Figure 46 shows the displacement provided by tube bending ( $\mathrm{Ch} 5$ ) and dishing graphed against the force per rod. Tube dishing resulted from plastic deformation under the plate washer region and the graph shows it provides significantly greater deformations than bending of the tube.

\subsubsection{Results of LSC2 and LSC2R Test}

LSC2 failed at an ultimate force of $154 \mathrm{kN}$ (34.63 kips) with a displacement of $10 \mathrm{~mm}(0.39 \mathrm{in})$ on Figure 47 . Weld failure occurred on Side B of the $8 \mathrm{~mm}\left(5 / 16^{\prime \prime}\right)$ weld joining the plate and angle at a maximum displacement of $10 \mathrm{~mm}(0.4 \mathrm{in})$. As explained in 
Section 4.1, LSC2 failed at a load below predicted. The design strength based on weld fracture of this connection was $255 \mathrm{kN}$ (57.33 kips) compared to an actual experimental strength of $154 \mathrm{kN}$ ( $34.63 \mathrm{kips})$. The actual strength of the connection failed at $61 \%$ of the designed strength. Figure 27 shows that the weld dimensions for LSC2 were longer and wider than specified. Using the actual size of weld in the original design calculation, the as-built weld strength is $257 \mathrm{kN}$. The $25 \mathrm{~mm}$ plate was loaded eccentrically thereby twisting and developing torque. Stress concentration in the steel near the weld occurred; along with concentric shear loading on the weld that combined to cause the weld to fail at a weaker value than had been predicted.

Figure 47 shows the force-displacement graph of LSC2. As discussed in Section 1.1, the plate component of the LSC connection is not expected nor designed to resist the load developed by the panel moving inward and outward from the building. Hence, this experiment represents an unintended loading as the specimen is subjected to out-of-plane movement. Comparing the results of the predicted model to the experimental data reveals a difference between the two data fields. Peak force occurred lower than anticipated. Once weld fracture began the resisted force remained constant, fracture was not sudden and the component continued to deflect after the peak force was recorded.

Figure 48 shows the comparison of LSC2 displacement at the tip of the plate and the displacement at the mid-length of the $25 \times 125$ plate. The tip and mid-length displacement of the plate were calculated using the formulas below:

Tip of Plate displacement

$$
\Delta_{\mathrm{tip}}=\left(\Delta_{\mathrm{CH} 5}+\Delta_{\mathrm{CH} 2}\right) / 2 \quad \text { Equation } 18
$$

Mid-Length of Plate displacement

$$
\Delta_{\text {mid }}=\Delta_{\mathrm{CH} 4}
$$

Equation 18 is the average of data channels two and five, and Equation 19 is the deflection measured as channel four. Both displacements were graphed relative to the force per angle, half of the total experimental force. Instrumentation and placement of 
the wire potentiometer for the tip and mid-length displacements are shown in Figure 21. Figure 48 shows that the displacement for each angle was greater at the tip than at the mid-length of the plate. This figure also shows that the plate was very stiff at initial loading. The plate was subjected to bending and torque after the plate initially yields. In addition, the plate did not bend as a pure cantilever as was initially predicted with the tip displacement being 35-45\% greater than the mid-length. According to this figure, the test data concluded that a single curvature bend of the plate developed.

Figure 49 shows the torque versus rotation of twist of Specimen LSC2. The instrumentation measured the displacement at the tip of the plate on Side A as shown in Figure 21. The predicted twist was calculated using the formula:

$$
\begin{aligned}
& \text { Twist } \\
& \qquad \begin{aligned}
& \phi=\Sigma(\mathrm{Tz}) /(\mathrm{GJ}) \\
& \mathrm{T}=\text { Area subjected to torque } \\
& \mathrm{G}=\text { Shear Modulus of elasticity of steel }(11200 \mathrm{ksi}) \\
& \mathrm{J}=\text { Torsional constant }=\mathrm{b}_{\mathrm{pt}} \mathrm{t}^{3} / 3 \\
& \mathrm{~L}=\text { length } \\
& \mathrm{b}_{\mathrm{pl}}=\text { width of the plate } \\
& \mathrm{t}=\text { thickness of the plate } \\
& \mathrm{z}=\text { distance of the specimen subjected to torque }
\end{aligned}
\end{aligned}
$$

The maximum measured twist of the $25 \mathrm{~mm}$ plate was 0.197 radians. Figure 49 shows that torque and twist remains relatively elastic until yielding begins to occur. At this point the experimental data plateaus and additional twist occurs with little added torque. Initially, the experimental data remained relatively linear and similar in slope to the predicted model, thus elastic stiffness accurately predicts the outcome of the graph up to the point of significant yielding. Twist based on instrumentation are provided below: 


$$
\begin{aligned}
& \phi=\operatorname{Tan}^{-1}\left(\Delta_{\mathrm{CH} 2}-\Delta_{\mathrm{CH} 5}\right) / 2 \\
& \text { where: } \\
& \Delta_{\mathrm{CH} 2} \text { measured the displacement along the rod bolt line } \\
& \Delta_{\mathrm{CH} 5} \text { measured the displacement on the tube, placed } \\
& \text { between the column plate and } \Delta_{\mathrm{CH} 2}
\end{aligned}
$$

LSC2R ultimately failed at a maximum force of $147.2 \mathrm{kN}$ (33.09 kips) and a displacement of $4.32 \mathrm{~mm}(0.17 \mathrm{in})$. The ultimate failure mode was fracture of the weld connecting the angle and plate on Side A of the W12 column. Figure 27 includes the dimensions for the re-welded section from LSC2. LSC2R failed at a load below expected, approximately $83 \%$ of the predicted design strength and $59 \%$ of the as-built strength of $248.9 \mathrm{kN}$ (55.96kips) based on a higher yield stress ( $\mathrm{F}_{\mathrm{y}}$ as a result of coupon tests) of the plate as the base material. Both the initial and retest of the LSC2 specimen revealed similar failure modes at small displacements and at lower experimental force.

Figure 50 shows the force-displacement graph of LSC2R. Similar behavior is seen in the retest. Once weld fracture begins, the connection loses a significant amount of strength but does continue to support as much as $75 \%$ of the peak load. This diagram is essentially linear up to $80 \mathrm{kN}$ of loading, however after peak strength significant deflection occurs before complete loss of strength.

Figure 51 compares the tip and mid-length displacement of the connection. As a result of the pre-existing plate deformation on Side B, loading on the cantilevered plate of Side A was more prominent. Side A displaced more because of the nonsymmetrical deformation from both sides of the cantilevered plate. The tip of the plate showed greater displacements than at the mid-length of the plate. This figure showed similar results to those of Figure 48 in that the plate was very stiff at the onset of loading. Once weld fracture begins the connection loses strength.

Figure 52 shows torque versus twist of Specimen LSC2R. This figure shows that the angle of twist significantly increases after initiation of the weld crack at peak torque. 
The weld fracture slowly progressed throughout the entire weld length. The overall twist for this specimen was $0.84 \mathrm{rads}$, however maximum torque of $4.67 \mathrm{kN}-\mathrm{m}$ occurred at a twist of $0.21 \mathrm{rads}$. Graphed against the predicted model of torque verses twist, the experimental model showed a similar relationship in terms of slope after the first $20 \%$ of torque was applied. Thus, the elastic stiffness accurately predicts what the graph will look like up to the point of significant yielding. The energy dissipated for LSC2 and $\mathrm{LSC} 2 \mathrm{R}$ was 1352.7 and $698 \mathrm{kN}-\mathrm{mm}$ respectively.

\subsubsection{Ductility of Tests}

Table 10 provides a comparison of ductility and energy dissipation for all three specimens. The energy dissipation values were calculated based on the area under the curve of the force-displacement graphs of each experiment. LSC1 and LSC2 provide little ductility out of the three tests. In fact, LPC3 was the most ductile specimen with values over 10 .

The ductility values based on Equations 9-12 were determined from the forcedisplacements data from each experiment. Ultimate and maximum displacements were identified according to their corresponding force values at maximum loads. The yield displacement, $\Delta_{\text {yield, }}$ was visually identified from the force-displacement graph of LSC2 and LPC3 specimen to determine the yield force $\left(\mathrm{F}_{\mathrm{y}}\right)$ of the specimen. For example, the yield displacement of $4.5 \mathrm{~mm}$ for LSC2 and LSC2R was chosen that corresponded to a force of $142 \mathrm{kN}$ and $144 \mathrm{kN}$ respectively. LPC3 had a yield displacement of $5 \mathrm{~mm}$, corresponding to a force of $178 \mathrm{kN}$. Table 11 lists the visual yield displacement values.

For LSC1, visual identification was not used for finding yield displacement. A $0.2 \%$ method was developed to record the yield displacement from the forcedisplacement graph of this specimen. As illustrated in Figure 53, experimental data within the first $3 \mathrm{~mm}$ of displacement were omitted and a tangent line was drawn from the experimental data to zero force. Data was omitted to illustrate a more accurate $0.02 \%$ offset line. The offset yield strength was determined by first drawing a straight line that bests fit the data in the linear portion of the force-displacement curve. A second line was 
then drawn parallel to the original line but offset by a specified amount of displacement. The intersection of this second line with the force-displacement curve determines the offset yield displacement. A value of $\Delta_{\text {yield }}=10.74$ was used for the ductility calculations. Table 11 lists the yield displacement values.

\subsection{Variation from Expected Test Specimen and Procedure}

LSC1 contained no variations in experimenting during testing. At the onset of loading for LPC3 the top wall of the tube began to dish and deform under the plate washer. This form (strength of the tube wall) of deformation was not accounted for in the calculations. On the other hand, the other failure mechanisms of LPC3 closely followed the sequence of the predicted failure modes, particularly the strength predictions.

LSC2 had more experimental variations than the other two experiments. As discussed in detail in Section 3.7, the fact that one actuator was not at the column centerline likely resulted in unequal forces applied to Side A and B. This eccentricity resulted in twisting of the column during loading. Side B, the side closer to the actuator, bent the $25 \mathrm{~mm}$ plate more than Side A. Figure 28 is a photograph of the bent plate of Side B, but this photograph fails to show the deformed plate on Side A. 


\section{CHAPTER 5. \\ COMPARISON OF TEST RESULTS}

\subsection{Secant and Tangent Stiffness of Experiments}

Secant and tangent stiffness were methods used to identify the initial yield of each specimen. The secant and tangent stiffness were calculated as:

$$
\begin{array}{ll}
\mathrm{k}_{\text {secant }}=\mathrm{F} / \Delta_{\mathrm{T}} & \text { Equation 22 } \\
\mathrm{k}_{\text {tangent }}=\mathrm{F}_{\mathrm{i}}-\mathrm{F}_{\mathrm{i}-1} / \Delta_{\mathrm{T}}-\Delta_{\mathrm{T}-1} & \text { Equation 23 }
\end{array}
$$

Where $\mathrm{F}$ is the total force of the specimen and $\Delta_{\mathrm{T}}$ is total displacement at the connection.

Four methods were used to identify initial yield displacement. Method 1 defined the yield displacement based upon a five percent decrease from the maximum secant stiffness value. Method 2 used a ten percent decrease. Methods 3 and 4 used a five and ten percent decrease from the maximum tangent stiffness. Table 11 lists the yield displacement for these specimens with regards to the four methods mentioned above.

Data recorded during experiments result in significant fluctuation in the values of secant stiffness and tangent stiffness. A smoothing method was used to reduce the fluctuations. To smooth the tangent stiffness graph an average of the stiffness calculated for eleven data points was used. Through the aid of an EXCEL spreadsheet, the five above and five below data values of a particular cell were used for the eleven data point average. The average of eleven numbers was used throughout the data field. Each eleven points of data were averaged to smooth the function. Only LPC3 required the use of smoothing the data points. The eleven-point average of the tangent stiffness aid in the removal of several spikes and valleys; Prior to using the eleven-point average, excessively high points above certain stiffness values were deleted. For example values over $1000 \mathrm{kN} / \mathrm{mm}$ are removed followed by values over $500 \mathrm{kN} / \mathrm{mm}$, and so forth until a smoother function was determined. Figure 54 shows the tangent stiffness of LPC3 prior to editing or smoothing. Note the wide fluctuations and erratic peaks and valleys. Figure 
55 shows the tangent stiffness curve after smoothing to remove valleys and spikes. The last displacement value just above 95 percent and 90 percent of the maximum stiffness value was recorded as the yield displacement. The secant stiffness curve was not as erratic as the tangent stiffness and required no smoothing. Extreme spikes and valleys however, were removed.

However, these methods yielded very small displacements as shown in Table 11. Visual inspections of yield displacement based on force-displacement graphs resulted in better values. When compared to the four methods, visual inspection produced better results and accuracy for the yield displacement of each specimen.

For the experiments, LSC1 resulted with a maximum secant stiffness of 21.79 $\mathrm{kN} / \mathrm{mm}$, LSC2 with $68.52 \mathrm{kN} / \mathrm{mm}$, LSC2R with $83.5 \mathrm{kN} / \mathrm{mm}$, and LPC3 with 86.54 $\mathrm{kN} / \mathrm{mm}$. Comparing secant stiffness reveals that before tube dishing occurred, LPC3 was the stiffest out of the three experiments.

\subsection{Performance Levels}

According to the FEMA 273 criteria listed in Table 1, nonstructural performance levels during a seismic event can be categorized for all three tests. Thresholds for each level, hazards reduced (N-D), life safety $(\mathrm{N}-\mathrm{C})$, immediate occupancy (N-B), or operational $(\mathrm{N}-\mathrm{A})$ were determined. Cladding connection should be designed to withstand in-plane and out-of-plane loading in a seismic event through all levels of performance. However, should the panel connection fail completely in both plate and push-pull connection. This would be catastrophic in that it may pose a hazard when the panel becomes detached from the building; human lives may be in jeopardy. In other instances, cladding can become economically expensive in terms of maintenance and replacement. In this study, the specimen moves from one performance level of life-safety to immediate occupancy level after yielding of the specimen. Yield displacements defines the transition for the performance level between one level to another.

Table 12 lists the displacement when damage thresholds were achieved for various performance levels for the three experiments. Deformations of each experiment 
were tabulated under four- damage criteria, the first at the maximum strength of the experiment, initial cracking of weld, displacement at $75 \%$ of maximum load, and the displacement at complete fracture. LPC3 attained the highest displacement of $67 \mathrm{~mm}$ at the maximum force, followed by LSC1 at $17 \mathrm{~mm}$ by seventy-five percent degradation of the maximum strength or initial cracking of the metal or weld was assigned a hazard reduced (N-D) level. Both LSC2 and LSC2R did not reach 75\% strength degradation because weld failure was sudden and the specimen failed to resist all load once fracture began.

\subsection{Comparison of Predicted and Experimental Values}

\subsubsection{Accuracy of Predictive Models}

The experiments showed that LSC1 and LPC3 resulted in higher failure strengths than originally expected by $49 \%$ and $10 \%$ respectively. Table 9 lists the comparisons of the actual, experimental, and as-built strengths of each experiment. Based on the predicted force-displacement model of the three experiments. The predicted models were poor and the predicted displacements were lower than the experimental data. However, LSC1 and LPC3 experiments yielded at a strength closely predicted. LSC2 failed at $61 \%$ of the predicted design strength. Predicted force-displacement models were inaccurate compared to experimental data. However, weld fracture was the ultimate failure mode of all three specimens. Appendix E shows that the tensile strength of the steel determined by the coupon tests was higher than the nominal minimum of A36 steel.

\subsubsection{Out-of-Plane Connection Behavior}

LPC3 contained a variation in predicted failure mode in that the rod did not yield as initially predicted. In fact, the dishing and bending of the tube prior to weld fracture governed the displacements of this experiment. The rod sustained large forces without much elongation, however visual inspection of the nut showed signs of minimal bearing stresses with the sides of the nut having been crushed against the plate washer. 
The result of LSC2 and LSC2R was quite different than LPC3. The experimental forces and final failure of the specimen failed at $61 \%$ and $83 \%$ of the nominal design strength. The plate component of lateral seismic connection revealed that this was the stiffest part of the connection for resistance to out-of-plane loading. When the panel moves in-plane, the plate and not the rod connection resist load. Should the panel move out-of-plane as was tested, the plate resists the majority of the load up to a deflection of $7 \mathrm{~mm}(1 / 4 \mathrm{in})$, when the weld on the plate fractures. After this fracture the rod alone will resist the load.

\subsection{Combined Out-of-Plane Behavior}

Combining LSC2 and LPC3 experiments aid in determining the forcedisplacement of the lateral seismic connection as an assembly, instead of individual components. One of the reasons for combining both out-of-plane behaviors was that the stiffness of the overall connection was heavily based on the unintended bending of the $25 \mathrm{~mm}$ plate in LSC2. The tube dishing and bending in LPC3 allowed large displacements at very little force. Together, this allows for the behavior of the lateral seismic connection to be characterized and analyzed when subjected to out-of-plane loading. Figure 56 was the result of the combined data of LSC2 and LPC3 into one graph depicting total force verses the displacement of the connection. Both data files were added together (LSC2 \& LPC3) by summing the force values at equivalent displacements. Looking for the first displacement reading greater than an integer value of every $\mathrm{mm}$, the force values pertaining to every integer was summed together. For example, at their respective 1,2 , or $3 \mathrm{~mm}$ of displacement, their respective forces from LSC2 and LPC3 were added together to illustrate the behavior due to out-of-plane loading. LSC2 data ended after $10 \mathrm{~mm}$; hence data points along the displacements for LPC3 were collected at even integers of displacement after $10 \mathrm{~mm}$. There was no interpolation involved in combining the values of both experiments. The displacement vector was so finely resolved that the error was very small for integer values of displacement. 
The maximum force of the combined connection was $364 \mathrm{kN}$ (81.82 kips) at $10 \mathrm{~mm}(0.40 \mathrm{in})$ of displacement. Figure 56 shows that the lateral seismic connection does reach a peak loading when subjected to out-of-plane loading. Significant post-peak strength degradation is seen after $10 \mathrm{~mm}$ of displacement. However, the connection does maintain some strength capacity after weld fracture. The connection continues to carry loading upwards of $70-80 \%$ of the maximum force. The connection continues to deflect until the connection completely fails at $297 \mathrm{kN}$ (67kips) at $69 \mathrm{~mm}$ of total displacement. The stiffness based on Figure 56 (out-of-plane behavior), was $36.4 \mathrm{kN} / \mathrm{mm}$ at a maximum force of $364 \mathrm{kN}$ (81.83 kips) while resisting a displacement of $10 \mathrm{~mm}(0.40 \mathrm{in})$.

\subsection{Similar Results of All Tests}

The mode of failure that governed the three test specimens in both predicted and actual ultimate load was the failure of the welds. The strains induced in the weld returns were large enough to cause the weld return to crack at a load below expected, especially in experiment LSC2. Ductile failures of the welds were induced in all experiments.

Based on the force-displacement graphs in Figures 42, 44, and 47 it can be seen that the specimens continue to deflect beyond the yield point and suddenly fracture. The secant and tangent stiffness process did not identify an accurate yield displacement value. As shown in these force-displacements graphs, accurate yield displacements can be visually identified. As discussed in Section 5.1 visual inspections were made to select the yield displacement from each force-displacement graph.

As tabulated in Table 11, similarities were in the yield displacements of LSC2 and LPC3 as determined by the secant and tangent stiffness methods. Methods 1 and 2, secant methods, identified similar yield displacements within $10 \%$ of each other. Methods 3 and 4, tangent methods produced identical values respectively for all four tests. There was not much difference with a $5 \%$ or $10 \%$ drop in Tangent stiffness because this curve drops so fast. However, when comparing secant to the tangent methods, both methods yielded different and incomparable displacement values. The secant and tangent methods indicated small displacements of the connection when 
compared to visual inspection displacements. The secant method varied from $30 \%$ to $90 \%$ of visual inspection value. The tangent stiffness method was not that much better than the secant stiffness method in which the values varied from $10 \%$ to $50 \%$ of the visual inspection value.

\subsection{Effect of Change of Test Variables}

Table 2 lists the variation in direction of loading for each specimen tested which was the primary test variable. The direction of panel loading specifies the movement that each specimen would resist in response to the actual movement of the panel. Figure 2 defines out-of-plane and in-plane movements of the designed connection. Testing replicated the intended loading of the connection with the exception of LSC2 where loading occurred out-of-plane instead of the designed in-plane loading. 


\section{CHAPTER 6. CONCLUSIONS AND RECOMMENDATIONS}

\subsection{Results of Original Research Objectives}

The four major objectives of this research were stated in Section 1.2. Forcedisplacement relationships determined the strength of each specimen; accuracy of the predictive models was poor compared to the experimental data. Failure modes of each experiment provided an indication of the failure sequence. Deflections associated with FEMA performance levels were visually identified as opposed to secant and tangent methods. Each experiment was designed to illustrate the characteristics and behavior of a specific component of the lateral seismic connection as they were subjected to different loadings. This chapter will provide an overview on the main conclusions and provide recommendations for future analysis on lateral seismic connection.

\subsection{Conclusions}

Based on the analysis of the data collected and the behavior observed during experimental testing, the following conclusions have been reached:

1. Predicted design strength based upon AISC methods were conservative for $\mathrm{LSC1}$ and $\mathrm{LPC} 3$ experiments. LSC1 resisted $149 \%$ and LPC3 $110 \%$ of the design strength based upon nominal

yield strength and dimensions. However, LSC2 and LSC2R failed at $61 \%$ and $83 \%$ of the designed strength.

2. Accuracy of the predictive model was poor, especially in predicting deflections; prediction models worked better with force.

3. For the performance level of immediate occupancy the lateral seismic connection can move $10 \mathrm{~mm}$ in-plane and $5 \mathrm{~mm}$ out-ofplane.

4. For the performance level of life safety the lateral seismic connection can move $17 \mathrm{~mm}$ in-plane and $67 \mathrm{~mm}$ out-of-plane. 
5. Based on experimental testing, the individual components of the lateral seismic connection are adequate when loaded as their intended design. However, unintended loading of the plate component resulted in fracture at low displacement, leading to a lack of lateral resistance. Particularly when the panel moves outof-plane (outward from the building) as was tested, the plate originally resists the majority of the load, not the push-pull connection. Once the plate component fails, the push-pull connection then resists the load. Unintended loading (as tested in LSC2) of the plate makes the connection very brittle as the welds fracture quickly.

6. Should the plate fail first due to out-of-plane loading and then begin to move in-plane, the connection would become unable to maintain lateral resistance due to the fracture of the weld at the plate component. This failure could result in an unstable situation of the lateral seismic connection.

7. Fracturing of the welds was the dominant mode of failure for all three components of the lateral seismic connection. Weld failure occurs after significant yielding, as was shown in experiments LSC1 and LPC3 with a maximum displacement of $21 \mathrm{~mm}$ and $69 \mathrm{~mm}$ respectively.

8. When data from experiment LSC2 and LPC 3 were added together, the results indicate that significant strength degradation was shown after peak load, but the connection did maintain $70-80 \%$ of strength capacity. As a result, the weld between the tube and column plate initially fractured at $7.62 \mathrm{~mm}$, but displaced a total of $69 \mathrm{~mm}$.

9. The UBC requirement (code section 1633.2.4.2) to not have brittle weld fracture was not met, although the welds fractured after 
significant yielding of the specimens (UBC, 1997). Unfortunately the code does not define what is considered brittle weld fracture. LPC3 was the most ductile component of this connection having values over 10 .

10. Predicted deflections did not reflect the behavior and properties of the tube component. The tube experienced local dishing at small displacements before tube elastic bending became significant.

11. The stiffness of the lateral seismic connection was $36.4 \mathrm{kN} / \mathrm{mm}$ at a maximum force of $364 \mathrm{kN}$ (81.83 kips) and resisting a displacement of $10 \mathrm{~mm}(0.40 \mathrm{in})$.

12. None of the four methods used to identify yield displacement $\left(\Delta_{y}\right)$, appeared to generate accurate results.

13. It appears that the strength of the lateral seismic connection or assembly is so large that most panel systems can never generate the loading needed for panel failure. Movement and displacements would need to come from other cladding connections within the panel system.

\subsection{Recommendations for Engineering Practice}

Experiment LPC3 illustrated an apparent lack of transverse stiffness on the tube to resist local bending. The side of the tube deformed easily rather than bending along the tubes cantilevered length. (The tube was heavily subjected to dishing of the tube walls.) Forces resisted by the rod were low until local bending deformed to completely collapse the tube. It should be noted that the addition of a plate at the end of the tube would significantly stiffen the resistance to seismic loading.

Without plate reinforcement this component of the connection would not resist out-of-plane movement of the panel as intended during design. The predicted deflections did not accurately reflect the properties and behavior of the tube. As concluded in Points 5 and 6 of Section 6.2 the connection may load components outside of the connection's 
intended designed load path. If so, it should be noted that, should the plate connection fail first there is no lateral resistance maintained by the connection. In-plane strength of the panel system is lost if the connection is originally fractured by out-of-plane loading.

\subsection{Recommendations for Contimuation of Research}

The data collected for the latter three experiments, LSC2, LSC2R, and LPC3 should be investigated using computer based regression or bi-linear models to accurately predict the yield point of each specimen. Finite element analyses can be performed to determine the initial stiffness, displacements, and ultimate strengths to which the specimens supporting precast panels of various geometries are subjected during service. In addition, better analysis of the data and an improved prediction model may allow for better identification of the yield point of each experiment and component.

Additional testing by subjecting the specimens to cyclic loading will predict and verify the severity and deformations of the specimens due to cyclic seismic forces. This type of testing will determine the amount of cyclic deflection that the connection can withstand without damage. The data from these tests would be useful for selecting the type of plates, tubes, and welds sizes best suited to support the precast cladding panel.

In terms of monotonic loading, a change in the loading direction of conducting LSC2 by in-plane loading instead of out-of-plane loading can further verify the stiffness and behavior of the connection due to this specific intended loading. In addition, an experimental retest of LSC2 using a new $25 \mathrm{~mm} \times 125 \mathrm{~mm}(1 \times 5)$ plate can further verify the data attained by LSC2 and LSC2R.

Based on Kwong and McMullin's (2002) pushover analysis of precast cladding connections, it is recommended that the analysis and values be updated with the forcedisplacement relationship from this research. By incorporating the values of strength and stiffness of the lateral seismic connection into their pushover analysis model, a more accurate analysis can result for precast concrete panels. 


\section{REFERENCES}

American Institute of Steel Construction (1994). Manual of Steel Design-LRFD. Vol. I Chicago.

American Institute of Steel Construction (1994). Manual of Steel Design-LRFD. Vol. II Chicago.

Chan, K., McMullin, K.M. (2003). "Experimental Investigations of Push-Pull Precast Cladding Connections." Report No. 2003-03 San Jose State University, Department of Civil and Environmental Engineering, San Jose, CA.

Cohen, J.M. (1995). "Seismic Performance of Cladding Responsibility Revisited." Journal of Performance of Constructed Facilities, ASCE, 9(4), 254-270.

Craig, J.I., Goodno, B.J., Pinelli, J.P., and Moor, C. (1992). "Modeling and Evaluation of Ductile Cladding Connections systems for Seismic Response Attenuation in Buildings." Proceedings of the $10^{\text {th }}$ World Conference on earthquake engineering, No 19-24, Vol. 7 C. 2, 4183-4188.

Craig, J.I., Leistikow, R., and Fennell, C.J. (1988). "Experimental Studies of the Performance of Precast Cladding Connections." Proceedings of Ninth World Conference on Earthquake Engineering, Vol. 6, C.2, 201-206.

Drake, R.M., and Bachman, R.E. (1996). "NEHRP Provisions for 1994 for Nonstructural Components." Journal of Architectural Engineering, ASCE, 2(1), 26-31.

Federal Emergency Management Agency (1997). NEHRP Guidelines for Seismic Rehabilitation of Buildings. FEMA-273. Building Seismic Safety Council, Washington, D.C.

Goodno, B.J., Craig, J.I., and Hsu, C.C. (1991). "Experimental Studies and Analytical Evaluation of Ductile Cladding Connections," Pacific Conference on Earthquake Engineering, Auckland New Zealand 20-23, 43-49.

Goodno, B.J., Meyyappa, M., and Nagarajaiah, S. (1988). "A Refined Model for Precast Cladding and Connections." Proceedings of Ninth World Conference on Earthquake Engineering, Vol. 6, C.2, 195-200.

International Conference of Building Officials (ICBO). (1997). Uniform Building Code, Whittier, Calif. 
Kwong, A., and McMullin, K.M. (2003). "Pushover Analysis and Vibration Characteristics of Precast Cladding Panels." Report No. 2003-07 San Jose State University, Department of Civil and Environmental Engineering, San Jose, CA.

McMullin, K.M., Chan, K., Choi, C., and Kwong, A. (2003a). "Performance Engineering of Precast Cladding Systems." 2003 Structures Conventions, ASCE, Seattle Washington, May 29-June 1.

McMullin, K.M., Merrick, D., Hildebrand, M., and Kwong, A. (2003b). "In-Situ Vibration Characteristics of Precast Cladding Panels." 2003 Structures Conventions, ASCE, Seattle Washington, May 29-June 1.

PCI (1999). PCI Design Handbook Precast and Prestressed Concrete, $5^{\text {th }}$ Edition, PCI, Chicago, Illinois, 1-17-18, 6-37-40.

Pietroforte, R. (1995). "Cladding Systems: Technological Change and Design Arrangements." Journal of Architectural Engineering, ASCE, 1(3), 100-107.

Pinelli, J.P., Craig, J.I., and Goodno, B.J. (1990). "Development and Experimental Calibration of Selected Dynamic Models for Precast Cladding Connections." Proceedings of Fourth U.S. National Conference on Earthquake Engineering, Vol. 2, $147-156$.

Pinelli, J.P., Moor, C., and Craig, J.I. (1992). "Experimental Testing of Ductile Cladding Connections for Building Façade." The Structural Design of tall Buildings, Vol. 1 , No 1, 57-72.

Pinelli, J.P., Moor, C., Craig, J.I., and Goodno, B.J. (1996). "Testing of Energy Dissipating Cladding Connections." Earthquake Engineering and Structural Dynamics, Vol 25, 129-147.

Rihal, S. (1988). "Earthquake Resistance and behavior of Heavy Facades/ Cladding and Connections in Medium Rise Steel Framed Buildings." Proceedings of Ninth World Conference on Earthquake Engineering, Vol. 6, C.2, 207-212.

Salmon, G.C., and Johnson, J.E (1996). Steel Structures: Design and Behavior, $4^{\text {th }}$ Ed. Harper Collins, New York.

Segui, W. T. (1998). LRFD Steel Design, $2^{\text {nd }}$ Ed. PWS Publishing, Pacific Grove.

Weston, N.R., Craig, J.I., and Goodno, B.J. (2002). "Passive Control of Seismic Response Using Ductile Cladding Panels." Seventh US National Conference on Earthquake Engineering, (7NCEE), Boston, MA, July 21-25. 


\section{APPENDIX A. NOTATIONS}

\author{
A \\ $A_{p}$ \\ $\mathrm{C}_{1}$ \\ C \\ $\mathrm{C}_{\mathrm{a}}$ \\ $\mathrm{CCW}$ \\ $\mathrm{Ch}$ \\ CL \\ D \\ Displ \\ E \\ $\mathrm{E}_{\text {total }}$ \\ F \\ FEMA \\ $F_{\text {exx }}$ \\ $F_{p}$ \\ $F_{u}$ \\ $\mathrm{F}_{\mathrm{y}}$ \\ $I_{p}$ \\ $\mathrm{I}_{\mathrm{y}}$ \\ L \\ LSC \\ LSCR \\ LPC \\ $\mathrm{L}_{\mathrm{w}}$ \\ NEHRP \\ $\mathrm{P}$ \\ PCI \\ $\mathrm{P}_{\mathrm{p}}$ \\ $\mathrm{R}_{\mathrm{n}}$ \\ $\mathrm{R}_{\mathrm{p}}$ \\ $\mathrm{W}_{\mathrm{p}}$ \\ WP \\ $a_{p}$ \\ b \\ $b_{p l}$ \\ $\mathrm{e}_{\mathrm{x}}$ \\ Cross sectional area of rod based on $d_{\mathrm{rms}}$ or of plate \\ Component acceleration factor, varies from 1.00 to 1.50 \\ Electrode strength coefficient from, use 1.0 for E70XX \\ Coefficient tabulated below, a function of a and $\mathrm{k}$ \\ Seismic coefficient at grade \\ Counter clockwise \\ Channel \\ Center Line \\ Number of sixteenth of an inch in the fillet weld size \\ Displacement \\ Modulus of Elasticity of steel \\ Total energy \\ Force \\ Federal Emergency Management Agency \\ Tensile strength of electrode material \\ Minimum seismic design force \\ Tensile strength of rod \\ Yield stress \\ Component importance factor, which varies from 1.00 to 1.50 \\ Moment of inertia about $\mathrm{Y}$-axis \\ Length \\ Lateral seismic connection \\ Lateral seismic connection Retest \\ Lateral push-pull connection \\ Characteristic length of weld group \\ National Earthquake Hazards Reduction Program \\ Load \\ Precast Concrete Institute \\ Predicted load \\ Strength of weld \\ Component-response modification factor, varies from 1.50-6.0 \\ Component operating weight \\ Wire potentiometer \\ Component amplification factor, varies from 1.00 to 1.50 \\ Length dimension, LSC2: from face of column flange to beginning of \\ weld; LPC3: from face of column plate to centerline of coil rod \\ Width of the plate \\ Horizontal component of eccentricity with respect to centroid of weld \\ group
}




$\begin{array}{ll}\text { in } & \text { Inches } \\ \mathrm{k}_{\text {secant }} & \text { Secant Stiffness } \\ \mathrm{k}_{\text {tangent }} & \text { Tangent Stiffness } \\ \mathrm{kips} & \text { Kilo-pounds } \\ \mathrm{kN} & \text { Kilo-newton } \\ \mathrm{t} & \text { Thickness of the plate } \\ \mathrm{t}_{\mathrm{e}} & \text { Effective throat dimension } \\ \Delta_{\text {connection }} & \text { The displacement at the centerline of specimen } \\ \Delta_{\text {dish }} & \text { Displacement due to tube dishing } \\ \Delta_{\mathrm{L}} & \text { Deflection of the angle } \\ \Delta_{\mathrm{T}} & \text { Total displacement } \\ \Delta_{\text {max }} & \text { Maximum displacement } \\ \Delta_{\mathrm{mid}} & \text { Mid-length displacement of the plate } \\ \Delta_{\mathrm{pL}} & \text { Deflection of the plate } \\ \Delta_{\mathrm{rod}} & \text { Rod displacement } \\ \Delta_{\mathrm{tip}} & \text { Tip displacement of the plate } \\ \Delta_{\mathrm{TS}} & \text { Tube displacement } \\ \Delta_{\mathrm{ult}} & \text { Ultimate displacement } \\ \Delta_{\text {Yield }} & \text { Yield displacement } \\ \mu_{\mathrm{E}} & \text { Energy ductility } \\ \mu_{\mathrm{max}} & \text { Maximum ductility } \\ \mu_{\mathrm{ult}} & \text { Ultimate displacement } \\ \end{array}$




\section{APPENDIX B.}

\section{GLOSSARY}

Actual Strength

As-built Strength

Column Beam

Component

In-plane Movement

Loading Direction

Local Bending

Nominal strength

Out-of-plane movement

Plate Bending Side of Tube
Values based on experimental data and failure strength of each experiment.

Calculations used LRFD or AISC equations, however dimensions of weld size, lengths, or yield stress were based on measurements from actual specimens.

W12X120 beam, $4.7 \mathrm{~m}$ (15ft) long. Specimens are welded to this column, and loading is applied through the web of this column to achieve failure.

Individual pieces or specimens that make up the lateral seismic connection.

Movement of the panel parallel to the cladding connection. (Figure 2)

Describes the direction that the specimen is being subjected. In this case, LSC1 is axial, LSC2, LSC2R, and LPC3 were applied in tension and pushed upwards by the column beam.

The process of crushing and folding the tube wall in the weak axis. Similar terms used are dishing and cupped.

Calculations for this strength were based on LRFD formulas using the nominal yield strength of the steel and nominal dimensions.

In-and-outward movement of the panel against the cladding connection. (Figure 2)

Similar process to local bending 
Reaction Blocks

Reaction Frame

Reaction Plate

Smoothing

Testing Arrangement

Testing Specimen

Whitewash
Composed of two-W24x68 beams that simulate precast concrete panels. (Figure 15)

A-frame bolted to the ground and W16 40 beam to guide the vertical rise of the loading column. (Figure 16)

$400 \mathrm{~mm} \times 480 \mathrm{~mm} \times 13 \mathrm{~mm}(16 \times 19 \times 1 / 2)$ steel plate connecting the top of both W24 reaction blocks. Eight-A325 bolts per plate connected the plate to the reaction blocks.

Process that was used to clear large spikes and valleys within the tangent stiffness data. This process was averaging 11 data points.

Describing non-essential parts to the experiment like the column beam, reaction blocks and reaction frame. Arrangement includes parts that do not govern the experiments.

Describing the components of the lateral seismic connection like the $25 \mathrm{~mm}$ plate, TS $8 \times 8 \times 3 / 8$, $\mathrm{L} 8 \times 8 \times 1$, and $25 \mathrm{~mm}$ diameter rod

Apply lime-coat wash to the specimen to aid in determining yielding of the specimen. 


\section{APPENDIX C.}

\section{TABLES}

Table 1. FEMA-273 Cladding Component Performance Levels (1997)

\begin{tabular}{|c|c|c|c|}
\hline $\begin{array}{l}\text { Hazards Reduced } \\
\text { N-D }\end{array}$ & $\begin{array}{l}\text { Life Safety } \\
\text { N-C }\end{array}$ & $\begin{array}{l}\text { Immediate } \\
\text { Occupancy N-B }\end{array}$ & $\begin{array}{l}\text { Operational } \\
\mathrm{N}-\mathrm{A}\end{array}$ \\
\hline $\begin{array}{l}\text { Severe damage to } \\
\text { connections and } \\
\text { cladding. Many } \\
\text { panels loosened. }\end{array}$ & $\begin{array}{l}\text { Severe distortion in } \\
\text { connections. } \\
\text { Distributed cracking, } \\
\text { bending, crushing, } \\
\text { and spalling of } \\
\text { cladding elements. } \\
\text { Some fracturing of } \\
\text { cladding, but panels } \\
\text { do not fall. }\end{array}$ & $\begin{array}{l}\text { Connections yield; } \\
\text { minor cracks }\left(<1 / 16^{\prime \prime}\right. \\
\text { width) or bending in } \\
\text { cladding. }\end{array}$ & $\begin{array}{l}\text { Connections yield; } \\
\text { minor cracks ( }<1 / 16^{\prime \prime} \\
\text { width) or bending in } \\
\text { cladding. }\end{array}$ \\
\hline
\end{tabular}

Table 2. Experimental Test Matrix

\begin{tabular}{ccccc}
\hline Test No. & $\begin{array}{c}\text { Connection } \\
\text { Component }\end{array}$ & $\begin{array}{c}\text { Mode of Component } \\
\text { Loading }\end{array}$ & $\begin{array}{c}\text { Direction of } \\
\text { Panel Loading }\end{array}$ & $\begin{array}{c}\text { Member of } \\
\text { Design Load Path }\end{array}$ \\
\hline LSC1 & Plate/Angle & $\begin{array}{c}\text { Axial } \\
\text { Shear }\end{array}$ & In Plane Horizontal & Yes \\
LSC2 & Plate/Angle & $\begin{array}{c}\text { Tension } \\
\text { Bending }\end{array}$ & In Plane Horizontal & No \\
& & Out-of-Plane Horizontal & \\
LPC3 & Tube/Rod & Tension & In Plane Horizontal & Yes \\
& & Compression & Out-of-Plane Horizontal & \\
& & Bending & & \\
\hline
\end{tabular}

Table 3. Predicted Results of Experiment: LSC1

\begin{tabular}{lccccccc}
\hline Failure Mode & \multicolumn{2}{c}{$\begin{array}{c}\text { Lower Bound } \\
\text { Value }\end{array}$} & & \multicolumn{2}{c}{ Mean } & \multicolumn{2}{c}{$\begin{array}{c}\text { Upper Bound } \\
\text { Value }\end{array}$} \\
\hline & $\mathrm{kN}$ & $\mathrm{kip}$ & $\mathrm{kN}$ & $\mathrm{kip}$ & $\mathrm{kN}$ & $\mathrm{kip}$ \\
\cline { 2 - 8 } & 155 & 34.85 & 206.7 & 46.46 & 258.3 & 58.07 \\
Weld fracture (Due to Shear) & 191.3 & 43 & 255 & 57.33 & 318.8 & 71.66 \\
Weld fracture (Due to eccentrically loaded & & & & & & \\
weld groups) & 504.5 & 113.4 & 560.5 & 126 & 613.9 & 138 \\
Plate yielding at tapered end & 720.6 & 162 & 800.7 & 180 & 880.9 & 198 \\
Plate yielding & 5465 & 1228.6 & 6072 & 1365.12 & 6679 & 1501.63 \\
Angle bending (Due to yield) & & & & & & \\
\hline
\end{tabular}


Table 4. Predicted Results of Experiment: LSC2/ LSC2R

\begin{tabular}{lccccccc}
\hline Failure Mode & \multicolumn{2}{c}{$\begin{array}{c}\text { Lower Bound } \\
\text { Value }\end{array}$} & \multicolumn{2}{c}{ Mean } & \multicolumn{3}{c}{$\begin{array}{c}\text { Upper Bound } \\
\text { Value }\end{array}$} \\
\hline & $\mathrm{kN}$ & $\mathrm{kip}$ & $\mathrm{kN}$ & $\mathrm{kip}$ & $\mathrm{kN}$ & $\mathrm{kip}$ \\
\cline { 2 - 8 } & 159.3 & 35.8 & 177 & 39.78 & 194.7 & 43.76 \\
$\begin{array}{l}\text { Weld fracture at W12 column beam and plate } \\
\text { (Due to Tension) }\end{array}$ & 167.6 & 37.68 & 186.2 & 41.86 & 204.8 & 46.04 \\
Plate bending & 191.3 & 43 & 255 & 57.33 & 318.8 & 71.66 \\
$\begin{array}{l}\text { Weld fracture at angle due to shear and torsion } \\
\text { (Due to eccentrically loaded weld groups) }\end{array}$ & & & & & & &
\end{tabular}

Table 5. Predicted Results of Experiment: LPC3

\begin{tabular}{lccccccc}
\hline Failure Mode & $\begin{array}{c}\text { Lower Bound } \\
\text { Value }\end{array}$ & & \multicolumn{2}{c}{ Mean } & \multicolumn{3}{c}{$\begin{array}{c}\text { Upper Bound } \\
\text { Value }\end{array}$} \\
\hline & $\mathrm{kN}$ & $\mathrm{kip}$ & $\mathrm{kN}$ & $\mathrm{kip}$ & $\mathrm{kN}$ & $\mathrm{kip}$ \\
\cline { 2 - 8 } & 69.3 & 15.57 & 92.3 & 20.76 & 115.4 & 25.9 \\
Rod Failure & 186 & 41.82 & 248 & 55.76 & 310.1 & 69.7 \\
$\begin{array}{l}\text { Weld fracture at tube and top of col plate (Due } \\
\text { to shear) (1 side) }\end{array}$ & 223 & 50.12 & 297.3 & 66.83 & 371.5 & 83.51 \\
$\begin{array}{l}\text { Weld fracture at Tube and top of col plate } \\
\text { (Due to tension) (1 side) }\end{array}$ & 403.1 & 90.61 & 537.4 & 120.81 & 671.8 & 151 \\
$\begin{array}{l}\text { Weld fracture at column plate and W12 } \\
\text { column }\end{array}$ & 409 & 91.94 & 545.3 & 122.59 & 681.6 & 153.2 \\
$\begin{array}{l}\text { Combined weld fracture of both 3 and 7in } \\
\text { length weld }\end{array}$ & 632.2 & 142.12 & 702.6 & 157.94 & 773.9 & 173.7 \\
\hline Tube Bending & & & & & & &
\end{tabular}

Table 6. Instrumentation of Experiment: LSC1

\begin{tabular}{cccc}
\hline Channels & Instrument/Serial \# & Placement & Measures \\
\hline 1 & Intemal Pressure Meter & Actuator & Force \\
2 & Dial Gage \#1 & Test Specimen & Vertical Displacement \\
3 & Dial Gage \#2 & Test Specimen & Horizontal Displacement \\
\hline
\end{tabular}


Table 7. Instrumentation of Experiment: LSC2/ LSC2R

\begin{tabular}{cccc}
\hline Channels & Instrument/Serial \# & Placement & Measures \\
\hline 1 & Load Cell/ 46296 & Actuator (Left Piston) & Force \\
8 & Load Cel1/ 47161 & Actuator (Right Piston) & Force \\
3 & Wire pot/ C1054469 & Column Beam (W12 Right) & Displacement \\
6 & Wire pot/ C1054470 & Column Beam (W12 Left) & Displacement \\
2 & Wire pot/ B1052679 & Test Specimen (Front Left Plate) & Displacement \\
5 & Wire pot/ C1054518 & Test Specimen (Front Right Plate) & Displacement \\
4 & Wire pot/ B1051980 & Test Specimen (Middle of Plate) & Displacement \\
\hline
\end{tabular}

Table 8. Instrumentation of Experiment: LPC3

\begin{tabular}{cccc}
\hline Channels Instrument/Serial \# & Placement & Measures \\
\hline 1 & Load Cell/ 46296 & Actuator (Left Piston) & Force \\
8 & Load Cell/ 47161 & Actuator (Right Piston) & Force \\
3 & Wire pot/ C1054469 & Column Beam (W12 Right) & Displacement \\
6 & Wire pot/ C1054470 & Column Beam (W12 Left) & Displacement \\
4 & Wire pot/ B1051980 & CL of Rod & Displacement \\
2 & Wire pot/ B1052679 & On the tube along the rod bolt line & Displacement \\
5 & Wire pot/ C1054518 & On tube at b/t the column plate and rod bolt line & Displacement \\
\hline
\end{tabular}

Table 9. Comparison of Predicted and Actual Strength

\begin{tabular}{ccccccc}
\hline Experiment & \multicolumn{2}{c}{ Actual Strength } & \multicolumn{2}{c}{ Design Strength } & \multicolumn{2}{c}{ As-built Strength } \\
& $\mathrm{kN}$ & $\mathrm{kip}$ & $\mathrm{kN}$ & $\mathrm{kip}$ & $\mathrm{kN}$ & $\mathrm{kip}$ \\
\hline LSC1 & 307.5 & 69.12 & 206.7 & 46.46 & 308.4 & 69.34 \\
LSC2 & 154.0 & 34.63 & 255.0 & 57.33 & 257.1 & 57.79 \\
LSC2R & 147.2 & 33.09 & 177.0 & 39.78 & 248.9 & 55.96 \\
LPC3 & 325.6 & 73.21 & 248 & 55.76 & 206.7 & 46.48 \\
\hline
\end{tabular}


Table 10. Ductility and Energy of Test Specimen

\begin{tabular}{ccccccc}
\hline Failure Mode & $\begin{array}{c}\text { Yield } \\
\text { Displ }\end{array}$ & $\begin{array}{c}\text { Ultimate Maximum } \\
\text { Ductility }\end{array}$ & $\begin{array}{c}\text { Energy } \\
\text { Ductility }\end{array}$ & $\begin{array}{c}\text { Total Energy } \\
\text { Dissipated } \\
\text { (kN-mm) }\end{array}$ \\
\hline LSC1 & 10.74 & 1.4 & 1.6 & 1.9 & 2829.0 & 4-Nov-02 \\
LSC2 & 4.50 & 2.0 & 2.2 & 4.2 & 1352.7 & 14-Feb-03 \\
LSC2R & 4.00 & 1.1 & 1.8 & 3.1 & 880.0 & $17-F e b-03$ \\
LPC3 & 5.00 & 13.4 & 13.8 & 41.2 & 18289.0 & 5-Feb-03 \\
\hline
\end{tabular}

Table 11. Stiffness Method for Defining Yield

\begin{tabular}{cccccc}
\hline Procedure & LSC1 & LSC2 & LSC2R & LPC3 & $\begin{array}{c}\text { LSC2 + } \\
\text { LPC3 }\end{array}$ \\
& $(\mathrm{mm})$ & $(\mathrm{mm})$ & $(\mathrm{mm})$ & $(\mathrm{mm})$ & $(\mathrm{mm})$ \\
\hline 1 & 3 & 4 & 5 & 6 & 7 \\
\hline Method 1 & 13.6 & 0.31 & 0.35 & 0.33 & 2.00 \\
Method 2 & 15.0 & 0.35 & 0.55 & 0.37 & 2.50 \\
Method 3 & 9.10 & 2.53 & 1.07 & 2.33 & 2.00 \\
Method 4 & 9.10 & 2.53 & 1.07 & 2.33 & 2.00 \\
0.2\% Offset & 13.74 & $\mathrm{n} / \mathrm{r}$ & $\mathrm{n} / \mathrm{r}$ & $\mathrm{n} / \mathrm{r}$ & $\mathrm{n} / \mathrm{r}$ \\
Visual Inspection & 10.00 & 4.50 & 4.00 & 5.00 & 4.50 \\
\hline Displacement used & 10.74 & 4.50 & 4.00 & 5.00 & $\mathrm{n} / \mathrm{r}$ \\
\hline
\end{tabular}

Notes:

1. For calculation of permanent deformation, four methods were used to predict the initial yielding of the specimen: Method $1=$ drop in secant stiffness of $5 \%$, Method $2=$ drop in secant stiffness of $10 \%$, Method $3=$ drop in tangent stiffness of 5\%, and Method $4=$ drop in tangent stiffness of $10 \%$.

2. $n / a$ means that the limit state was not observed during the test.

3. $\quad \mathrm{n} / \mathrm{r}$ means that the limit state was not recorded or measurable during the test. 
Table 12. Displacement Damage Thresholds for Performance Based Design

\begin{tabular}{|c|c|c|c|c|c|c|}
\hline $\begin{array}{l}\text { Damage } \\
\text { Criteria }\end{array}$ & $\begin{array}{c}\text { FEMA-273 } \\
\text { Performance } \\
\text { Level } \\
(\mathrm{mm})\end{array}$ & $\begin{array}{l}\text { Specimen } \\
\text { LSC1 } \\
\text { (mm) }\end{array}$ & $\begin{array}{l}\text { Specimen } \\
\text { LSC2 } \\
\text { (mm) }\end{array}$ & $\begin{array}{l}\text { Specimen } \\
\text { LSC2R } \\
\text { (mm) }\end{array}$ & $\begin{array}{l}\text { Specimen } \\
\text { LPC3 } \\
\text { (mm) }\end{array}$ & $\begin{array}{c}\text { Specimen } \\
\text { LSC2 + } \\
\text { LPC3 } \\
(\mathrm{mm})\end{array}$ \\
\hline 1 & 2 & 3 & 4. & 5 & 6 & 7 \\
\hline $\begin{array}{c}\text { Strength } \\
\text { Degradation }\end{array}$ & $\mathrm{N}-\mathrm{C}$ & 17.0 & 8.8 & 4.3 & 67.0 & 10.0 \\
\hline $\begin{array}{c}\text { Strength } \\
\text { Degradation of } \\
75 \%\end{array}$ & N-D & 19.0 & 8.8 & 4.3 & 69.0 & $\mathrm{n} / \mathrm{a}$ \\
\hline $\begin{array}{c}\text { Initial Cracking } \\
\text { of Metal or } \\
\text { Weld }\end{array}$ & N-D & 7.5 & 7.6 & 7.1 & 36.0 & 7.6 \\
\hline $\begin{array}{l}\text { Complete } \\
\text { Fracture of } \\
\text { Component }\end{array}$ & $\mathrm{n} / \mathrm{a}$ & 21.3 & 10.0 & 7.1 & 69.0 & 69.0 \\
\hline
\end{tabular}

Notes:

1. n/a means that the limit state was not observed during the test.

2. $n / r$ means that the limit state was not recorded or measurable during the test. 


\section{APPENDIX D. FIGURES}

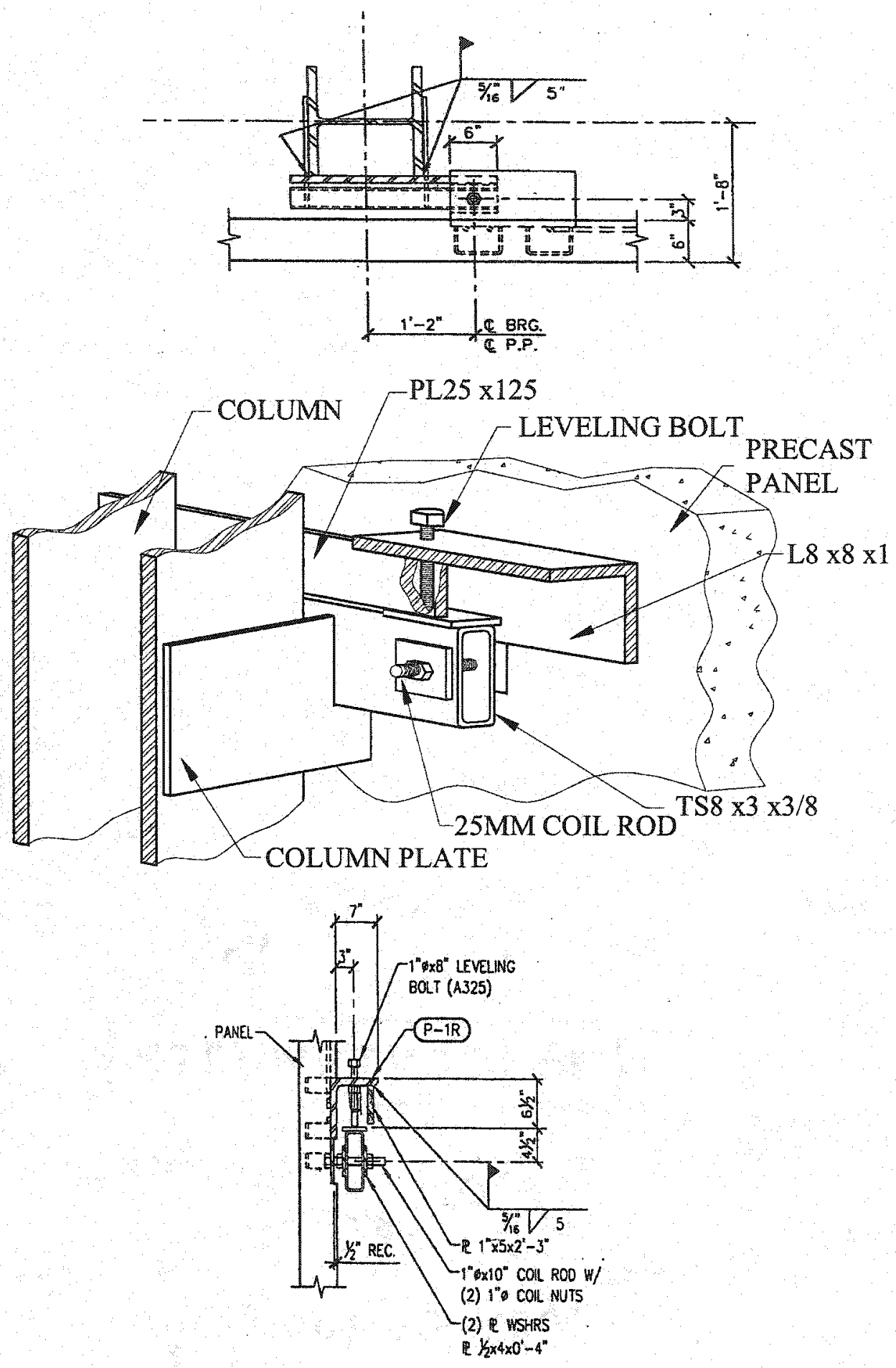

Fig. 1. Lateral Seismic Connection based upon Detail Drawings provided by Willis Construction 


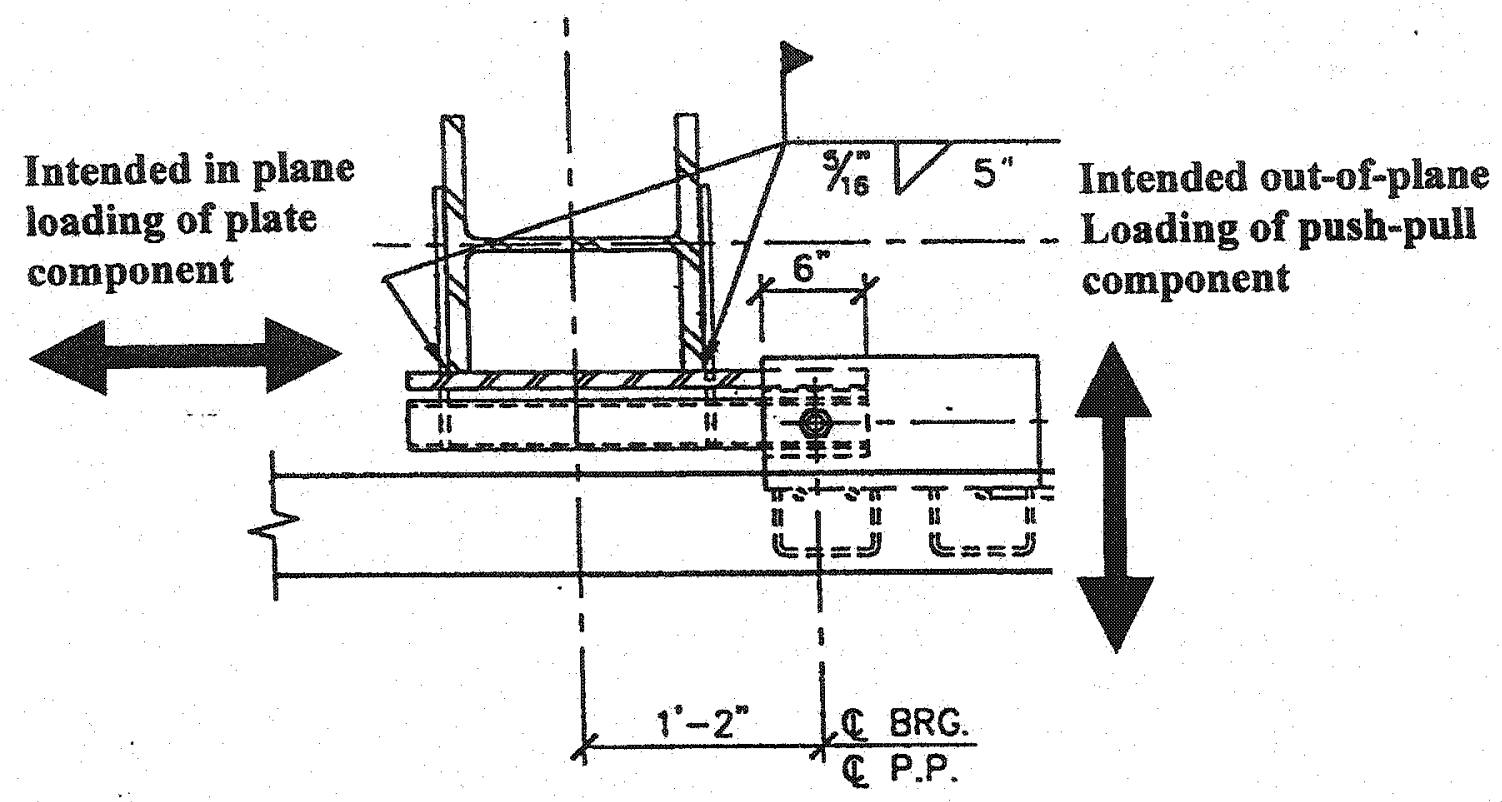

Fig. 2. Intended Designed Loading of Lateral Seismic Connection

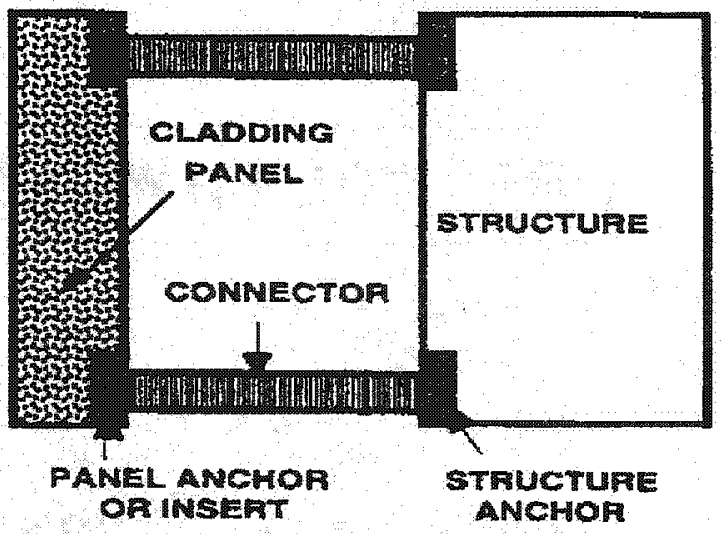

Fig. 3. Three Main Components in an Advanced Connection (Pinelli et al, 1992) 


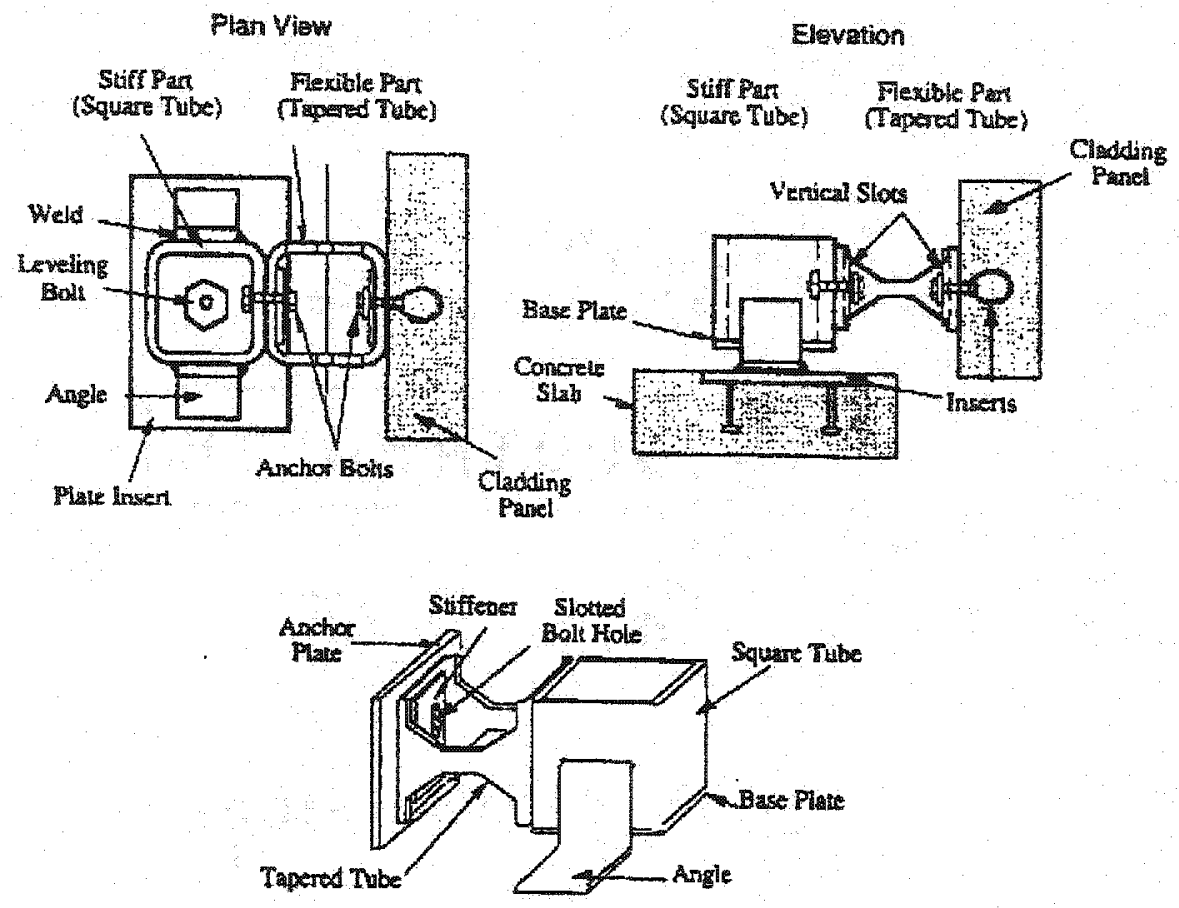

Fig. 4. Slotted Bolted Connection (Pinelli et al, 1996) 

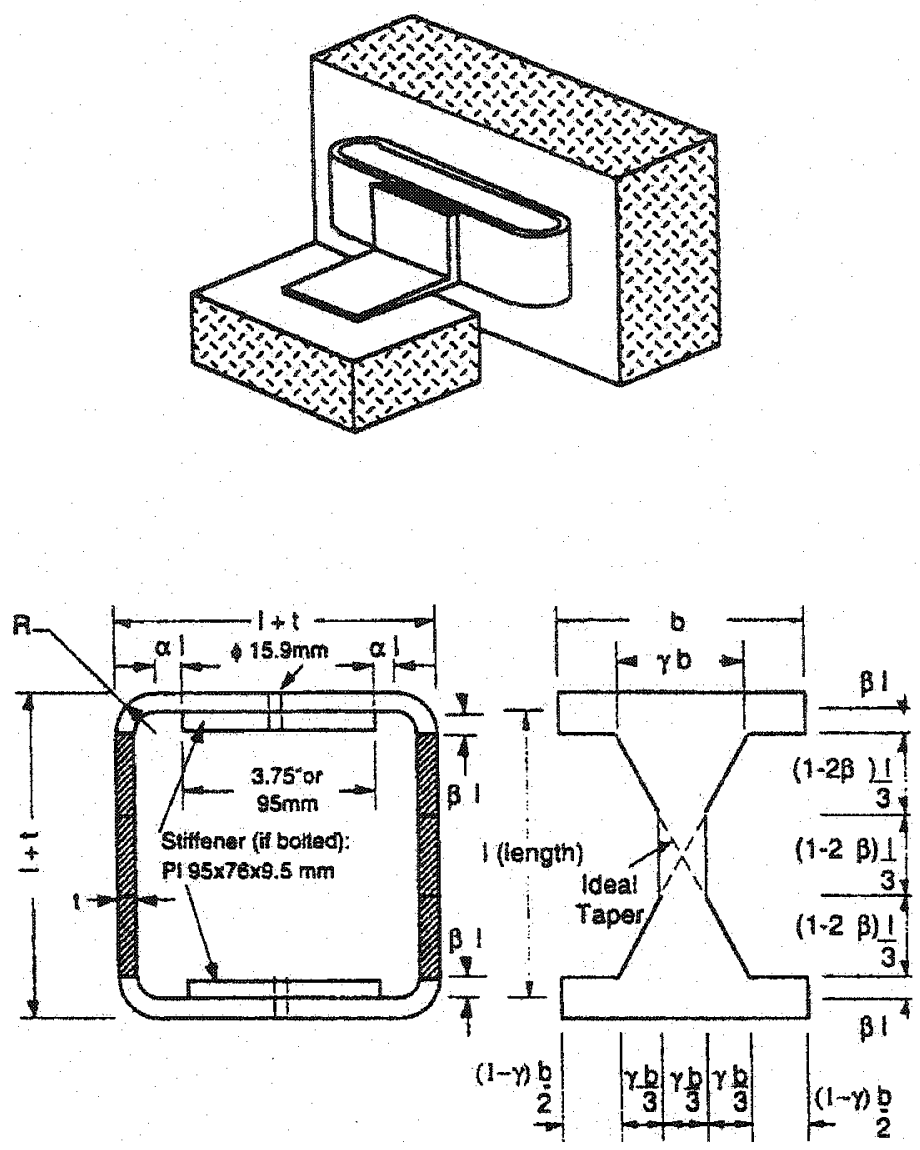

Fig. 5. Tapered Connection Geometry of Slotted Bolted Connection (Pinelli et al, 1996) 


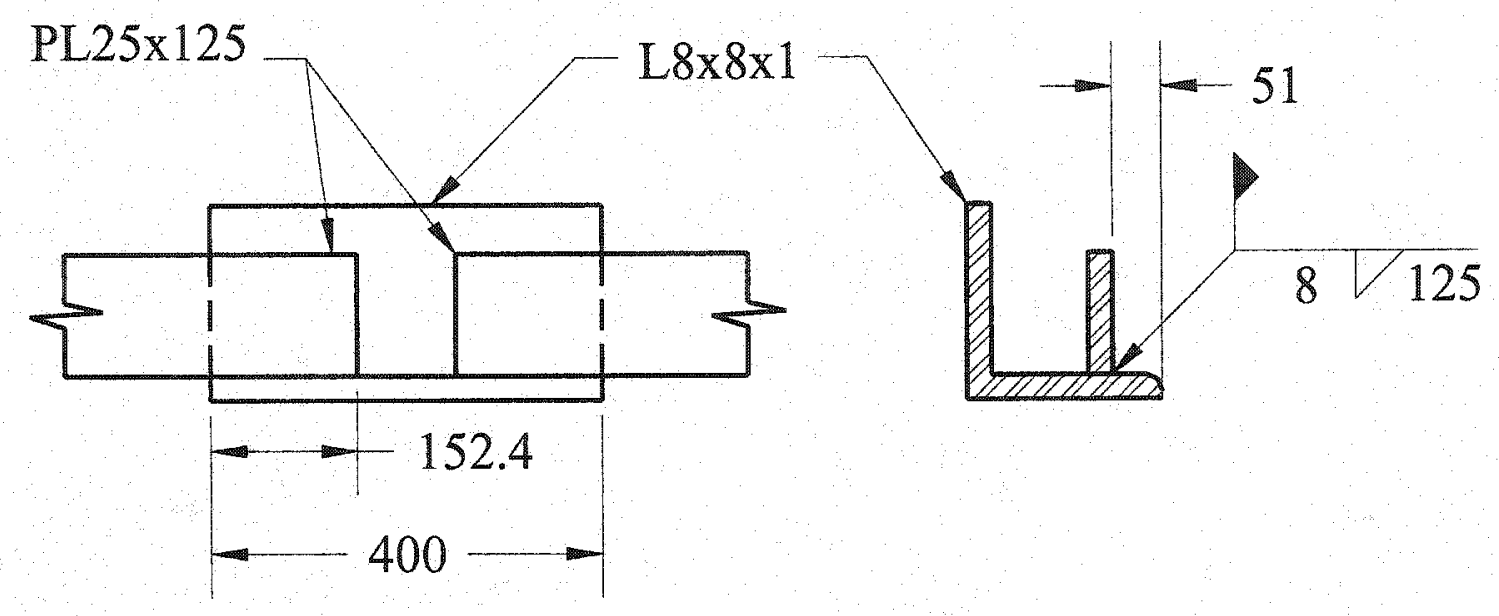

FRONT VIEW

CROSS SECTIONAL VIEW

Fig. 6. LSC1 Test Specimen

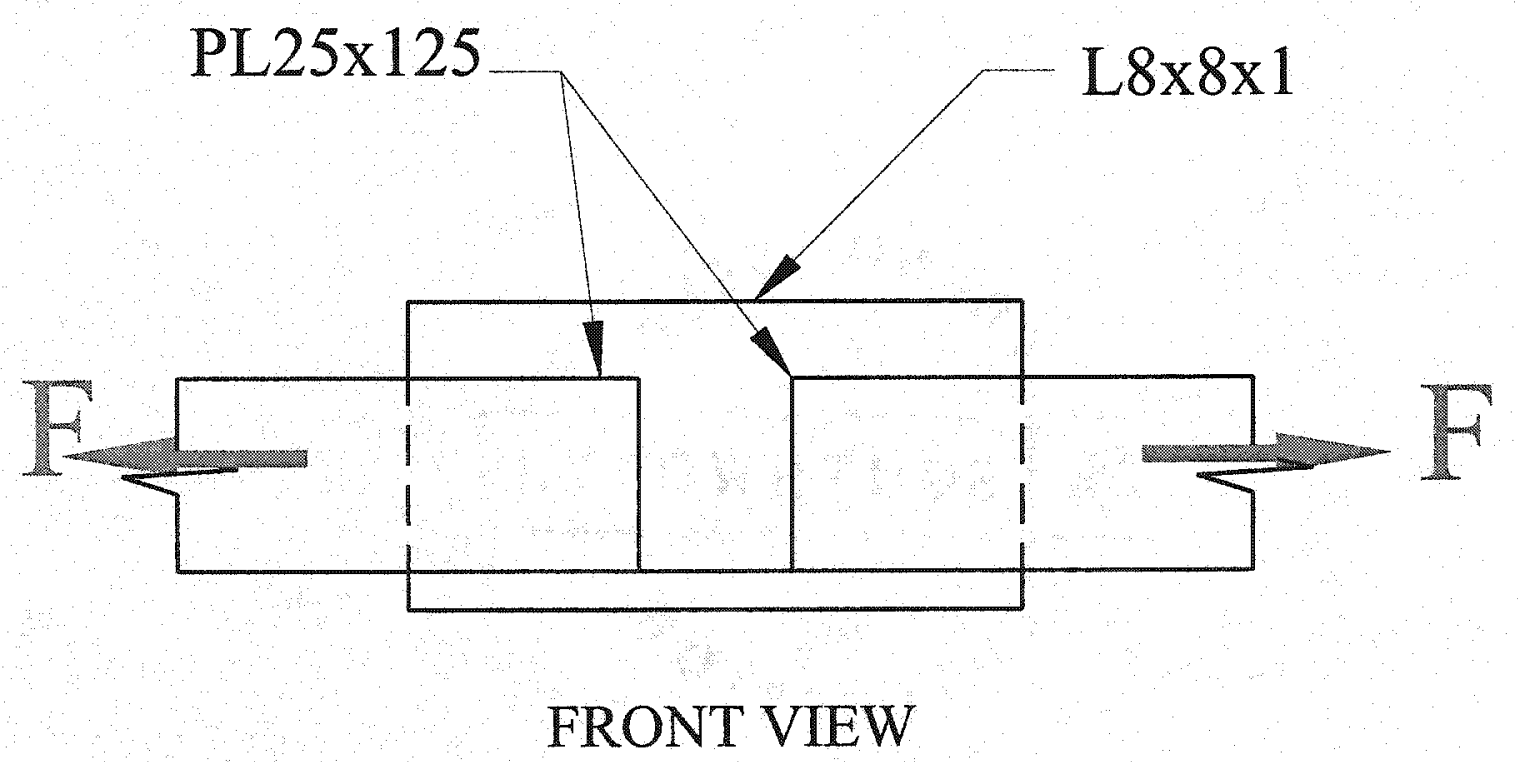

Fig. 7. LSC1 Force Loading Diagram 


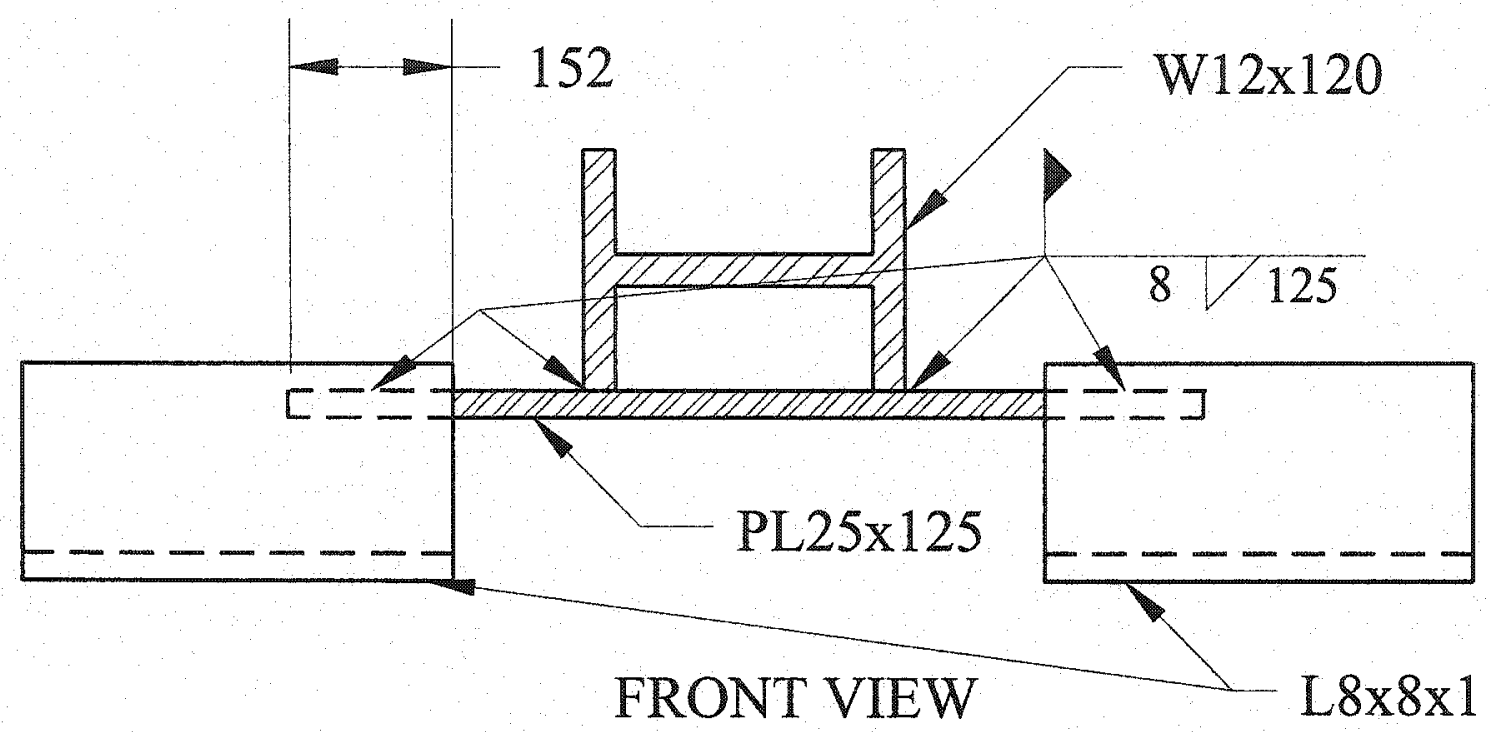

Fig. 8. LSC2 Test Specimen

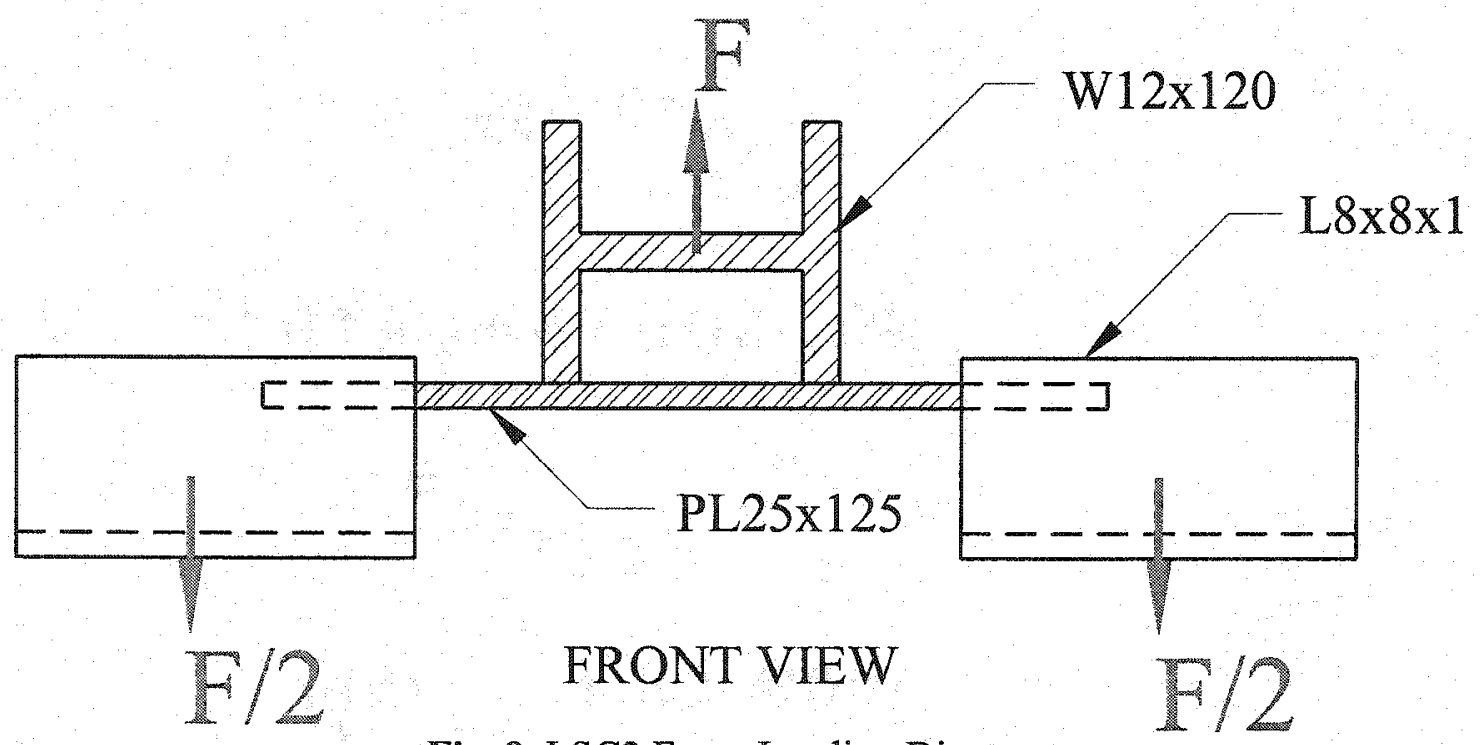

Fig. 9. LSC2 Force Loading Diagram 


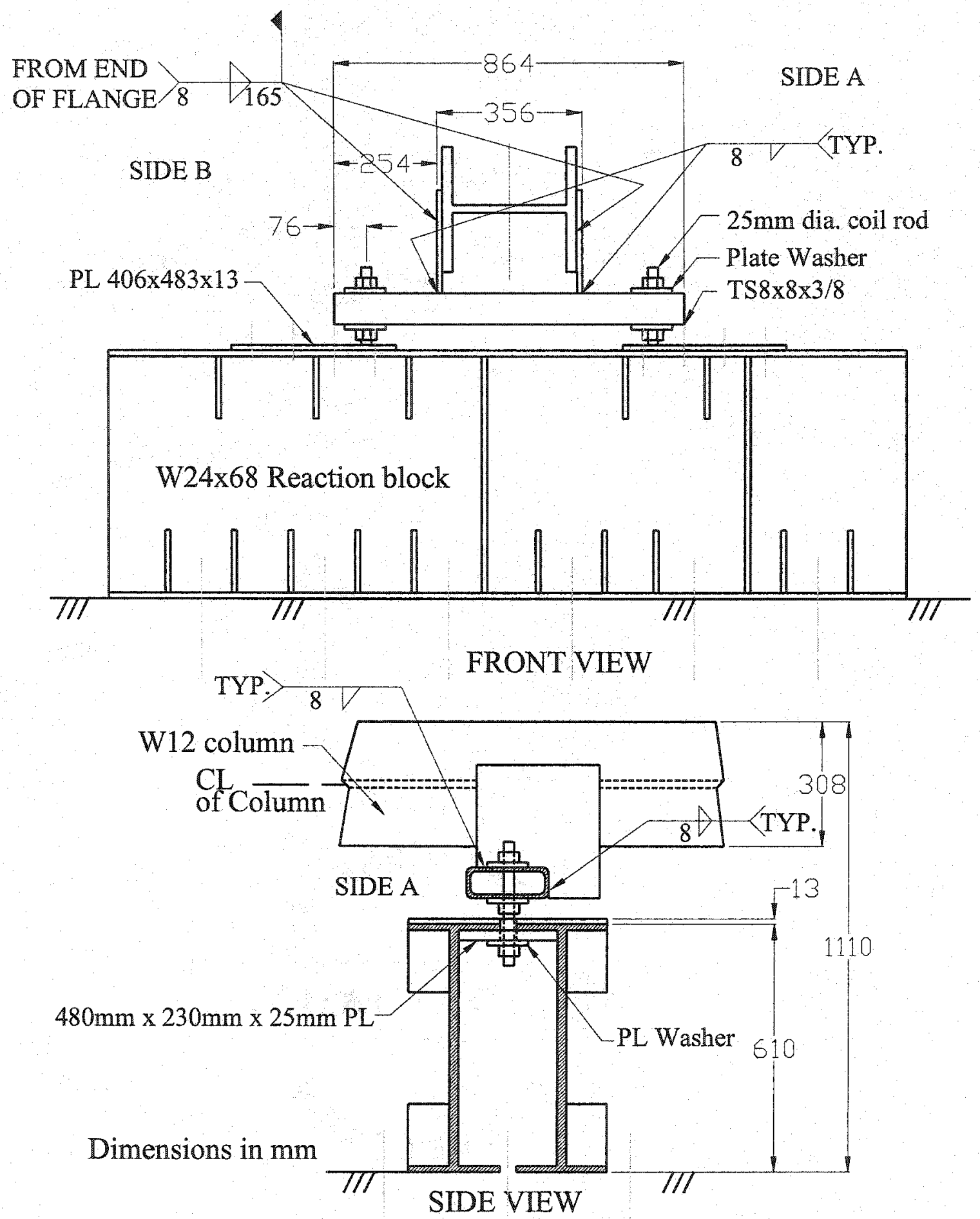

Fig. 10. LPC3 Test Specimen 


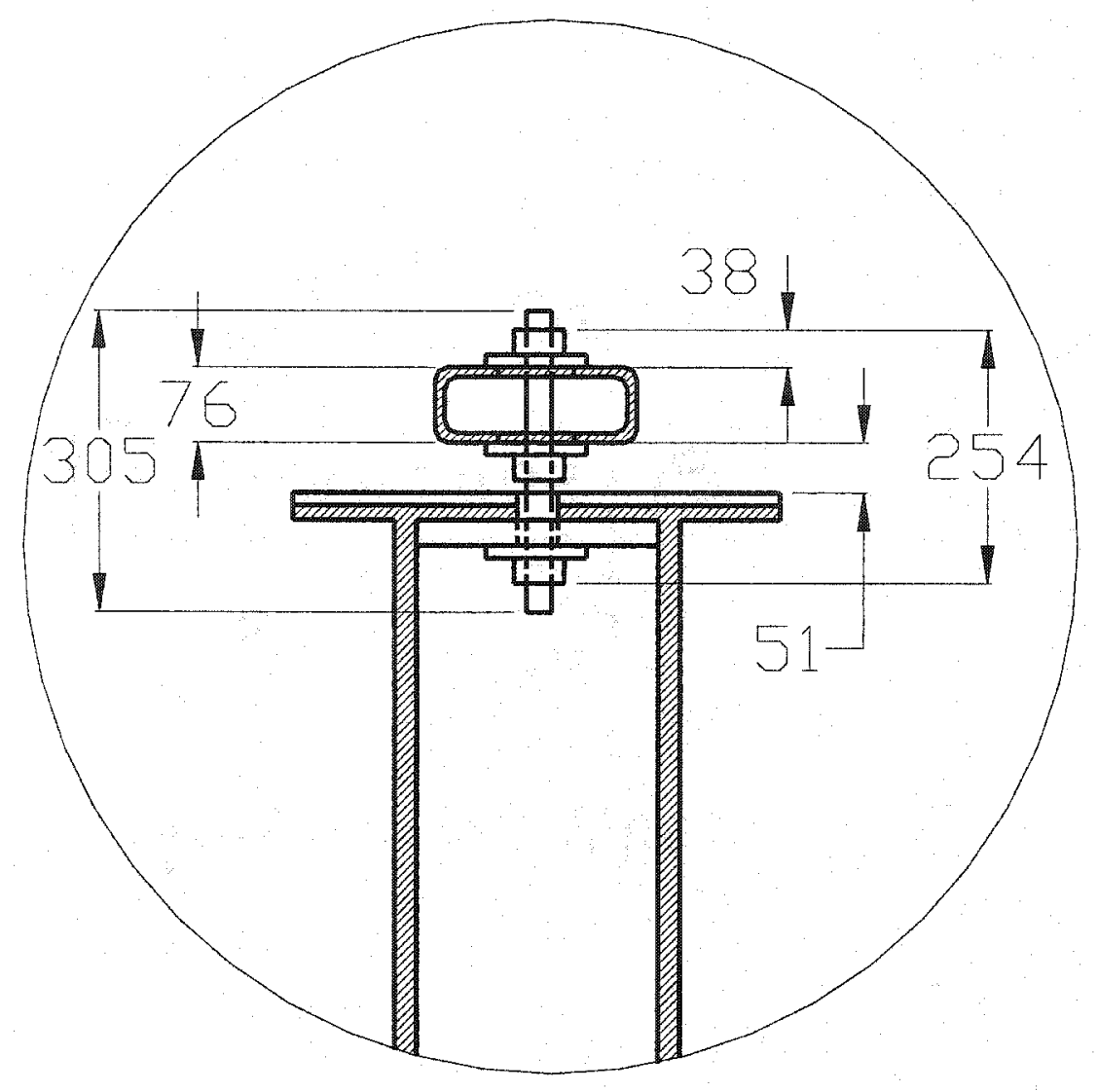

Fig. 11. Enlarged Section of Rod Region of LPC3 


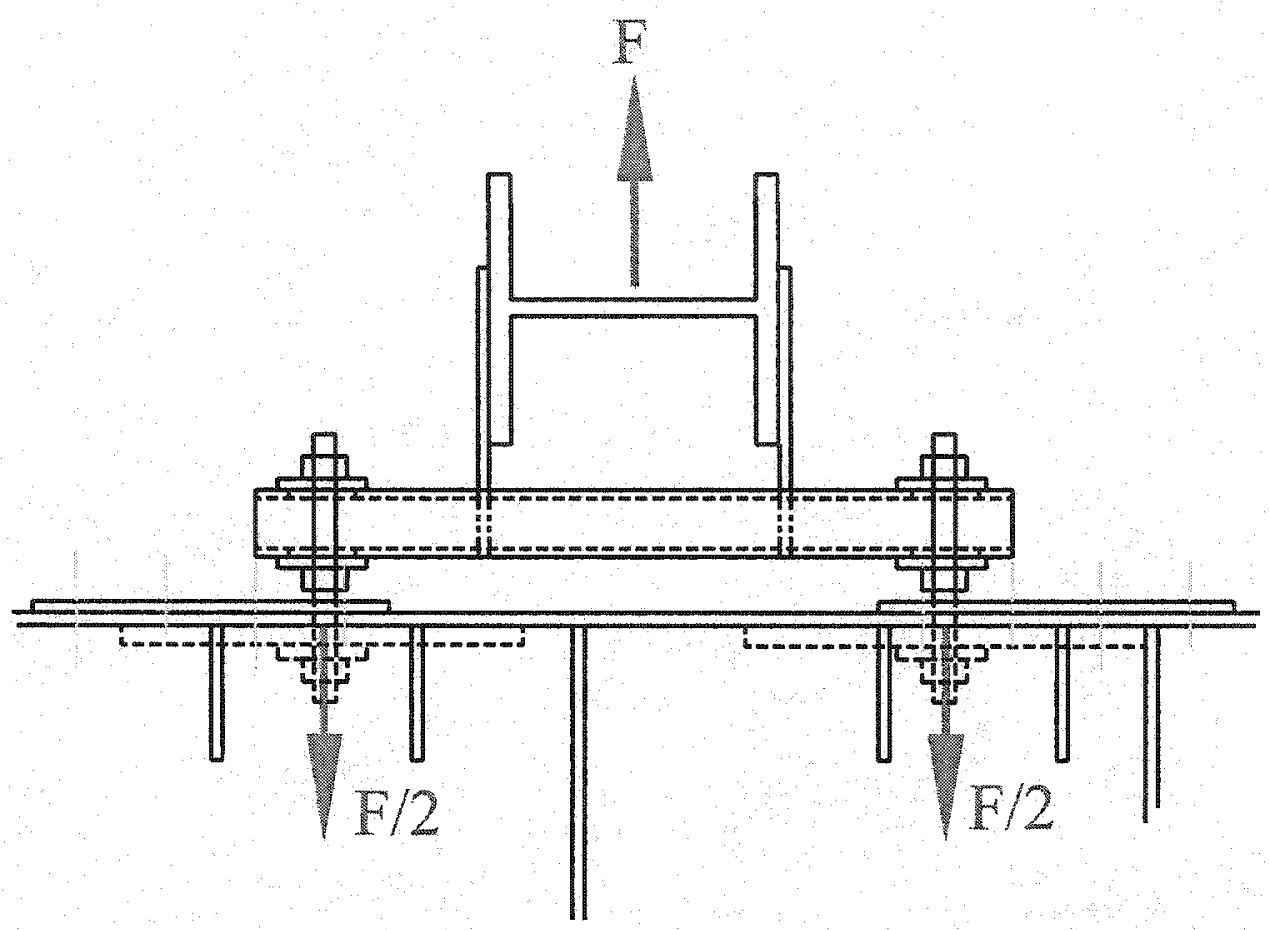

Fig 12. LPC3 Force Loading Diagram

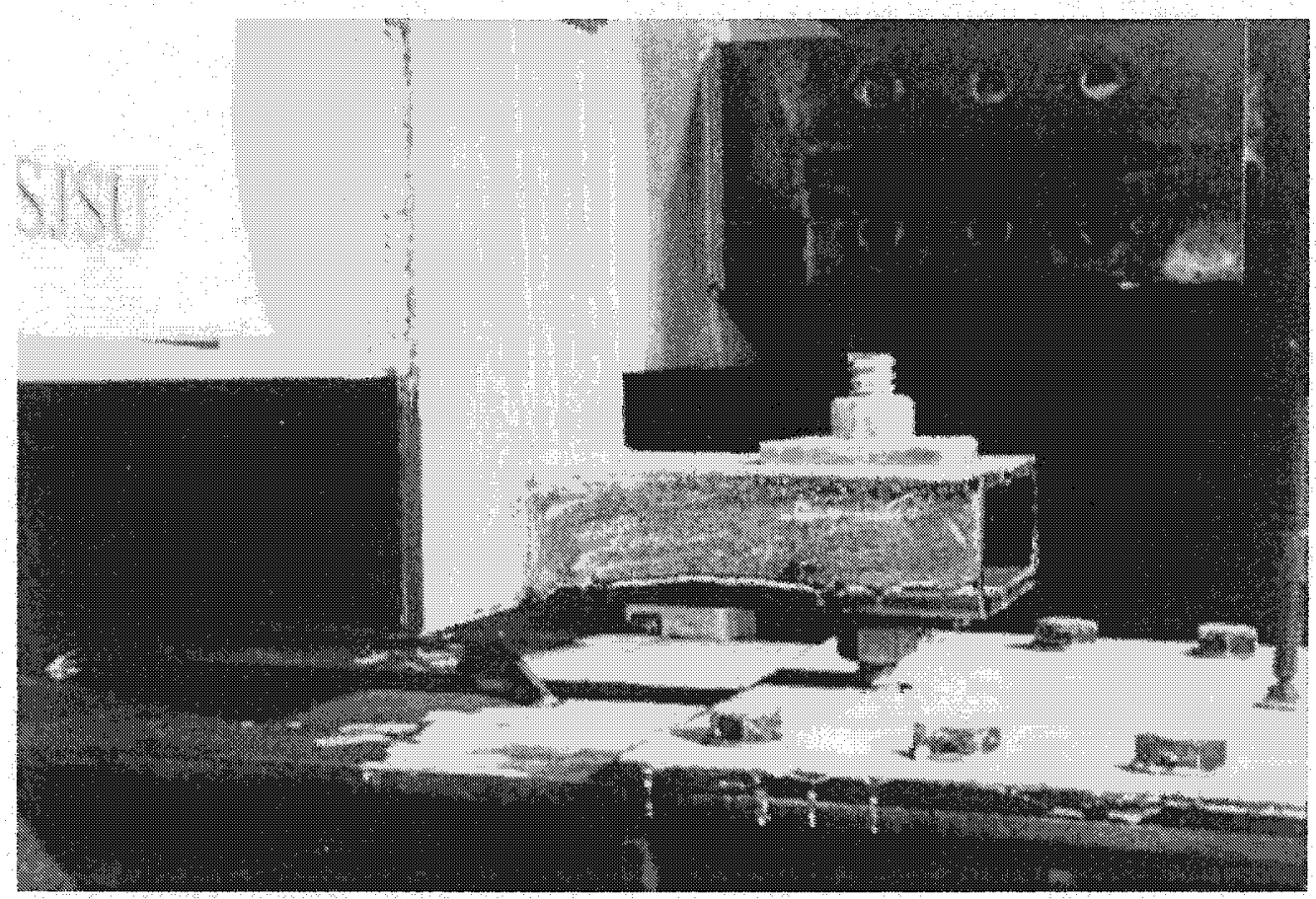

Fig. 13. Whitewashed Side B of LPC3 Before Loading 


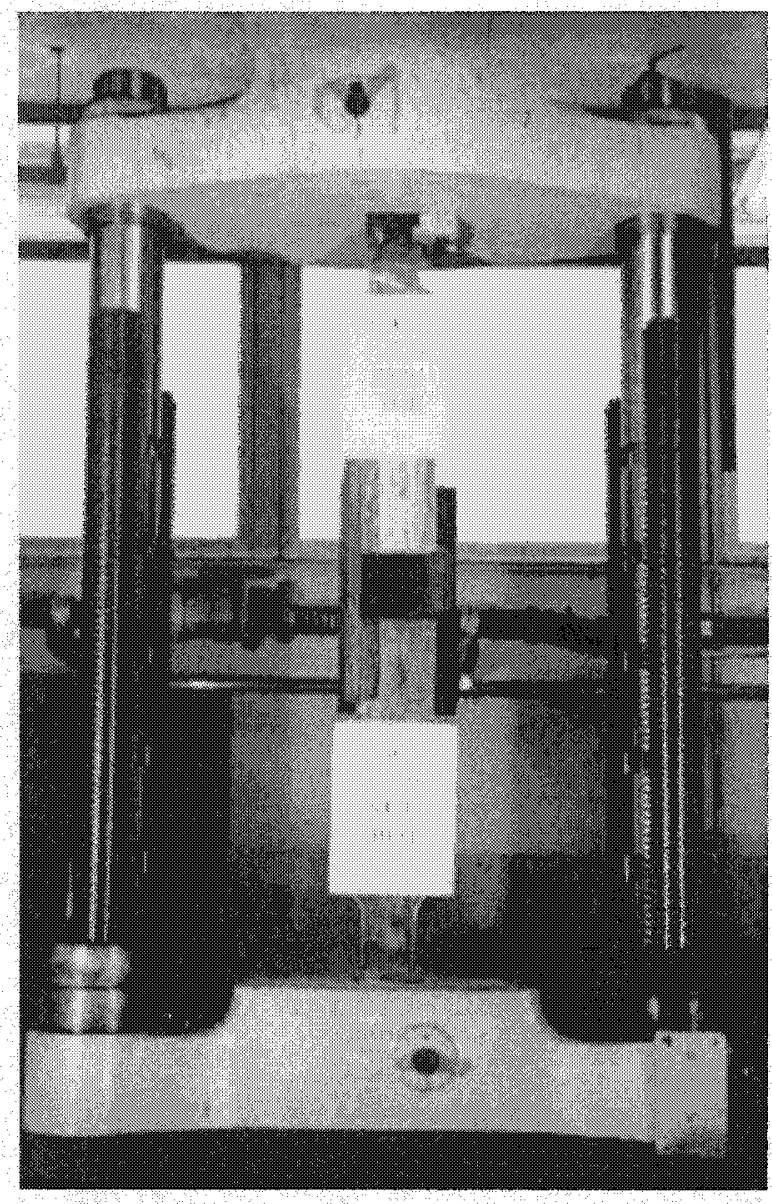

Fig. 14. Photograph of LSC1 Test Arrangement

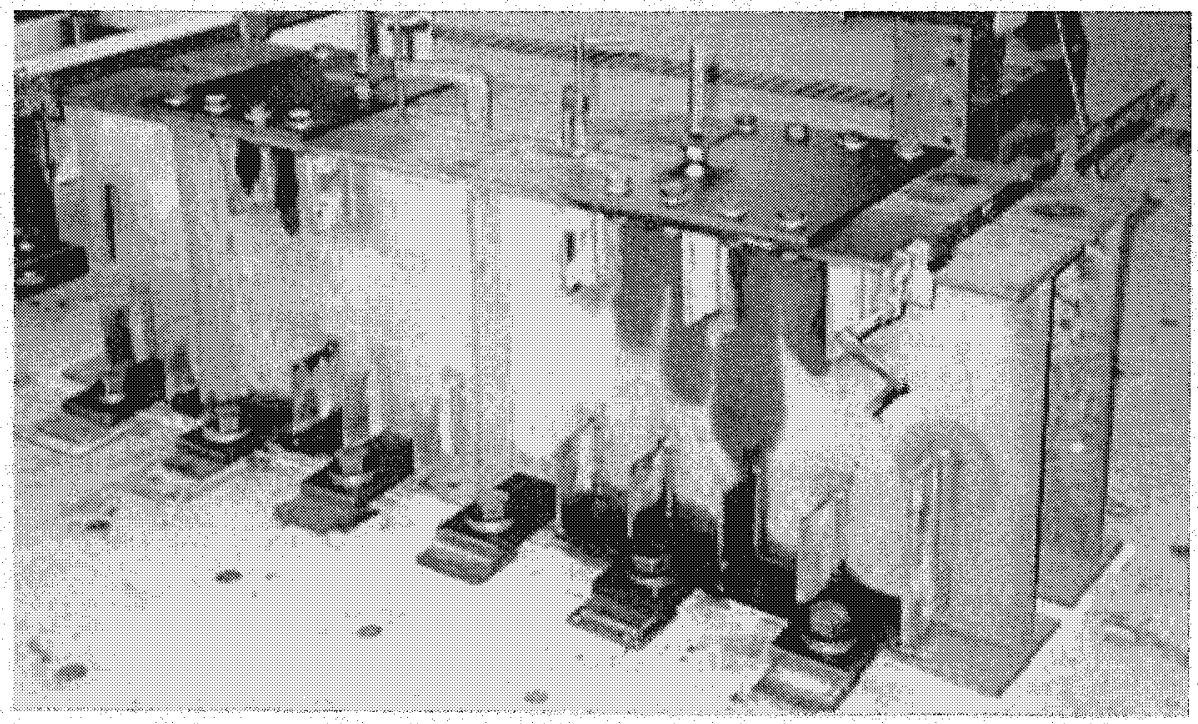

Fig. 15. Reaction Blocks for LSC2 and LPC3 


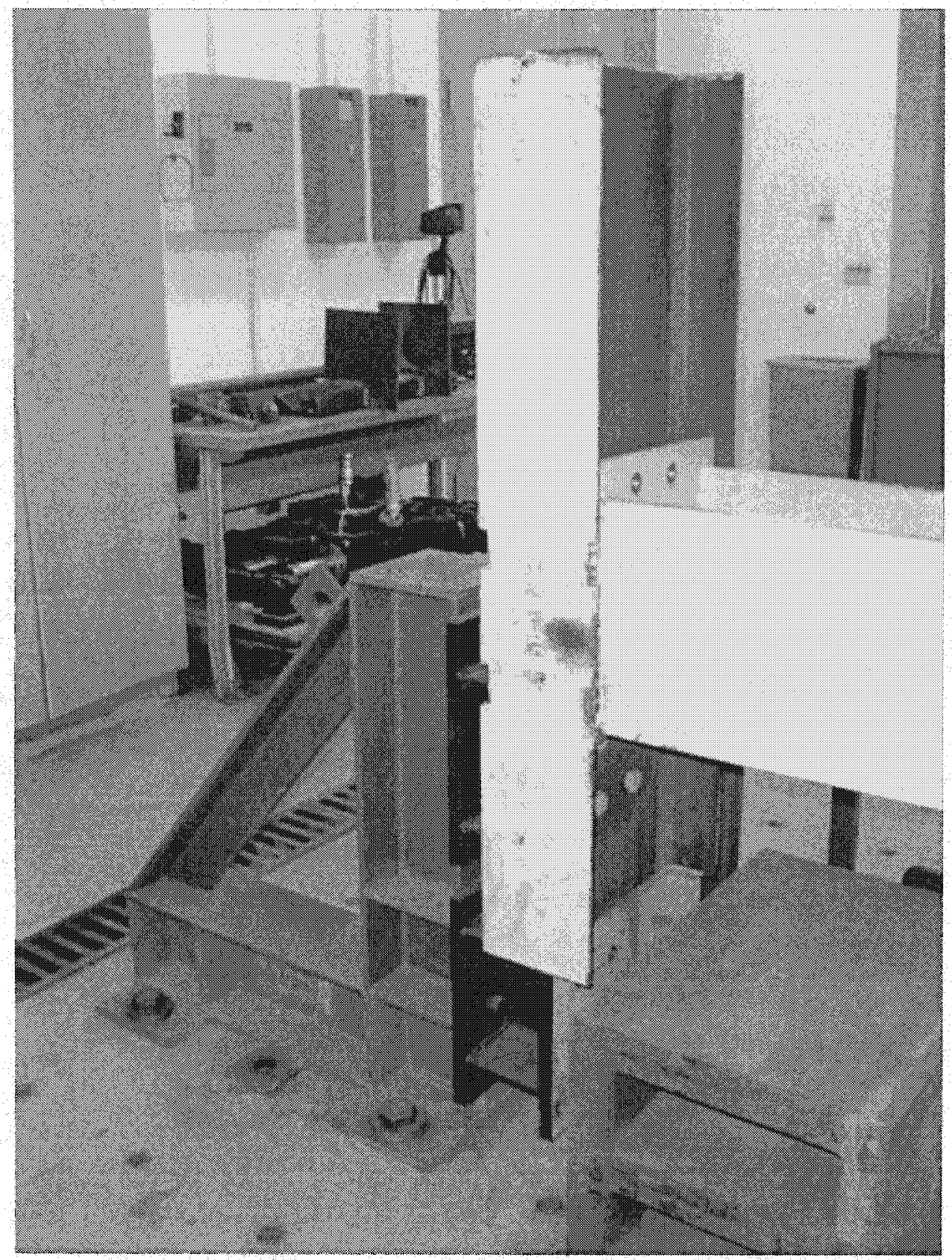

Fig. 16. Reaction Frame with W16x40 beam attached 

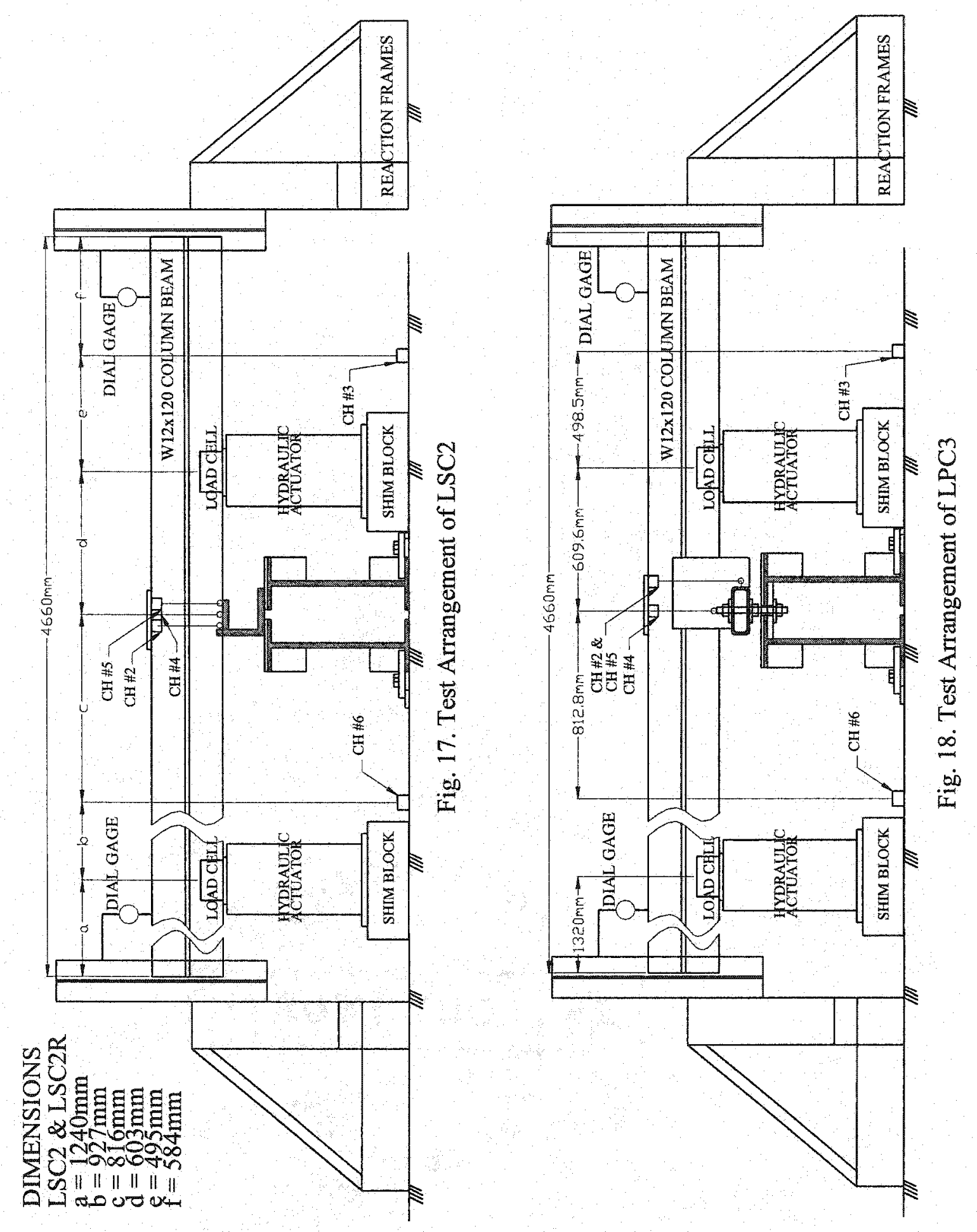


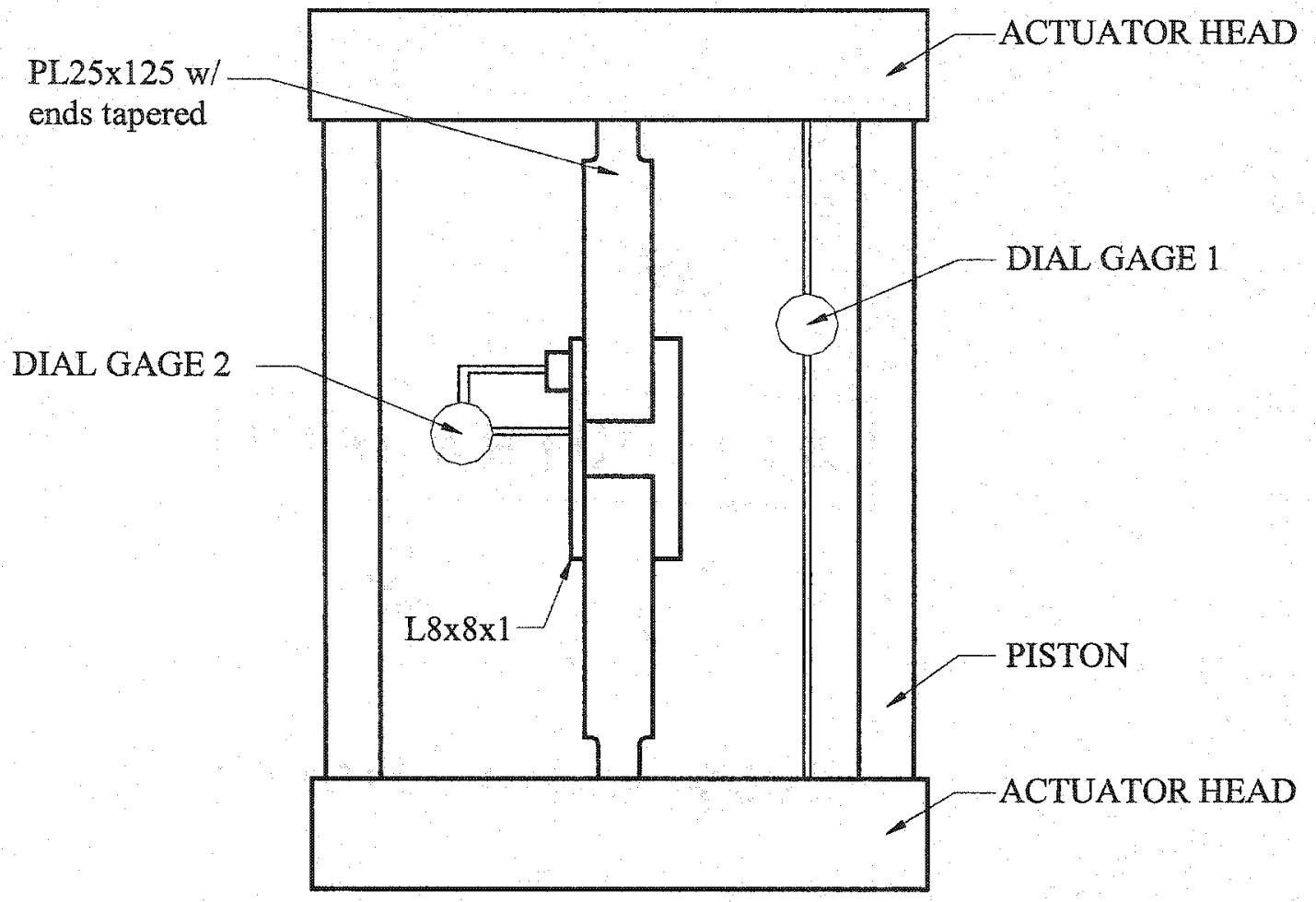

Fig. 19. Instrumentation of LSC1

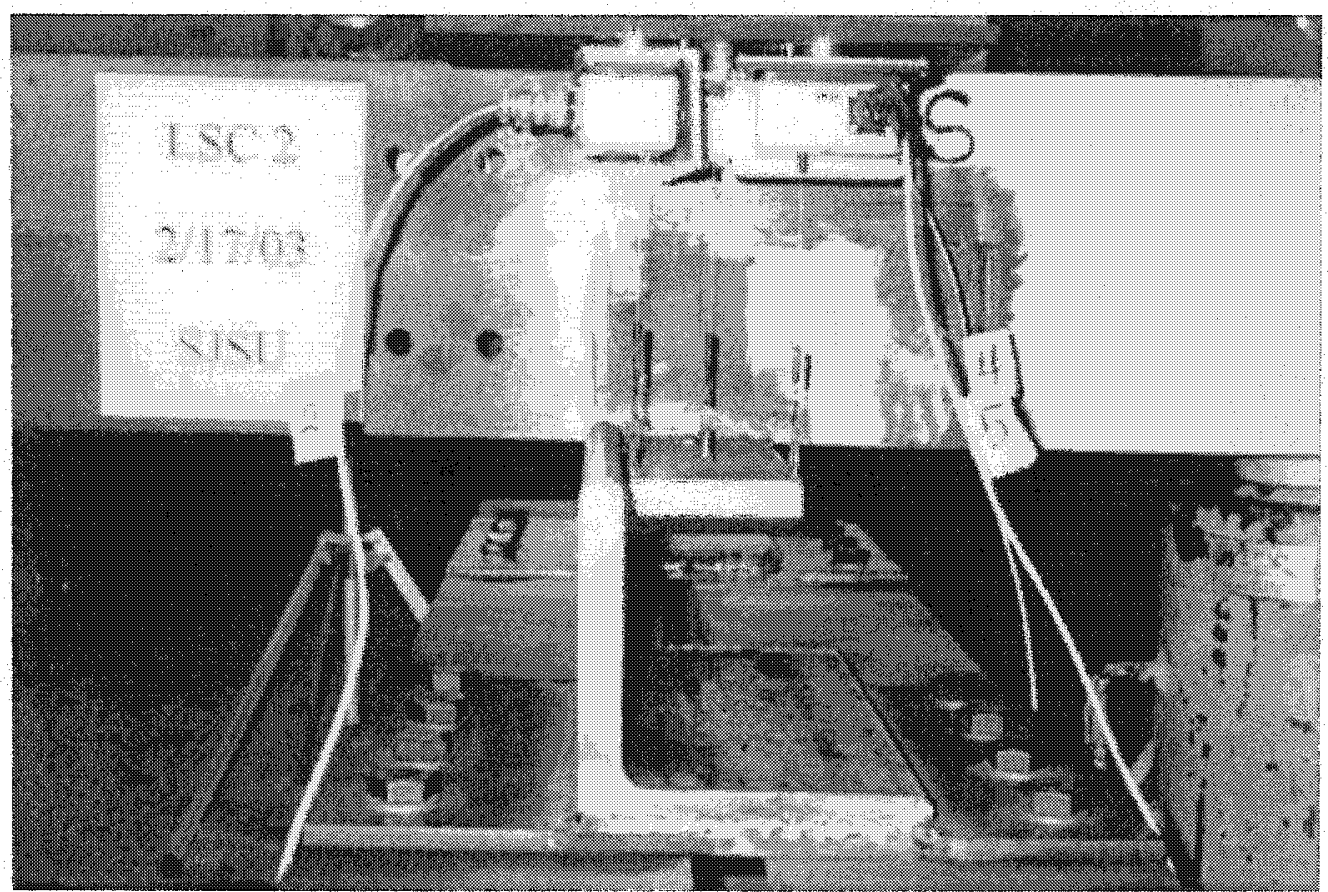

Fig. 20. Wire Potentiometer on the plate of LSC2 and LSC2R 


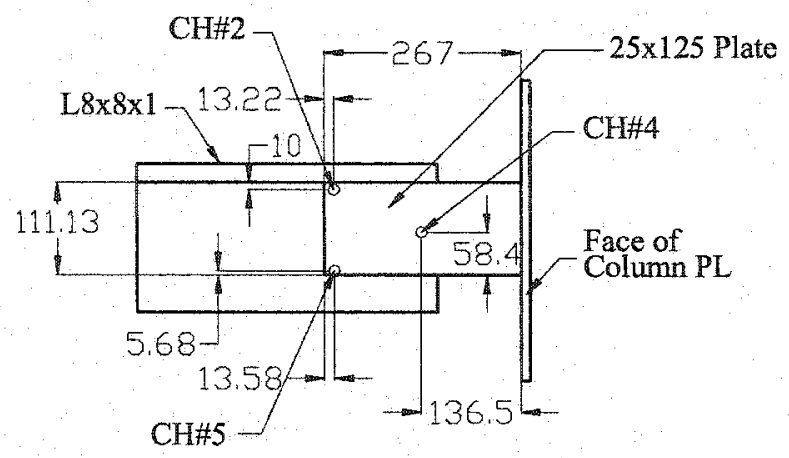

DIMENSION SETUP OF WP

TOP VIEW AT SIDE A

SECT 1-1

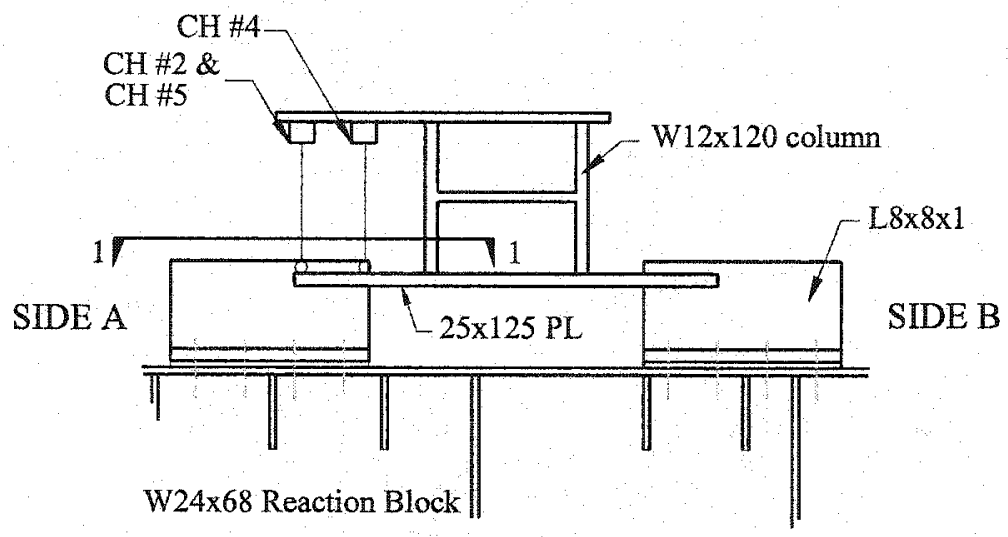

FRONT VIEW

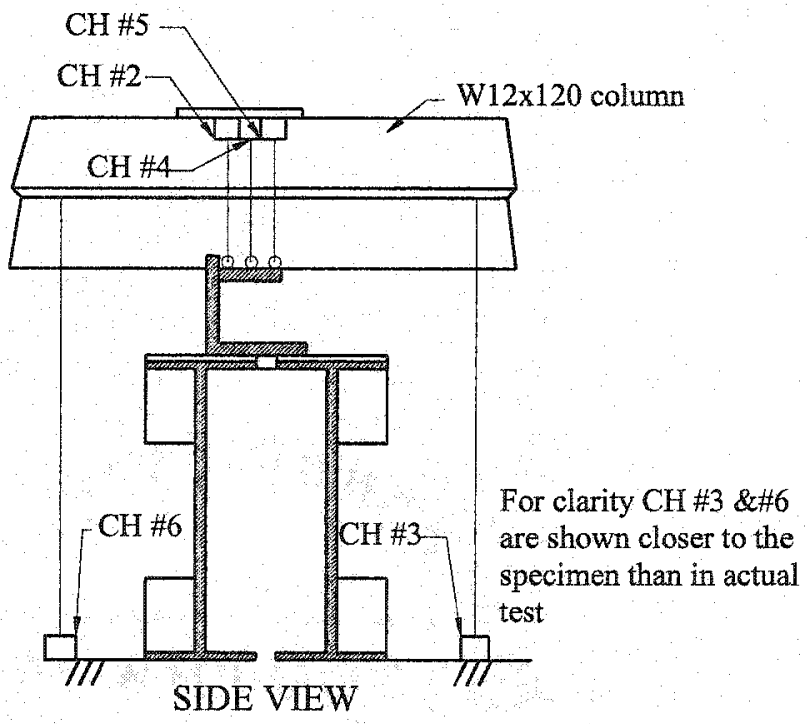

Fig. 21. Diagram of Instrumentation Used in Testing, LSC2 

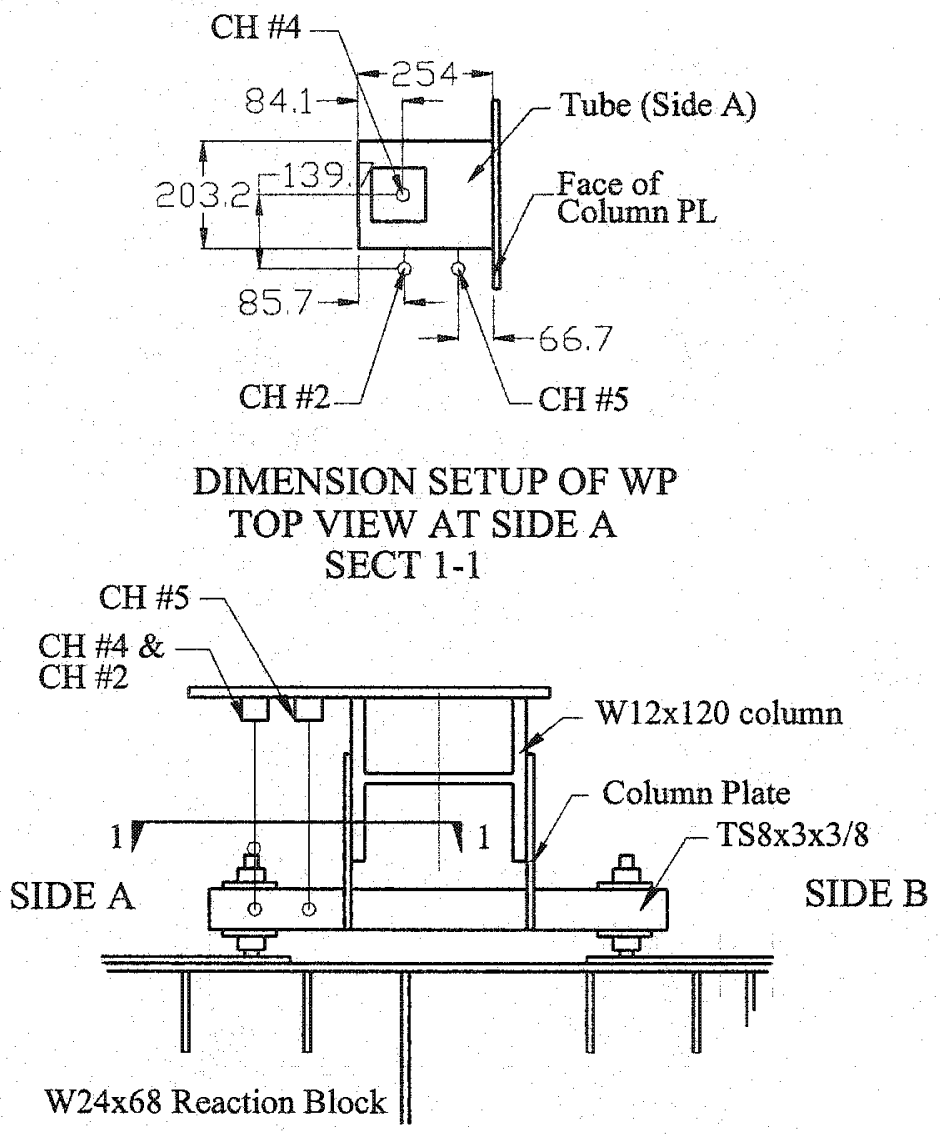

FRONT VIEW

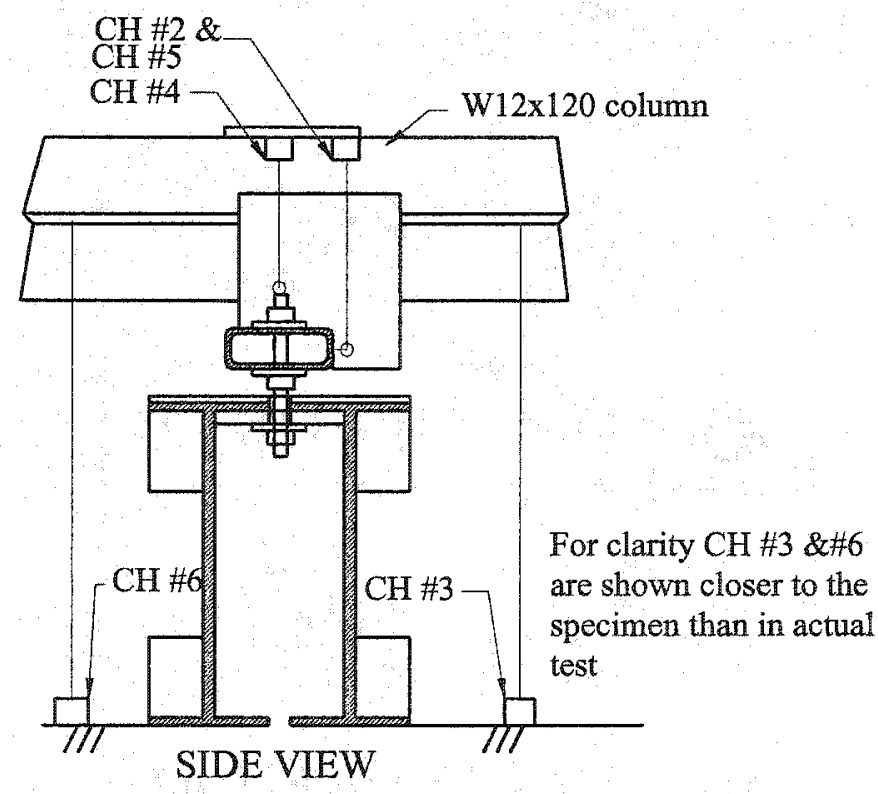

Fig. 22 Diagram of Instrumentation Used in Testing, LPC3 


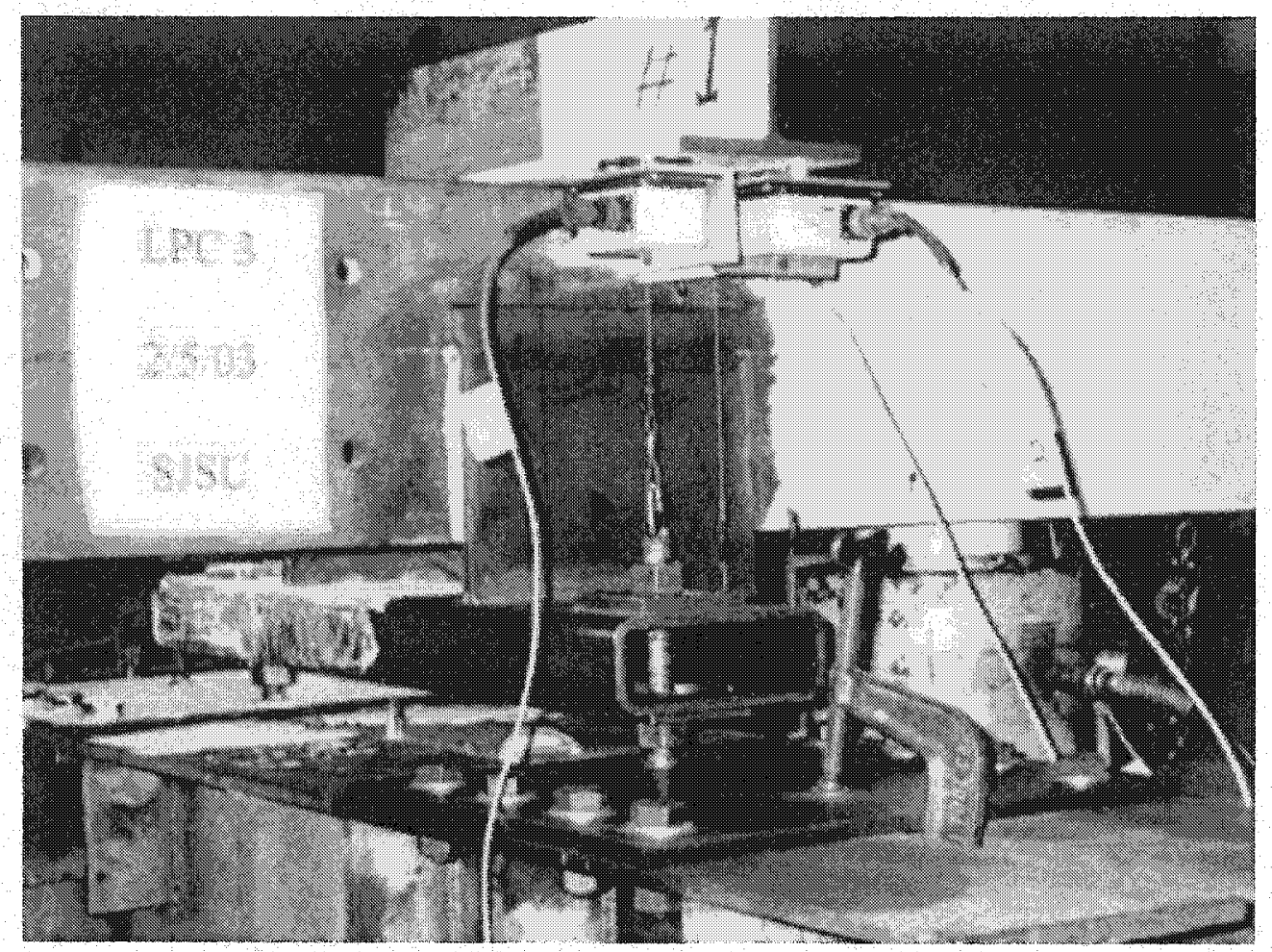

Fig. 23. Instrumentation on Side A of the Tube of LPC3 


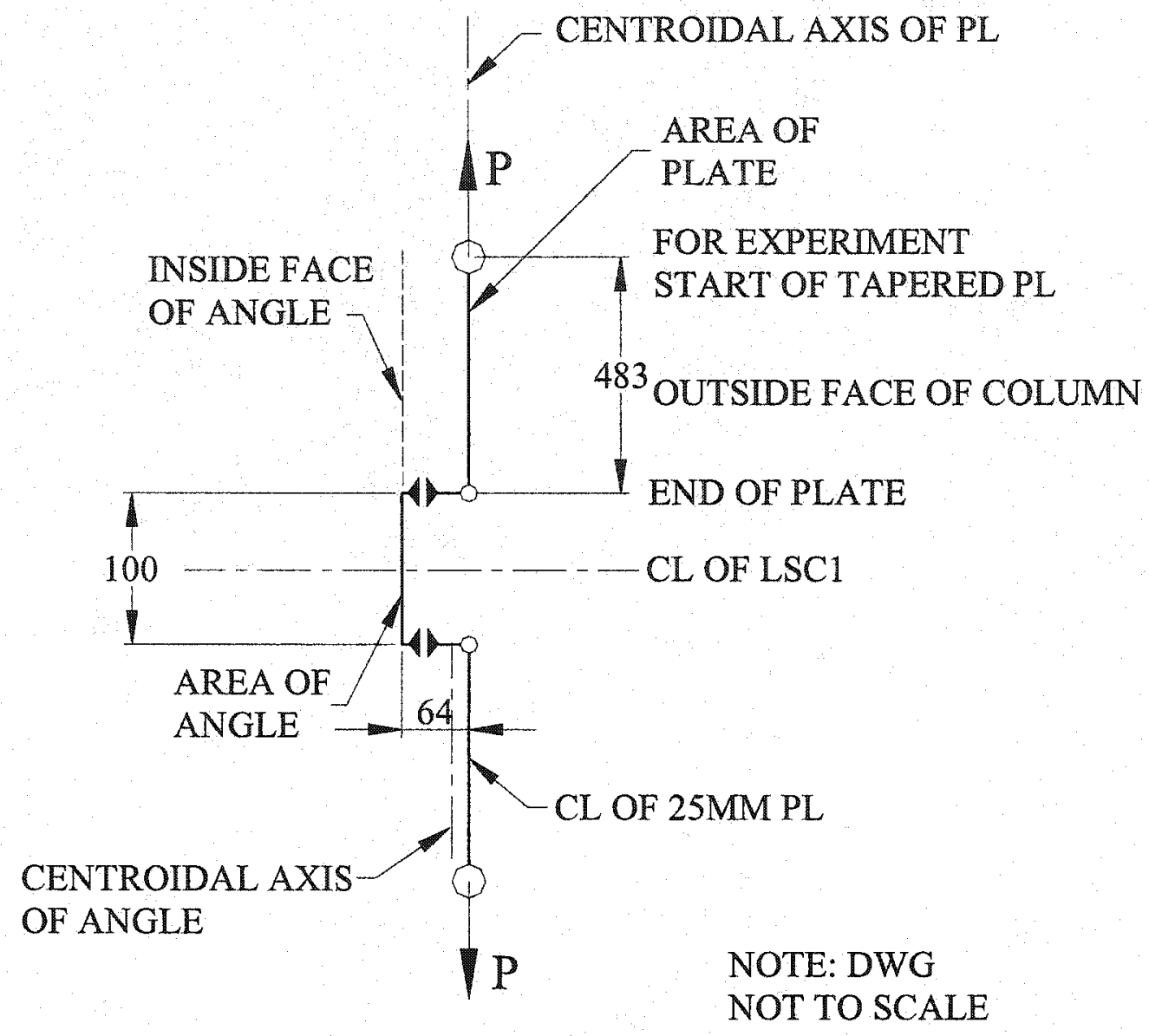

Fig. 24. Eccentric loading of LSC1

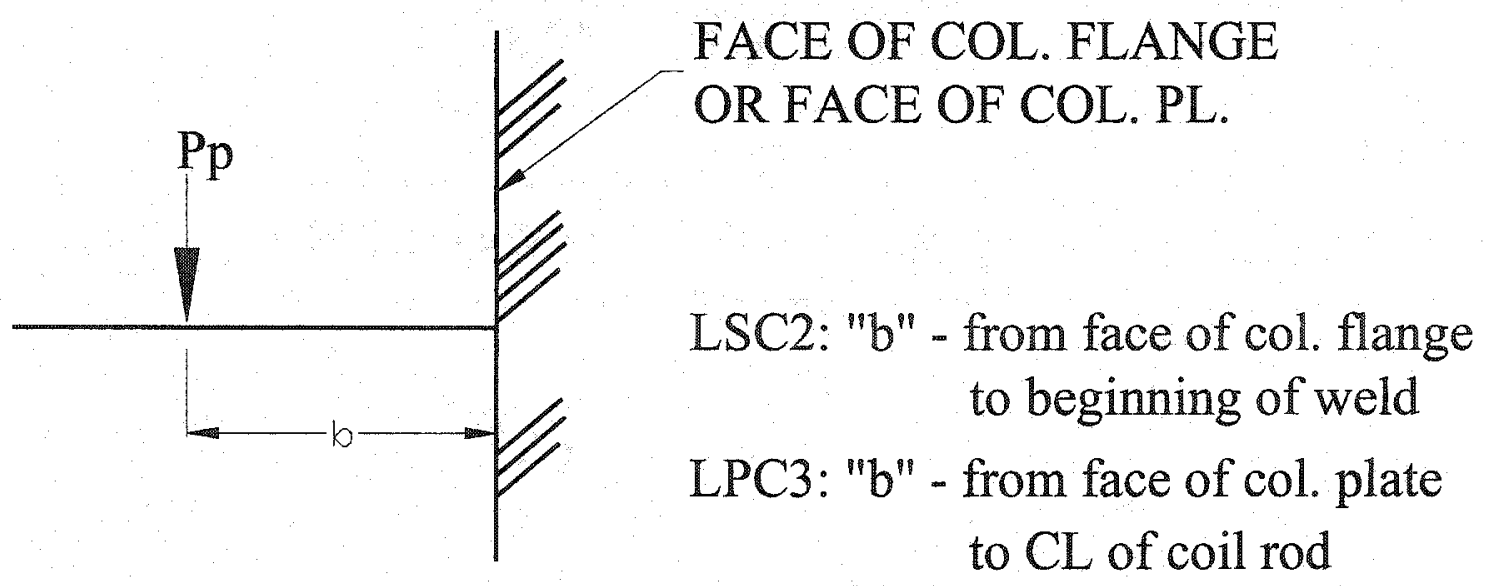

Fig. 25. Cantilever Displacement of the Tube and Plate 


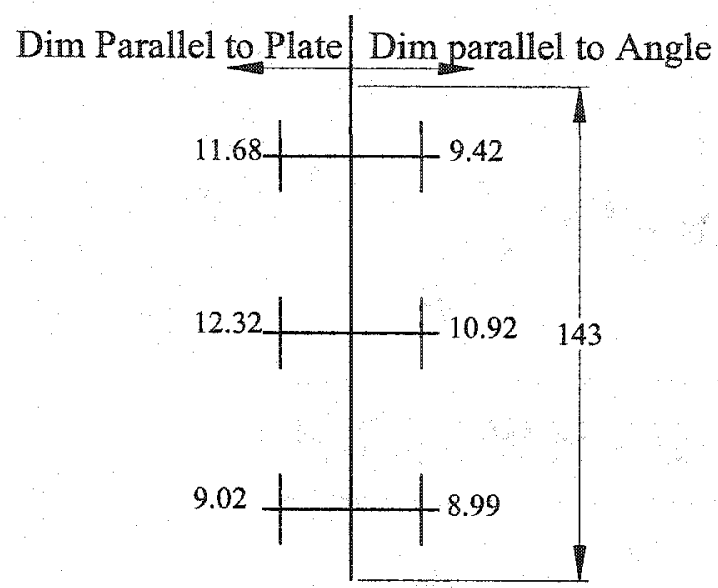

LSC1: Top Weld

Specified $\mathrm{L}=127 \mathrm{~mm}$ $8 \mathrm{~mm}$ thick

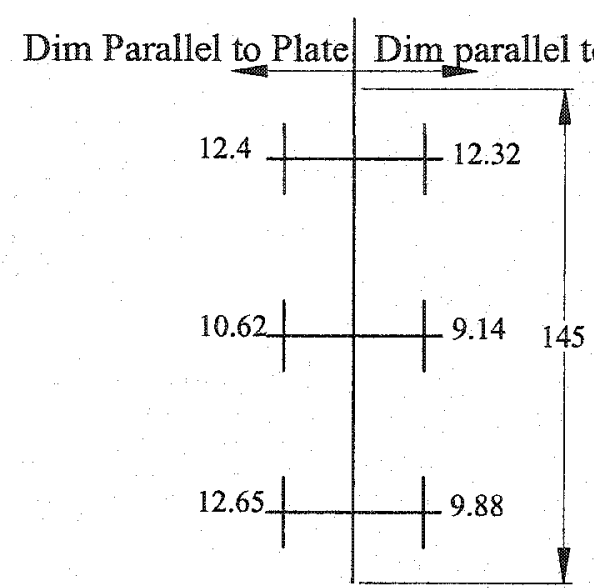

LSC1: Bottom Weld

Specified $\mathrm{L}=127 \mathrm{~mm}$

$8 \mathrm{~mm}$ thick

Fig. 26. Weld Dimension of LSC1 


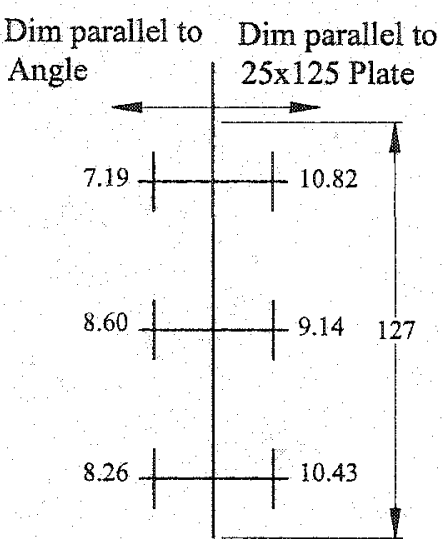

LSC2: A1 Weld Specified $L=125 \mathrm{~mm}$ $8 \mathrm{~mm}$ thick

Dim parallel to Dim parallel to Angle

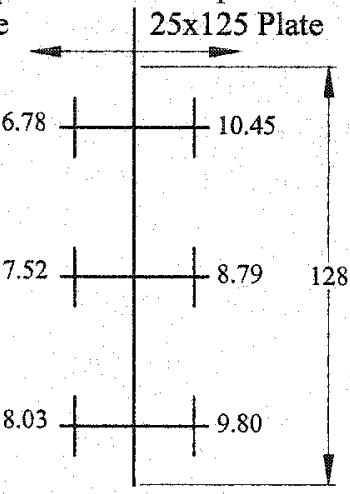

LSC2: B1 Weld

Specified $\mathrm{L}=125 \mathrm{~mm}$ $8 \mathrm{~mm}$ thick

Dim parallel to Dim parallel to Angle

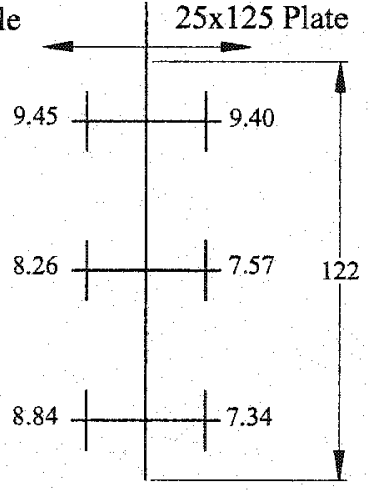

LSC2R. B1 Weld

Specified $\mathrm{L}=125 \mathrm{~mm}$

$8 \mathrm{~mm}$ thick

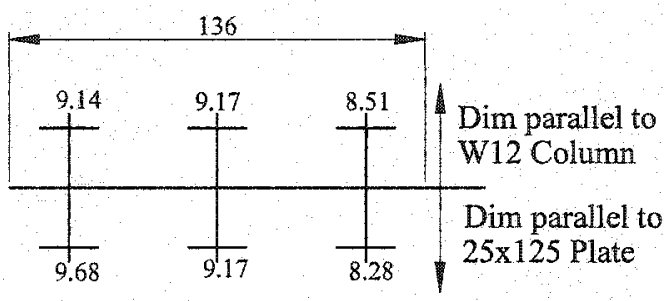

LSC2: A2 Weld

Specified $\mathrm{L}=125 \mathrm{~mm}$

$8 \mathrm{~mm}$ thick

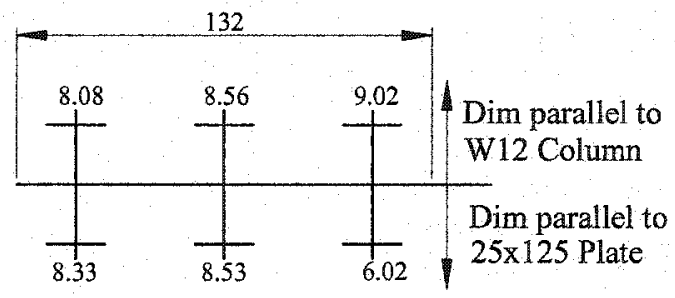

LSC2: B2 Weld

Specified $\mathrm{L}=125 \mathrm{~mm}$

$8 \mathrm{~mm}$ thick

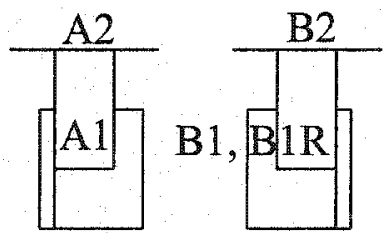

Fig. 27. Weld Dimension of LSC2 


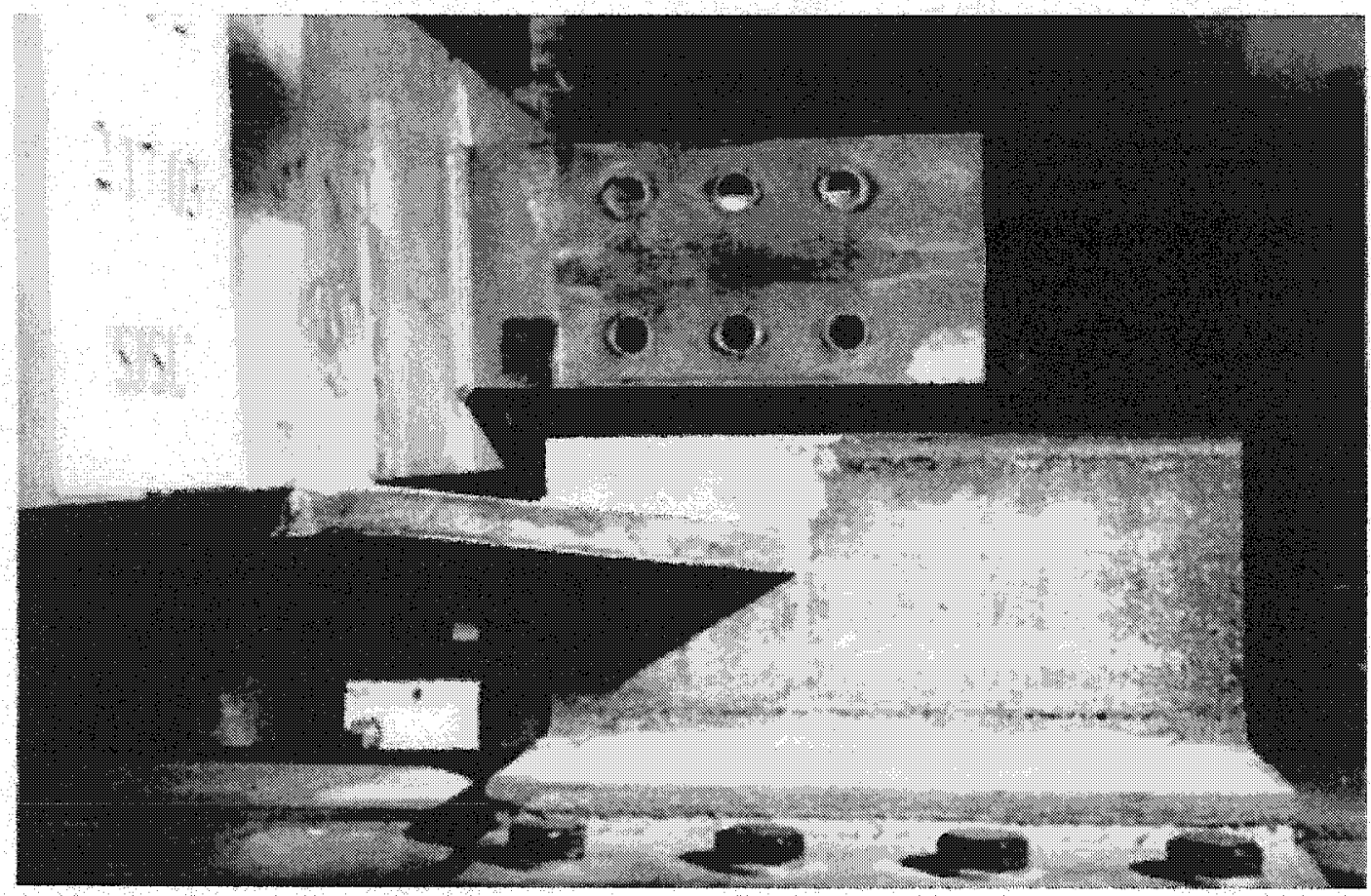

Fig. 28. Plate Deformation on Side B of LSC2 Prior to Retest 
Dim parallel to Dim parallel to W12 Column Column Plate

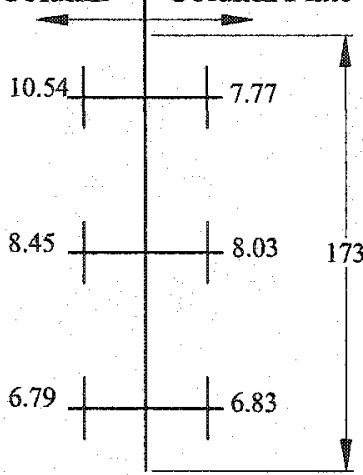

LPC3: A1 Weld

Specified $L=165 \mathrm{~mm}$

$8 \mathrm{~mm}$ thick

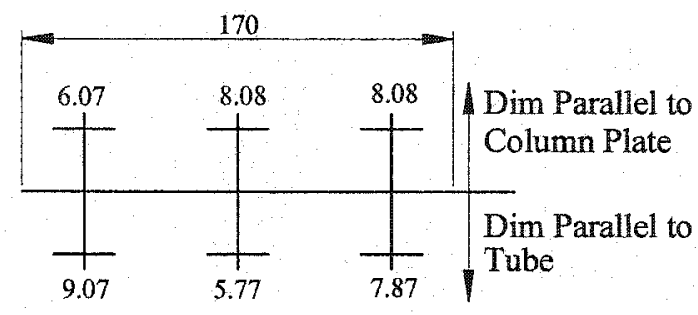

LPC3: A3 Weld

Specified $\mathrm{L}=178 \mathrm{~mm}$

$8 \mathrm{~mm}$ thick

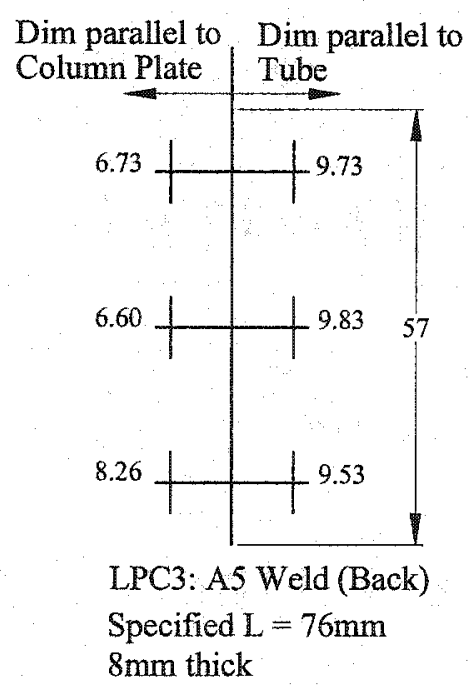

Dim parallel to Dim parallel to Column Plate $\mid$ W12 Column

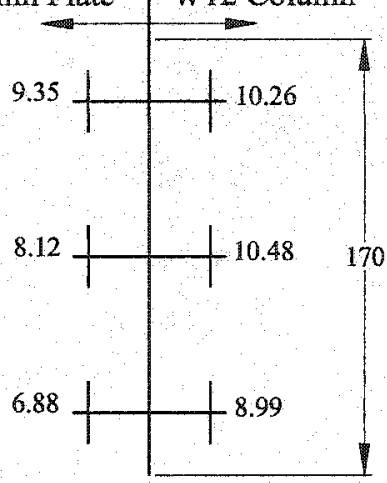

LPC3: A2 Weld Specified $\mathrm{L}=165 \mathrm{~mm}$ $8 \mathrm{~mm}$ thick

Dim parallel to Dim parallel to Tube

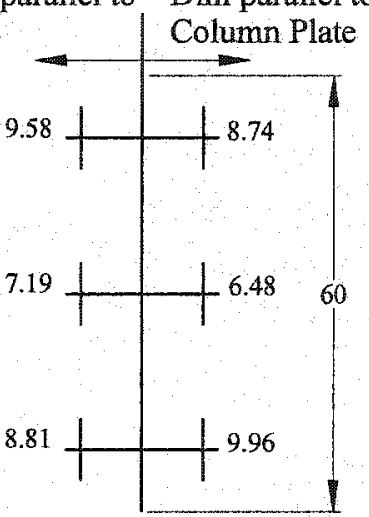

LPC3: A4 Weld (Front)

Specified $\mathrm{L}=76 \mathrm{~mm}$

$8 \mathrm{~mm}$ thick

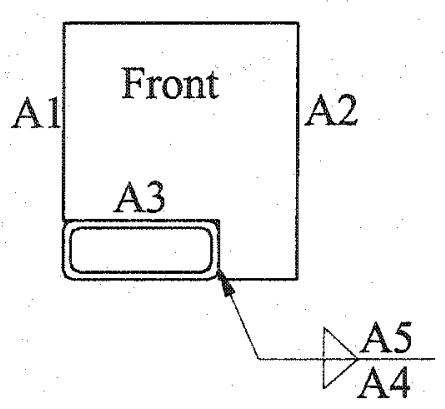

Fig. 29a. Weld dimension of LPC3 Side A 


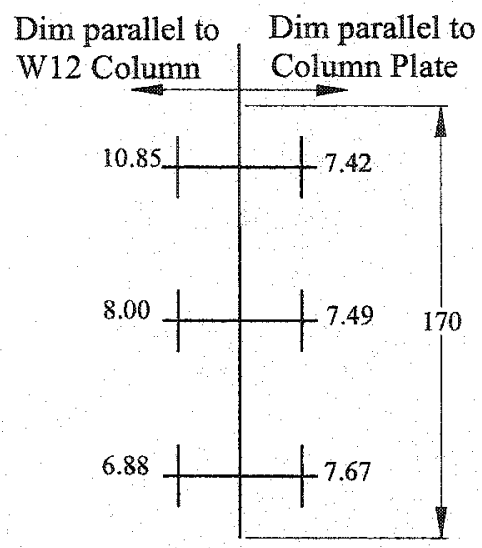

LPC3: B1 Weld

Specified $\mathrm{L}=165 \mathrm{~mm}$

$8 \mathrm{~mm}$ thick
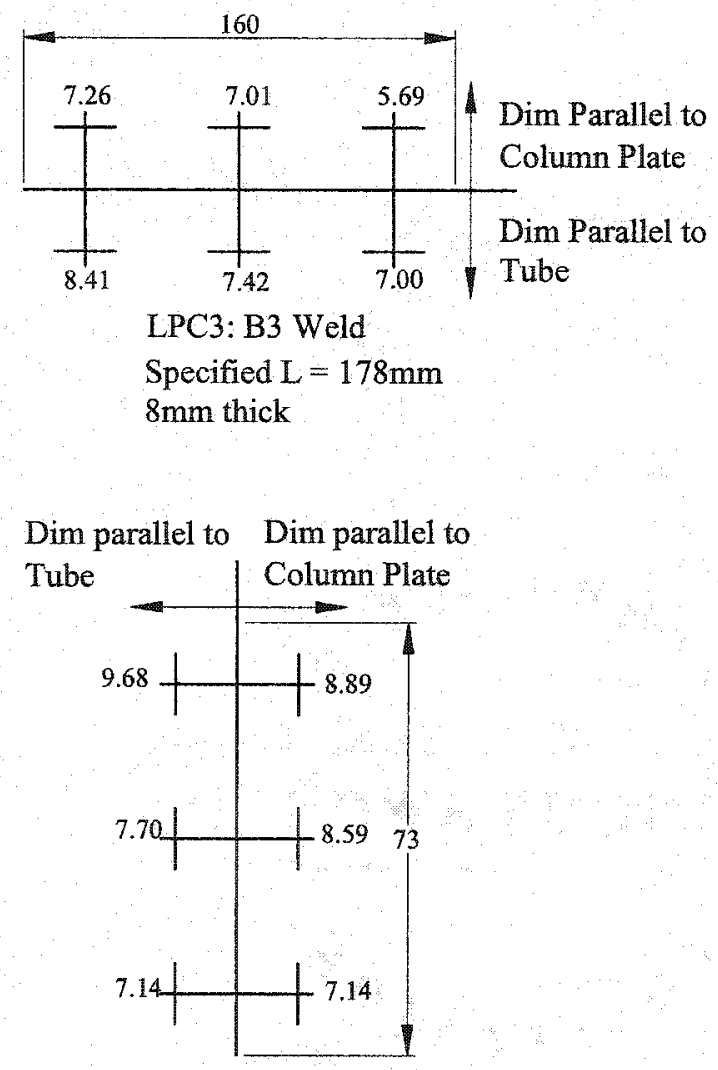

LPC3: B5 Weld (Back)

Specified $\mathrm{L}=76 \mathrm{~mm}$

$8 \mathrm{~mm}$ thick
Dim parallel to Dim parallel to \begin{tabular}{l|l} 
Column Plate & W12 Column
\end{tabular}

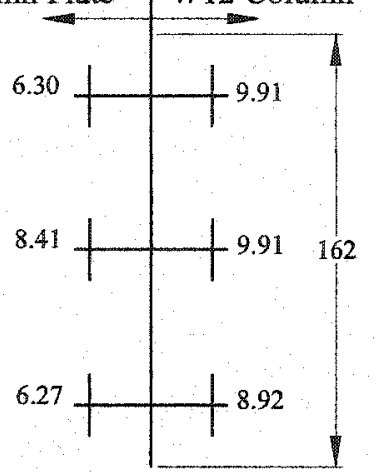

LPC3: B2 Weld

Specified $\mathrm{L}=165 \mathrm{~mm}$ $8 \mathrm{~mm}$ thick

Dim parallel to Dim parallel to Column Plate $\mid$ Tube

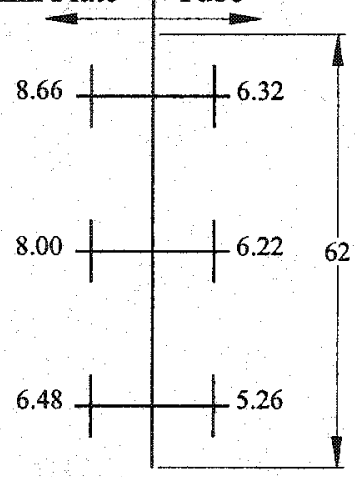

LPC3: B4 Weld (Front)

Specified $L=76 \mathrm{~mm}$

$8 \mathrm{~mm}$ thick

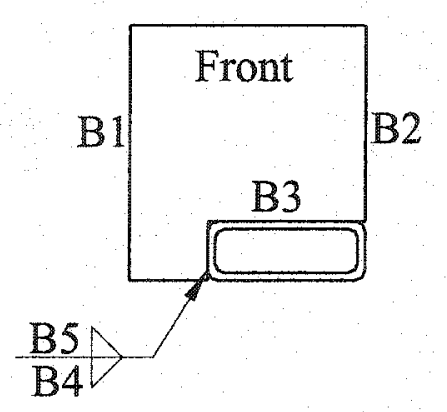

Fig. 29b. Weld Dimension of LPC3 Side B 


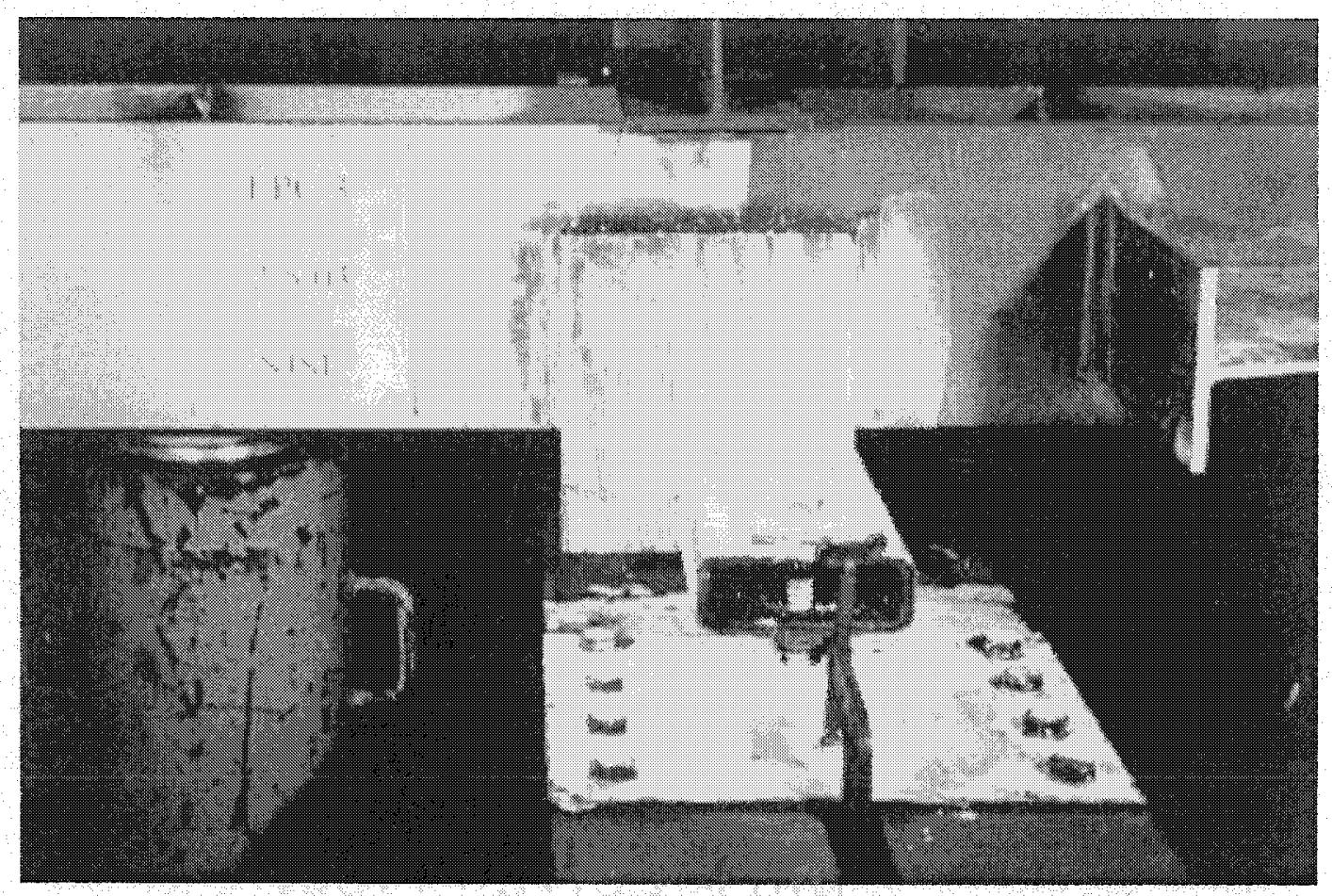

Fig. 30. Lime-coated Side B of LPC3 Specimen

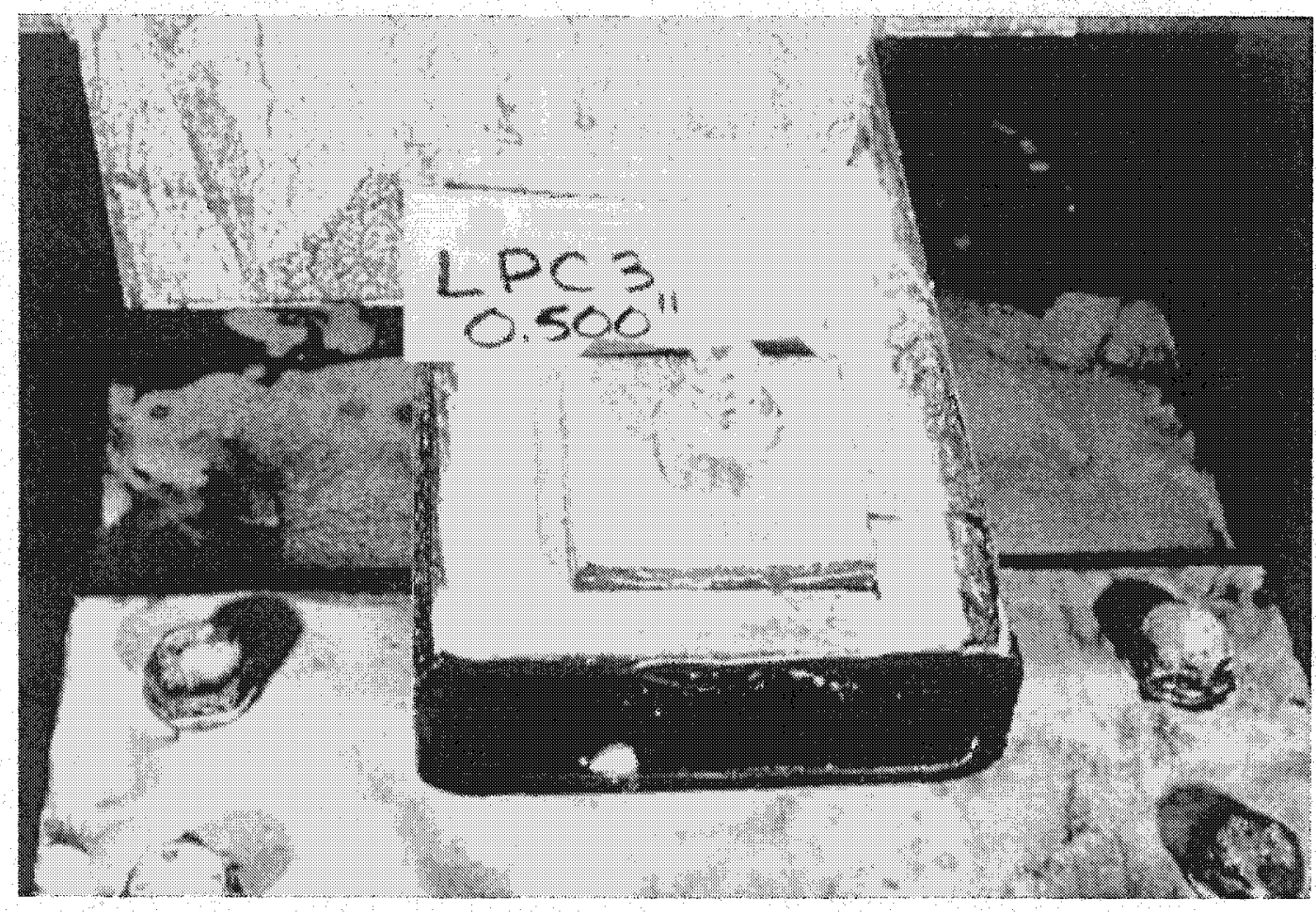

Fig. 31. Flaking and Initial Yielding Detected at $1 / 2$ in of movement 


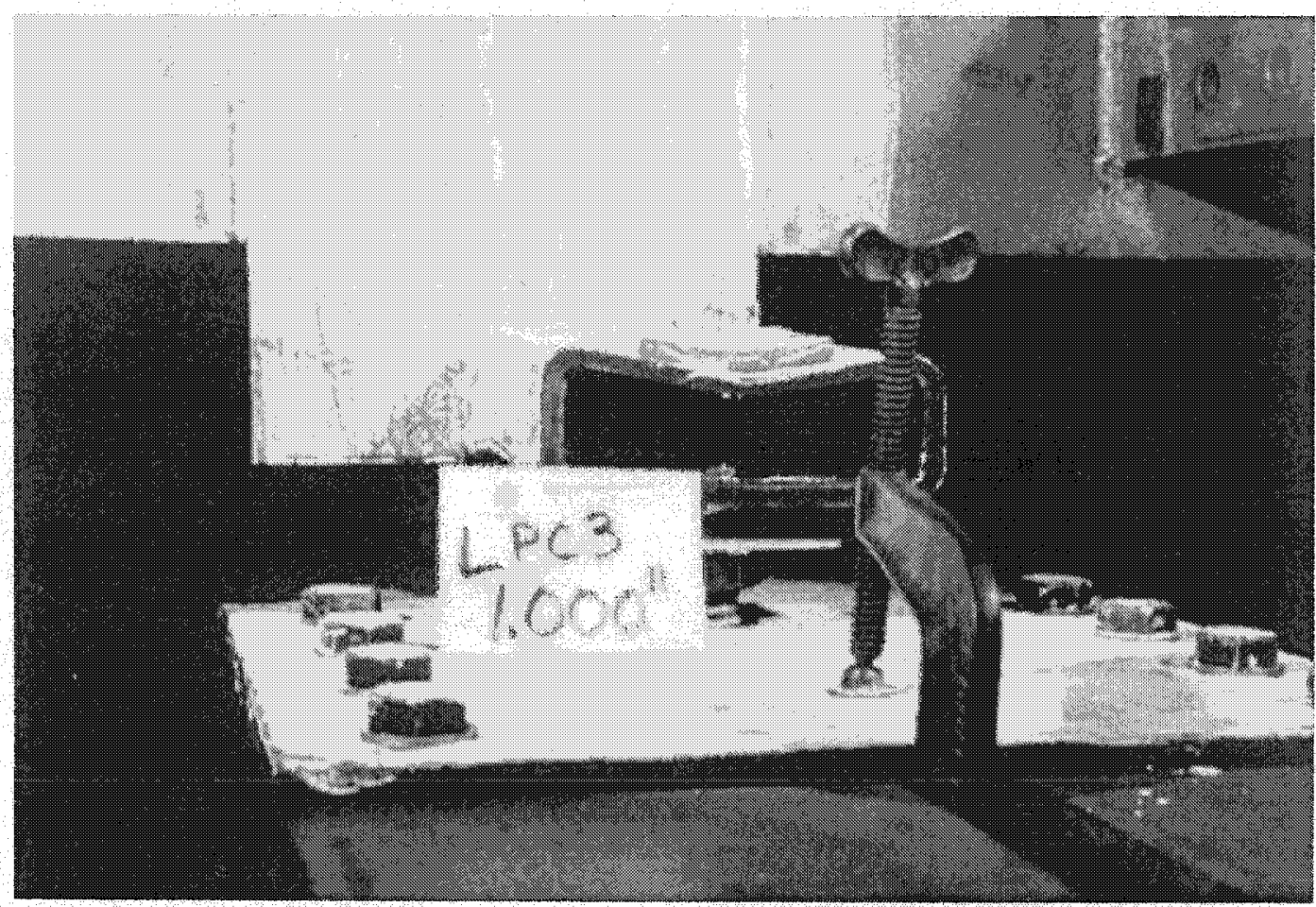

Fig. 32. Local Bending of the Tube Wall at lin. of movement

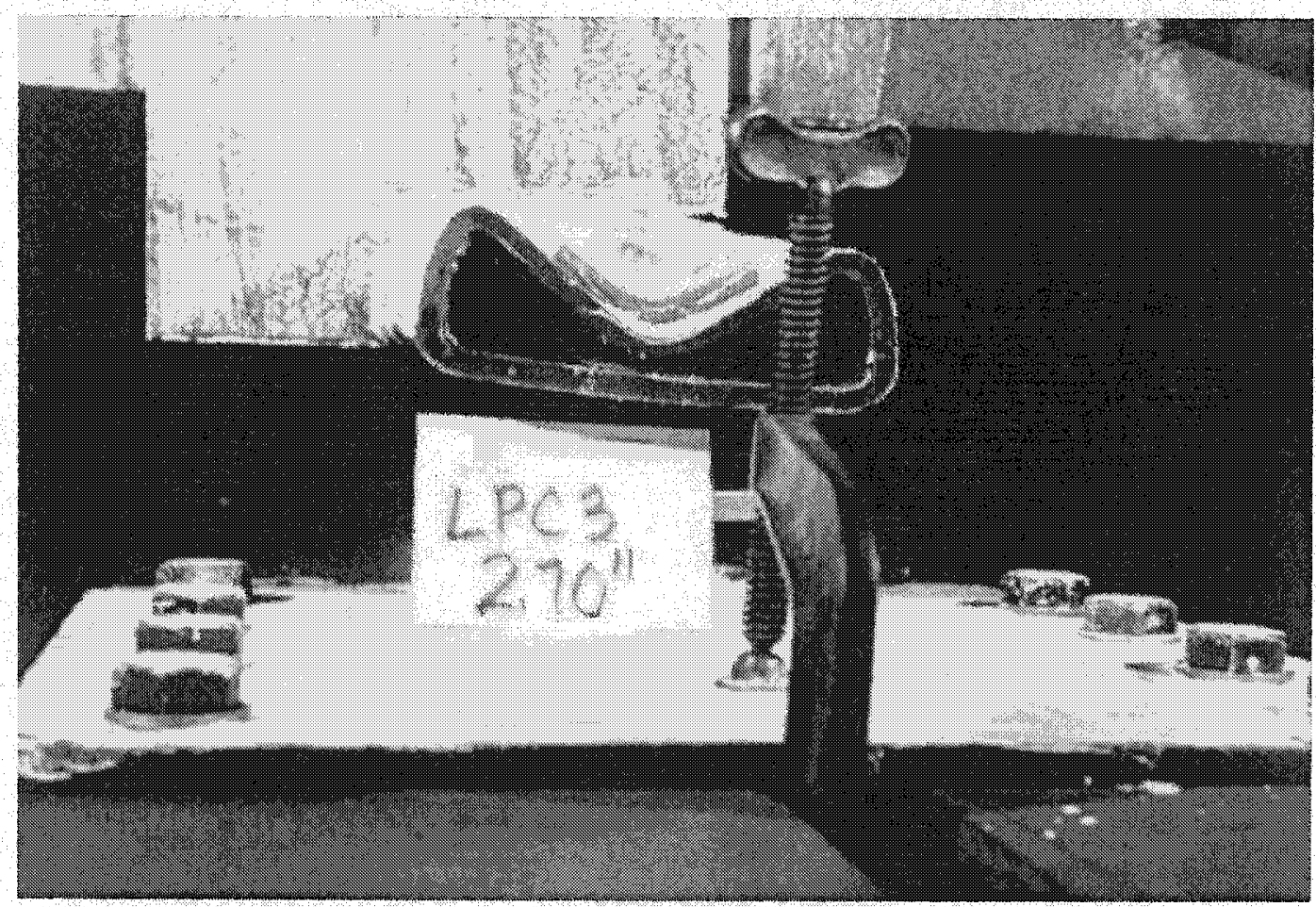

Fig. 33. Local Bending of the Tube Wall at 2.7 in. of movement 


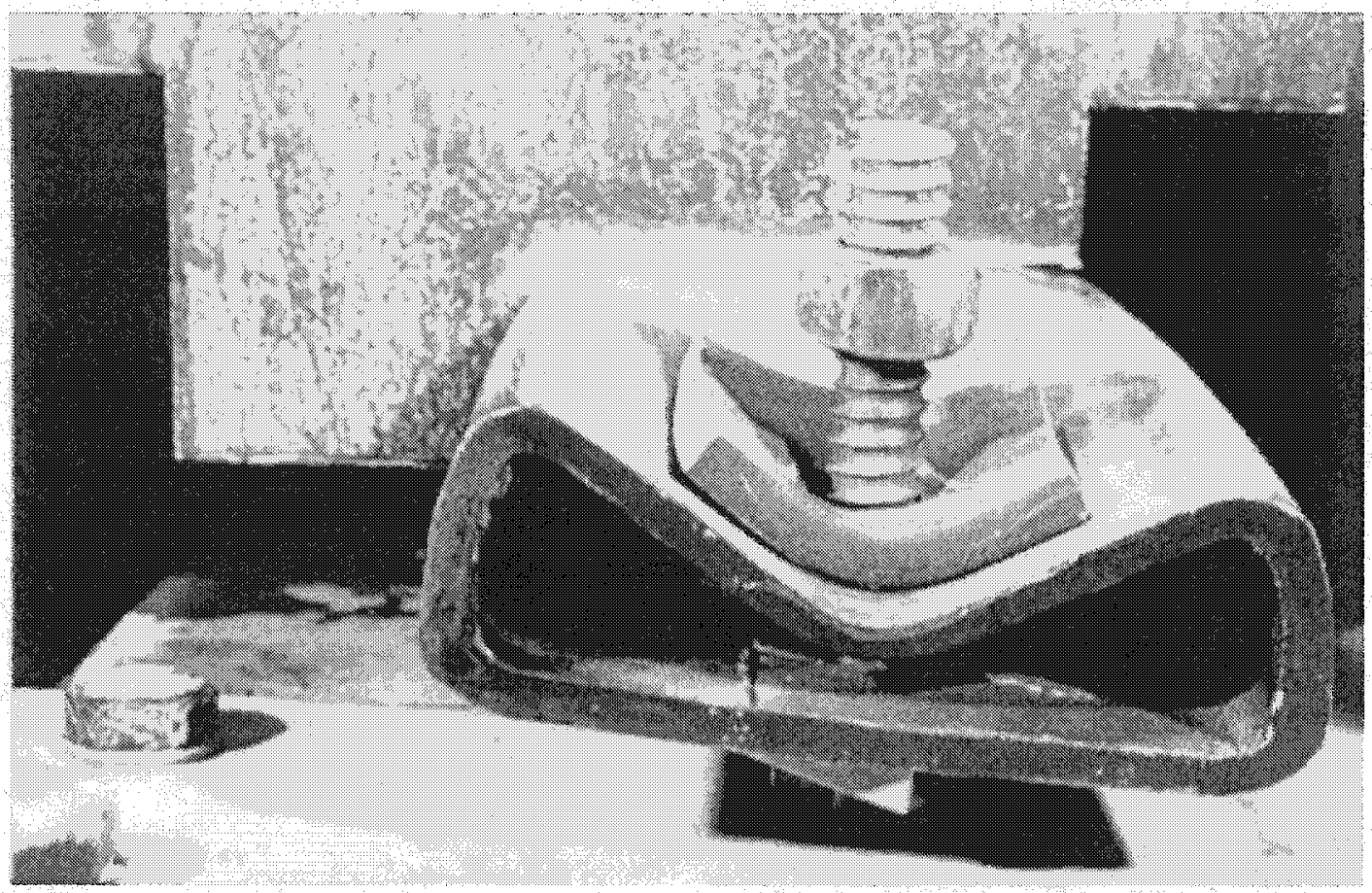

Fig. 34. Local Bending of the Tube wall on Side B of Column for Test LPC3

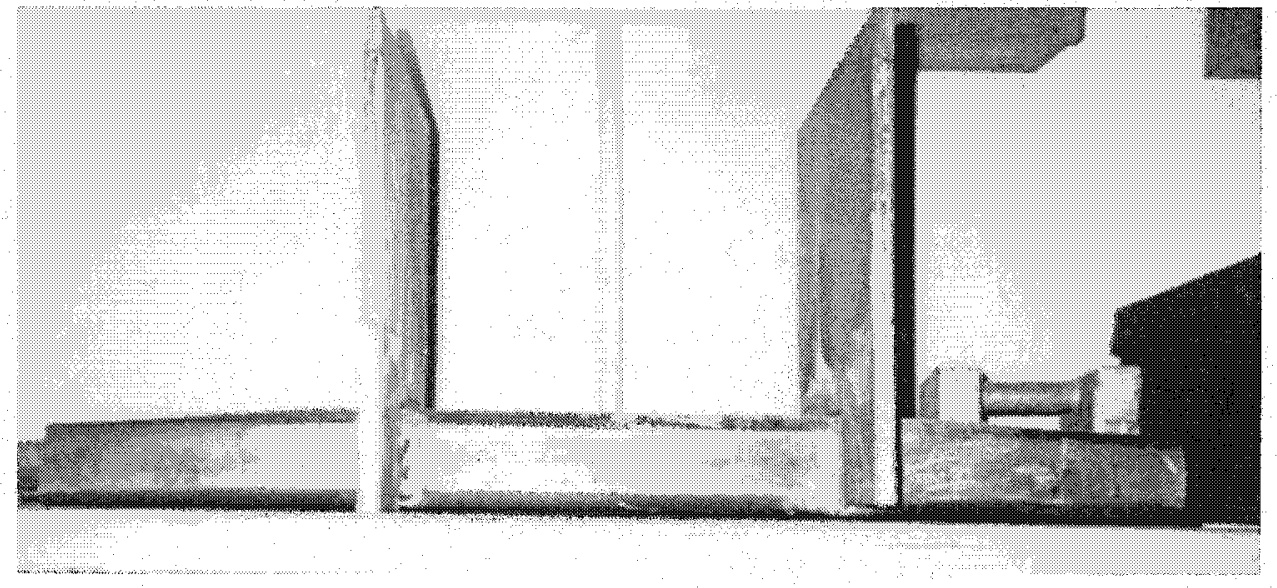

Fig. 35. Bowing of the Tube for LPC3 


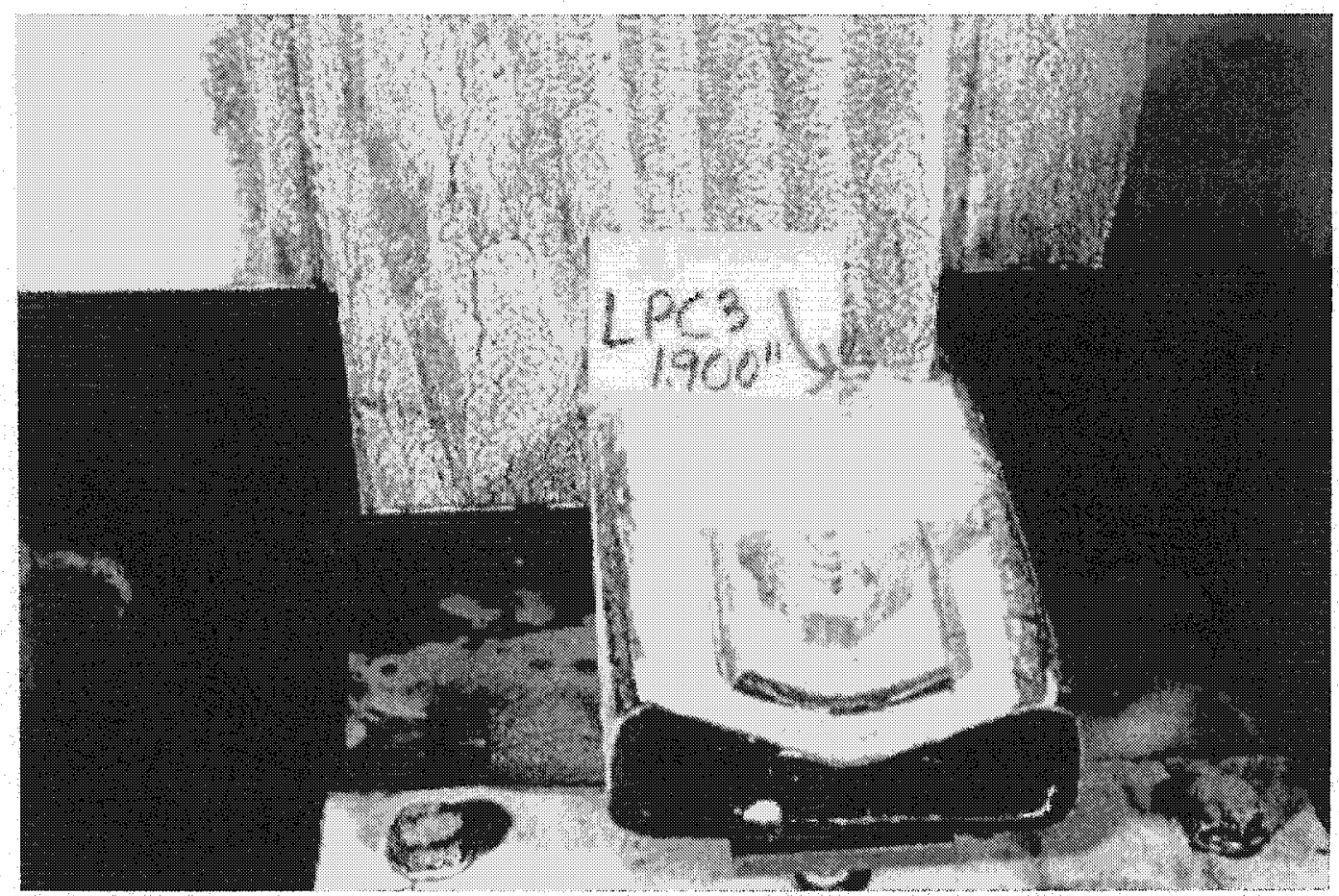

Fig. 36. Initial Crack on the Weld Return on Side B of LPC3

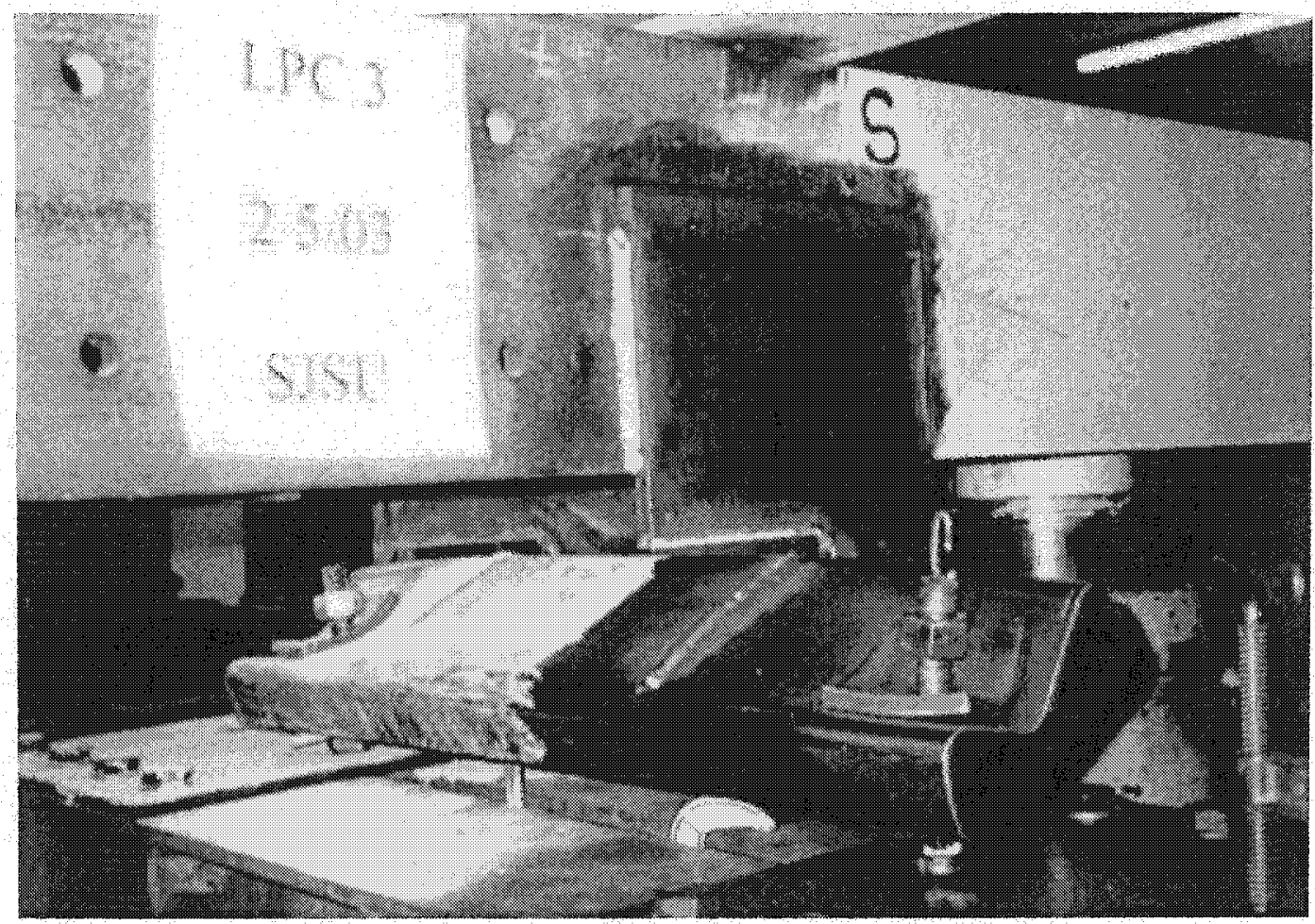

Fig. 37. Complete Weld Fracture of LPC3 specimen 


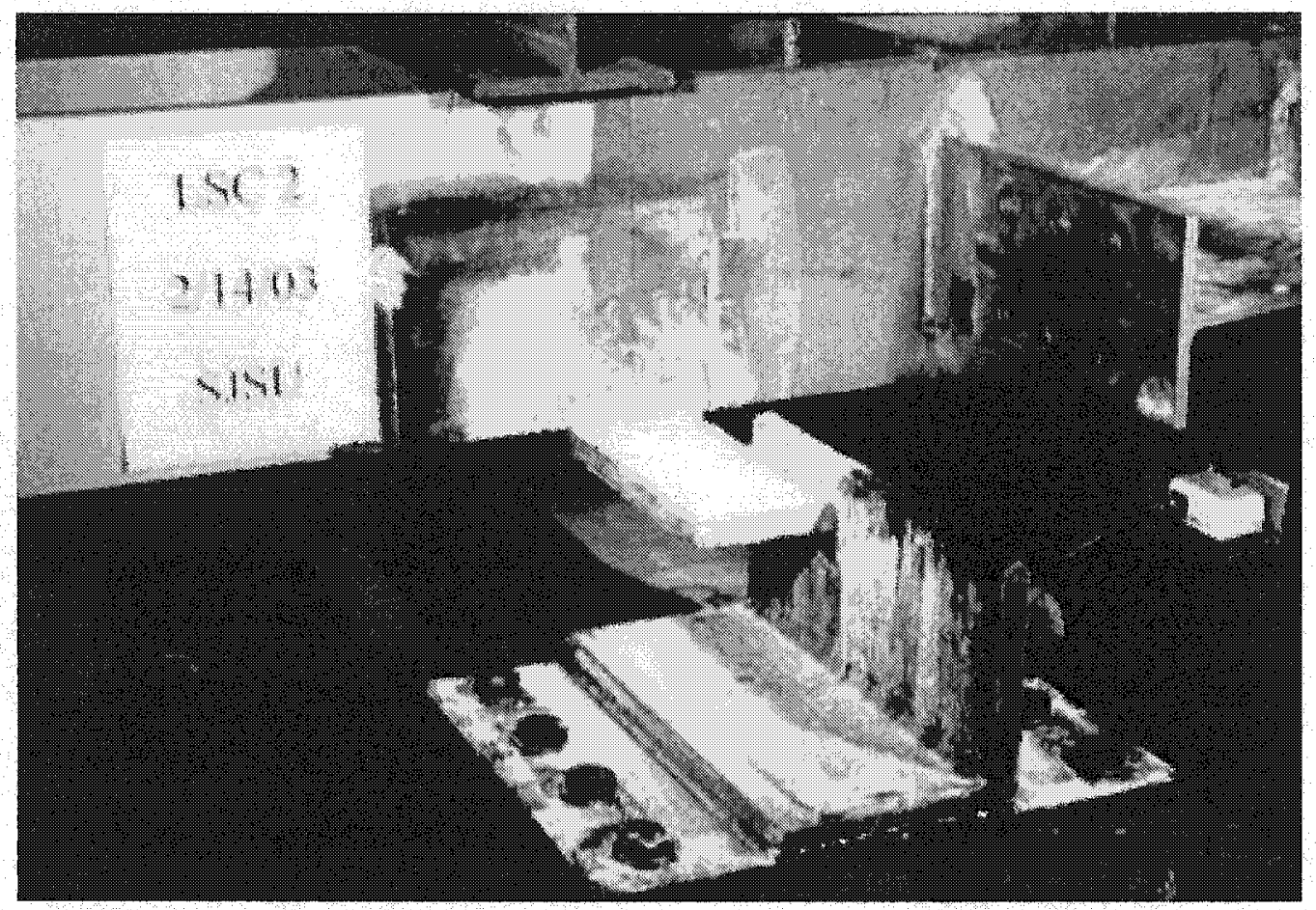

Fig. 38. Lime-coated Side B of LSC2

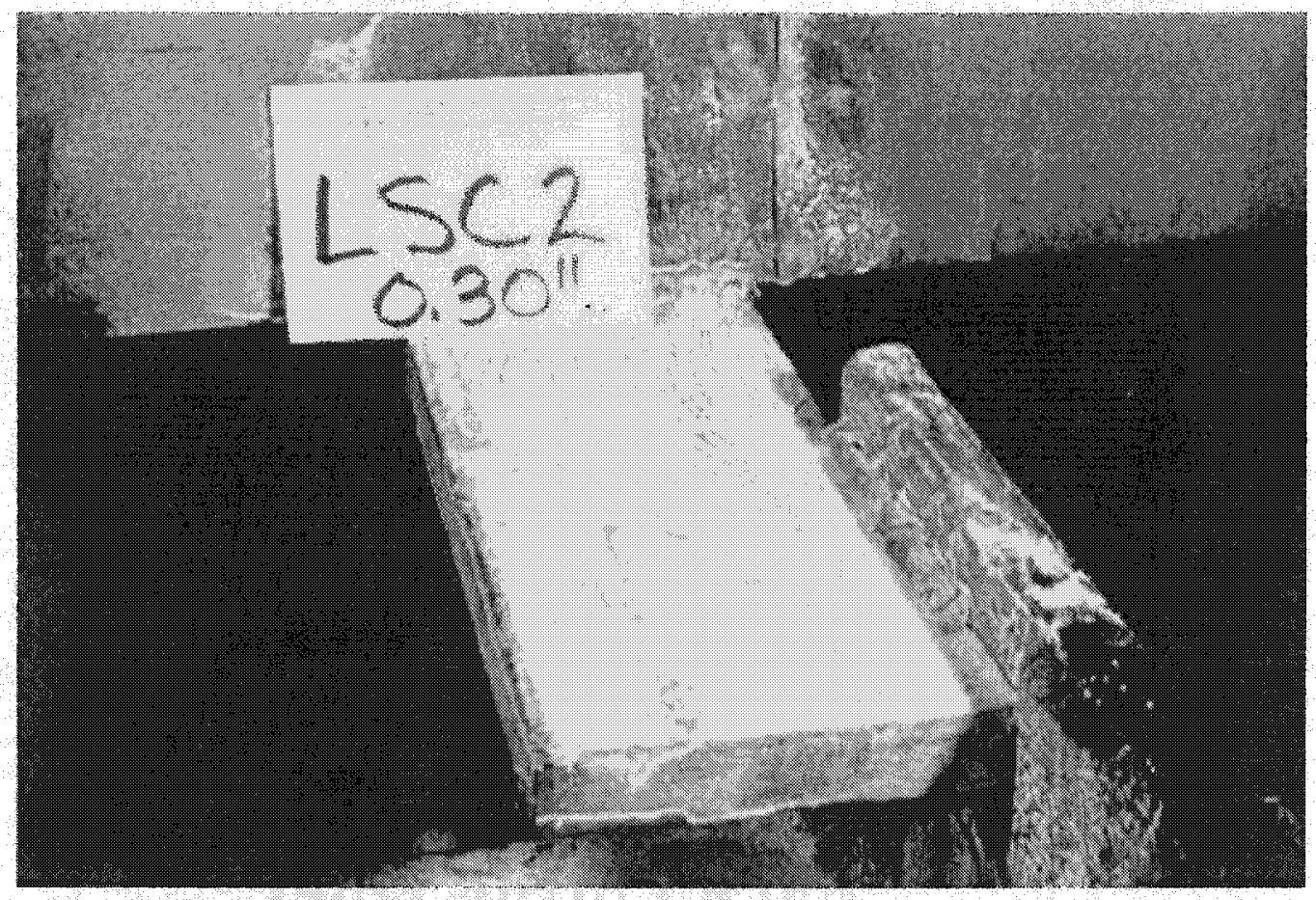

Fig. 39. Flaking of Lime-coat on Side B of LSC2 


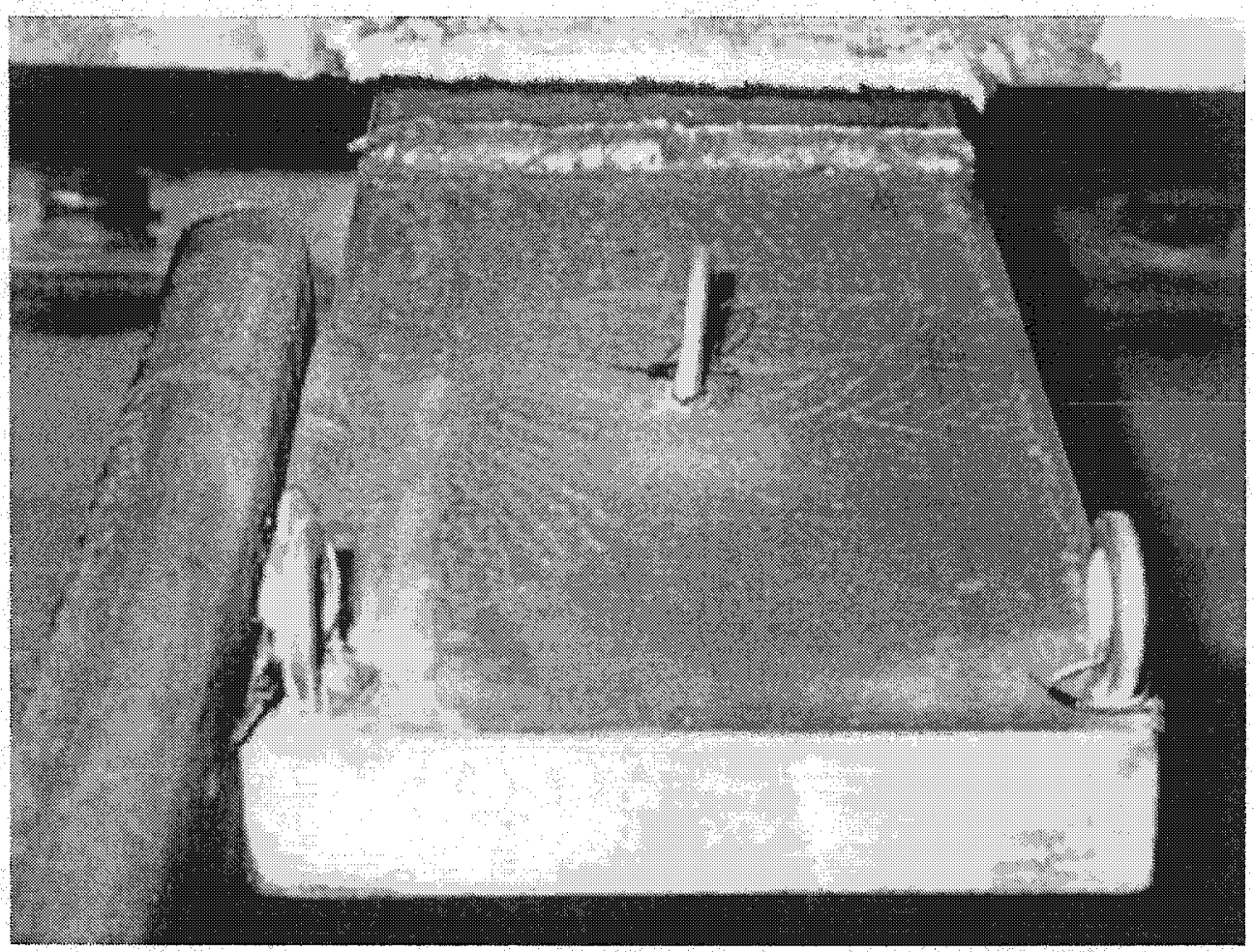

Fig. 40. Weld Fracture on Side A of LSC2R 


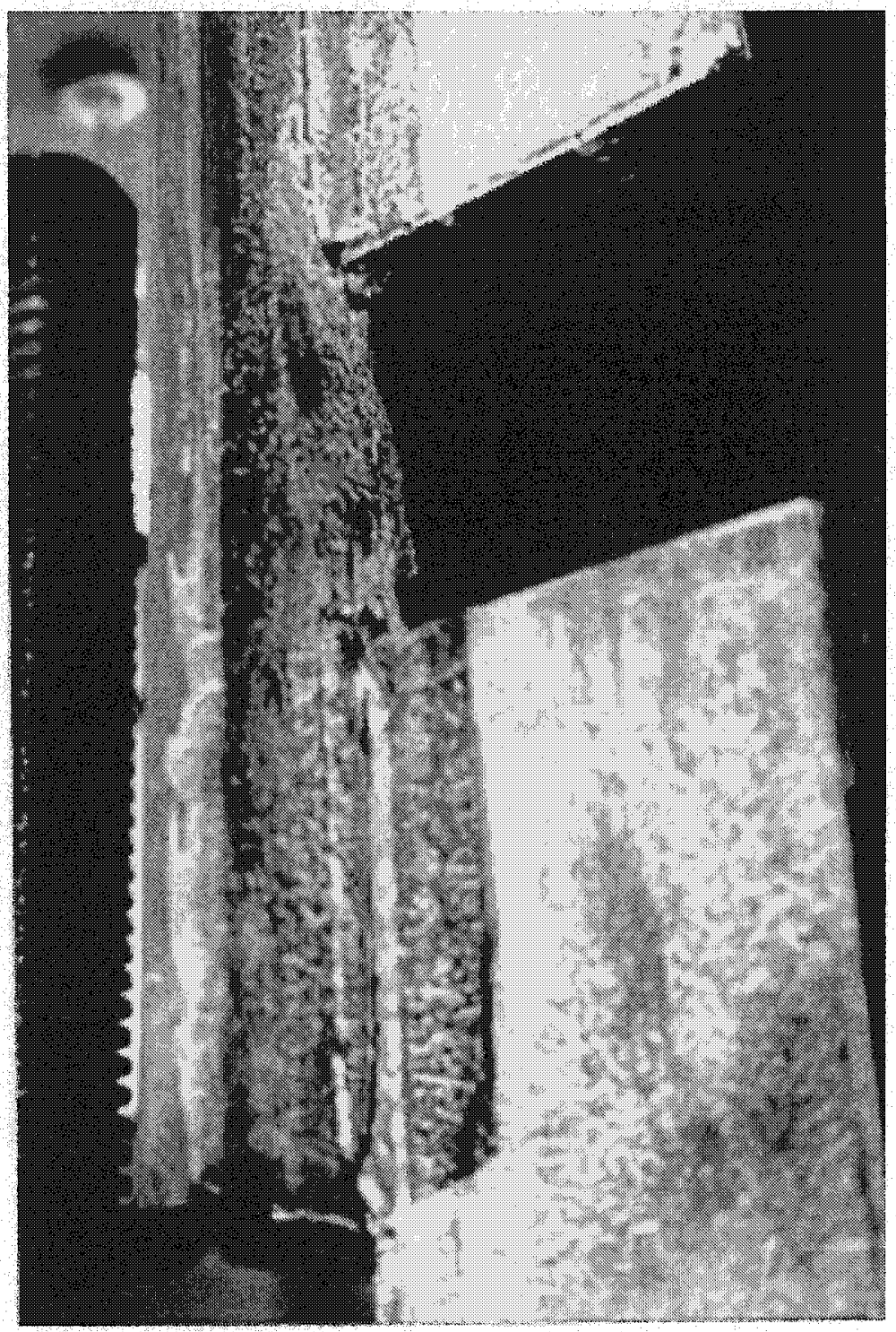

Fig. 41. Weld Fracture at the Bottom Plate of LSC1 


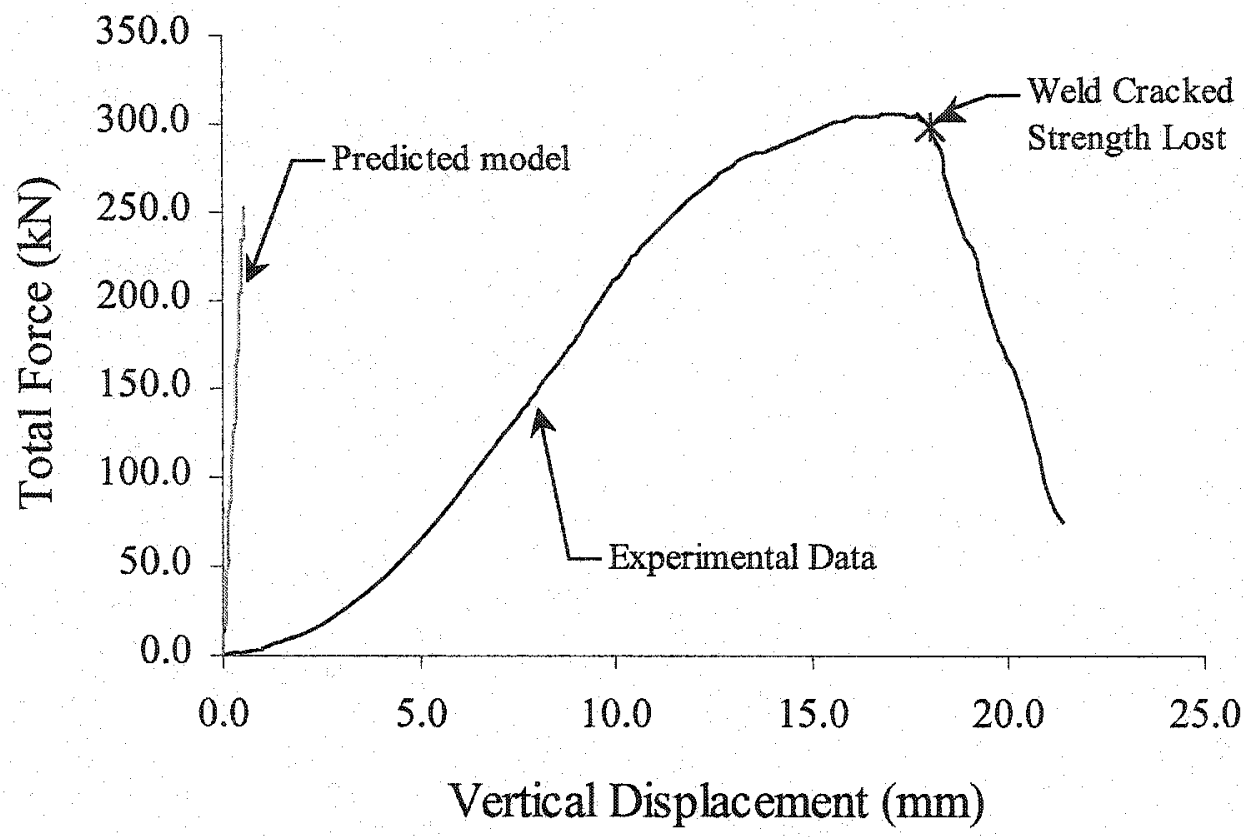

Fig. 42. LSC1 In-Plane Force Displacement Graph

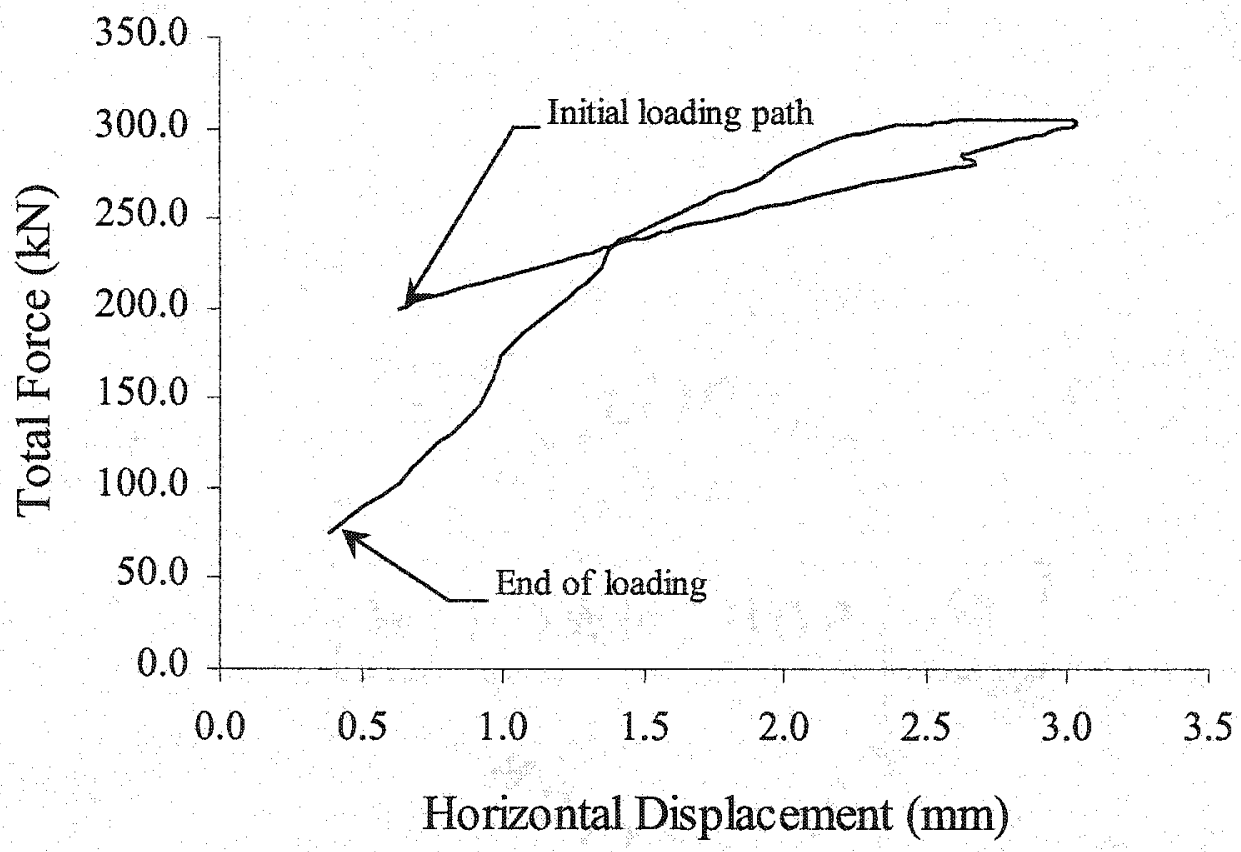

Fig. 43. LSC1 Force-Displacement graph measuring Twist of the Angle 


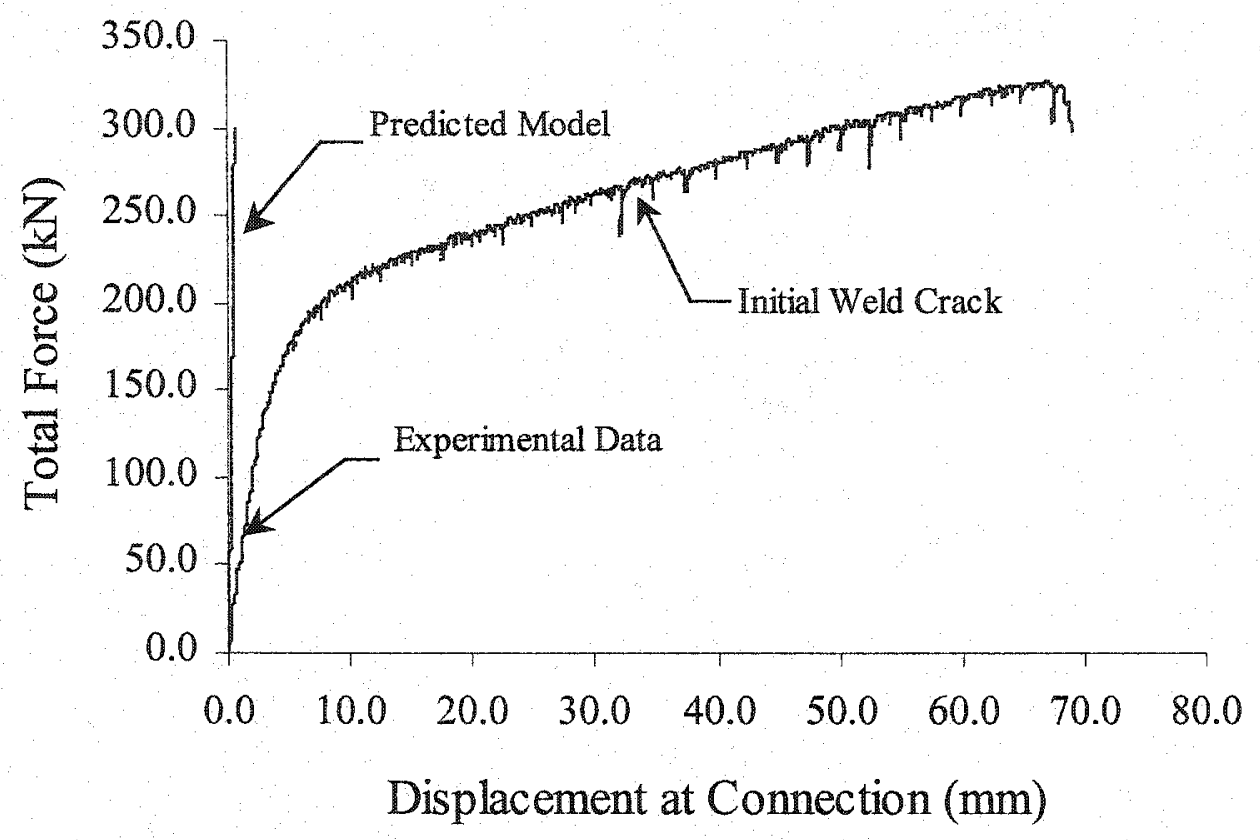

Fig. 44. LPC3 Force-Displacement Graph at the Connection

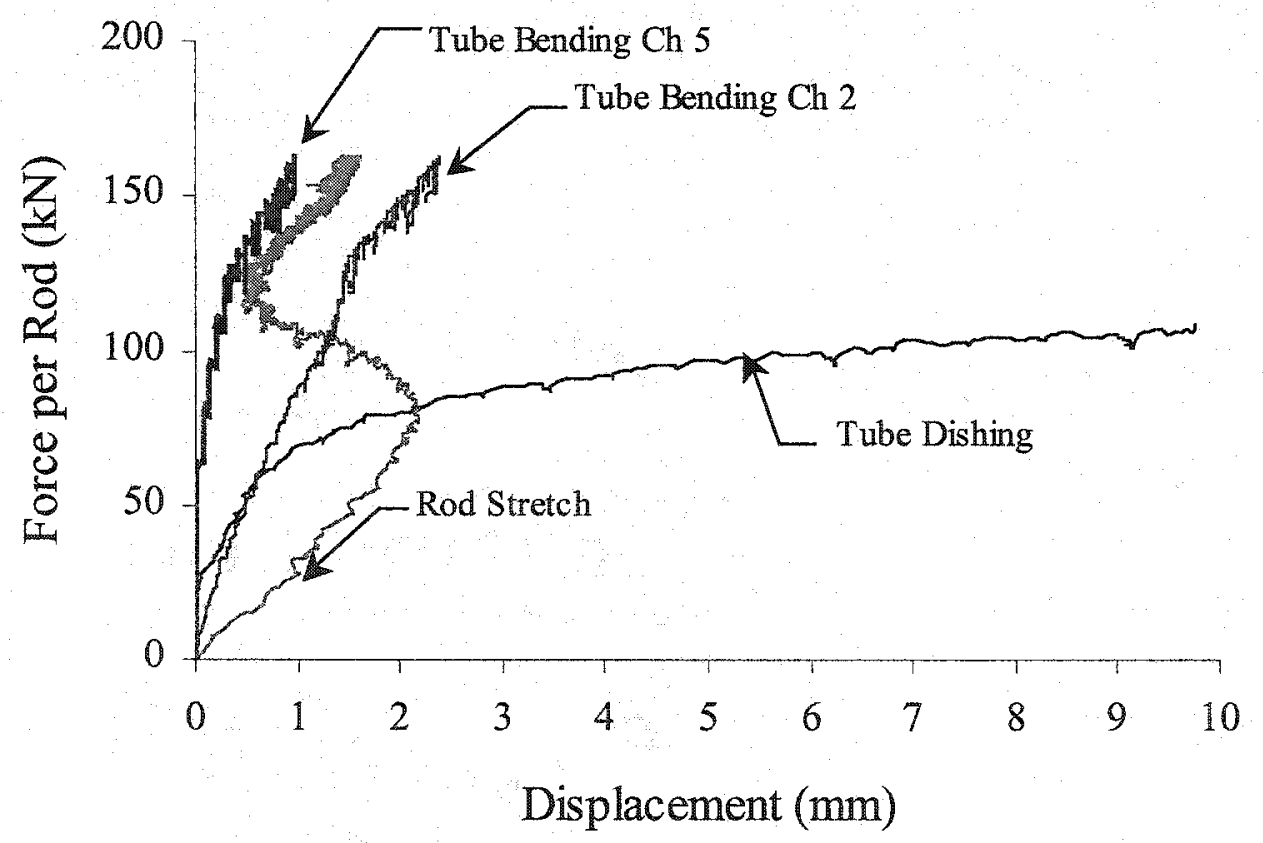

Fig. 45. LPC3 Force versus Displacement of the Rod Stretching, Dishing, and Bending of the Tube 


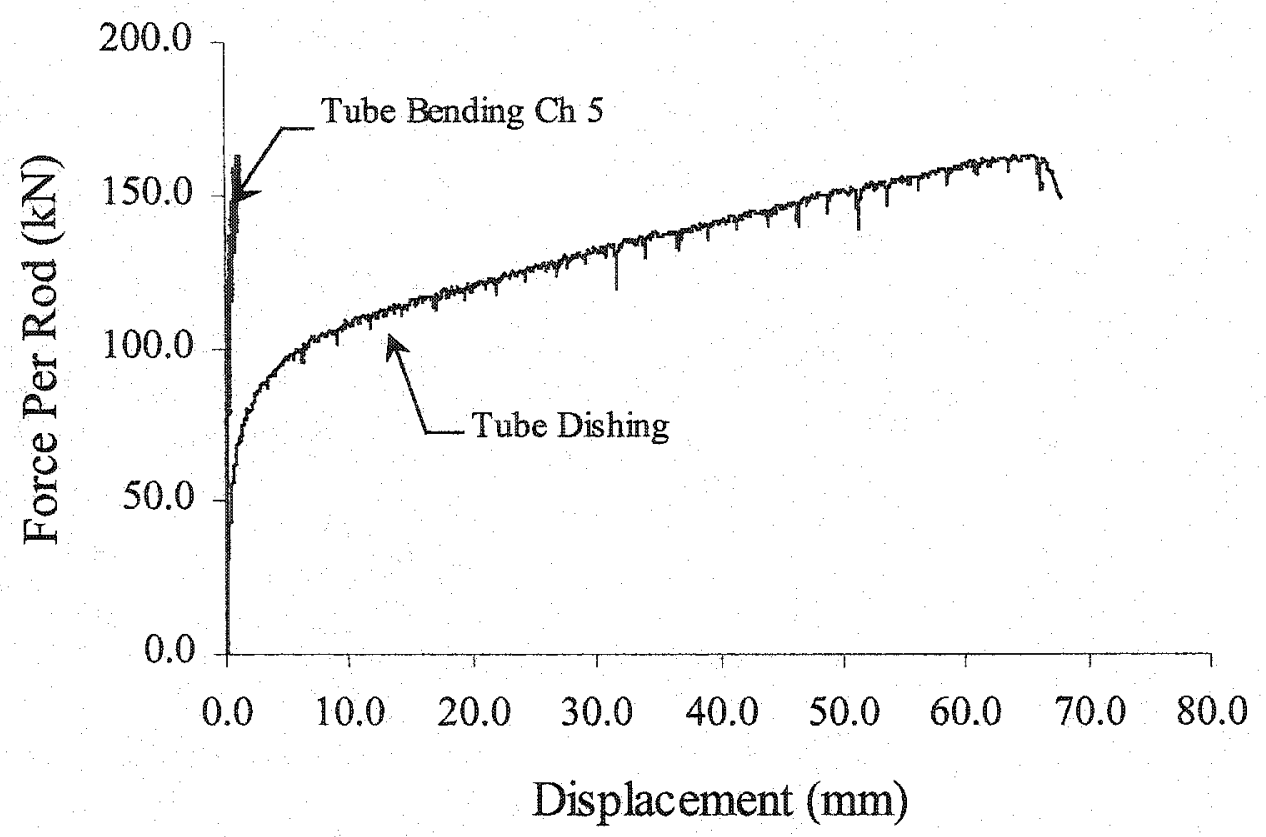

Fig. 46. LPC3 Force versus Displacement of the Tube Bending (Ch 5) and Dishing of the Tube

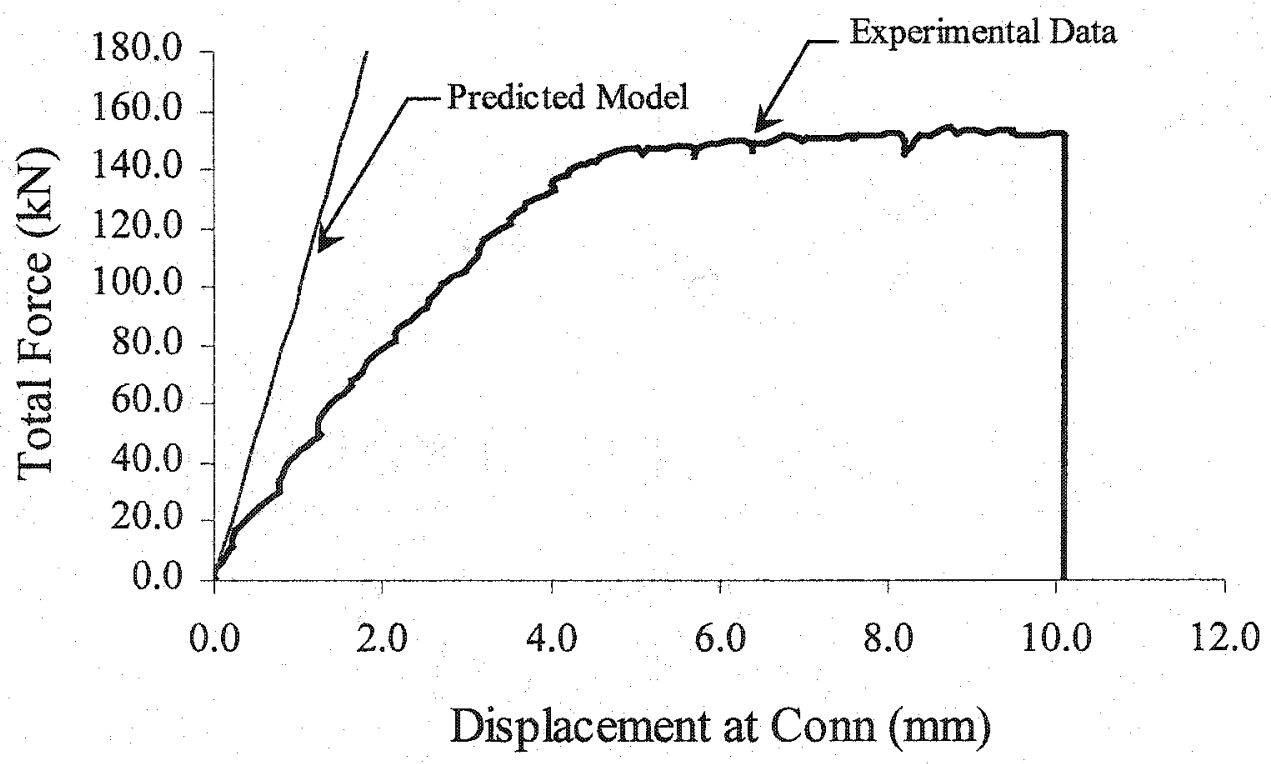

Fig. 47. LSC2 Force-Displacement Graph at the Connection 


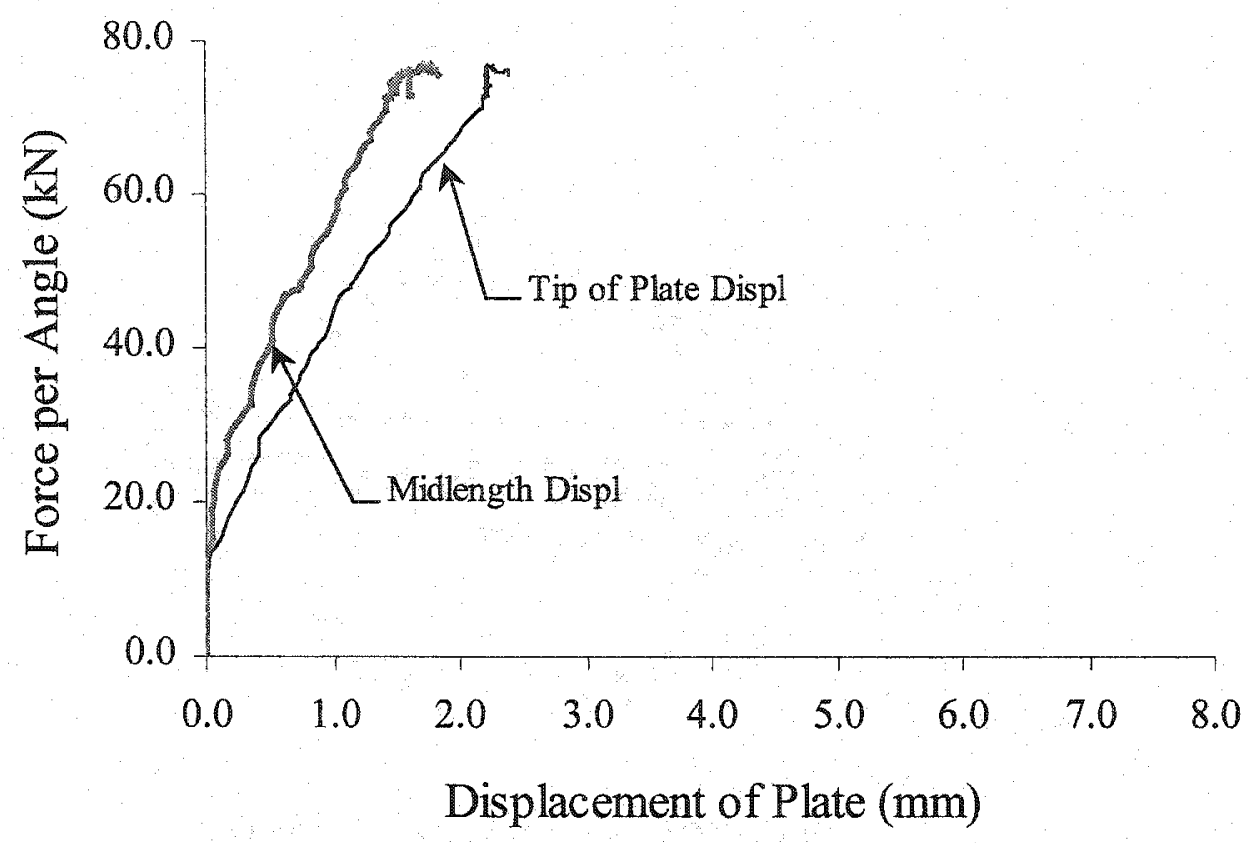

Fig. 48. LSC2 Comparison of Tip and Mid-length Displacement per Angle

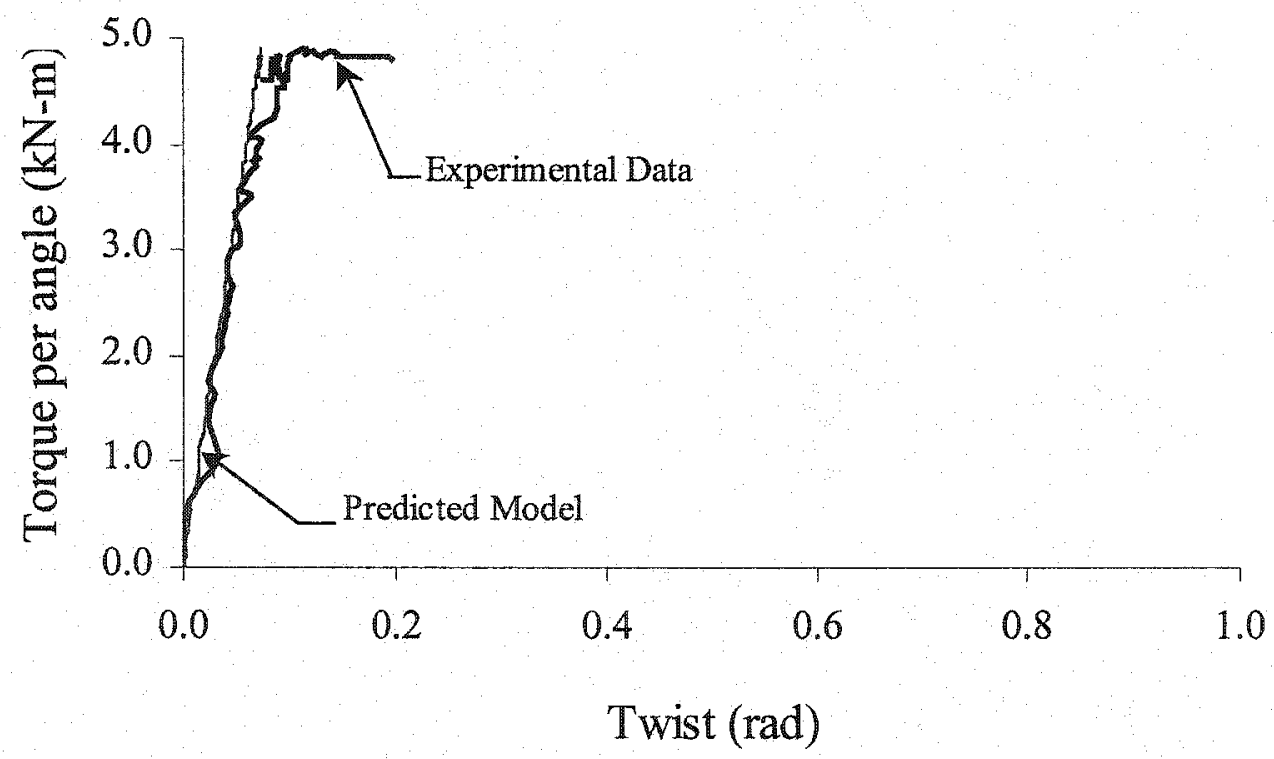

Fig. 49. LSC2 Torque versus Twist at the Tip of the Plate (Side A) 


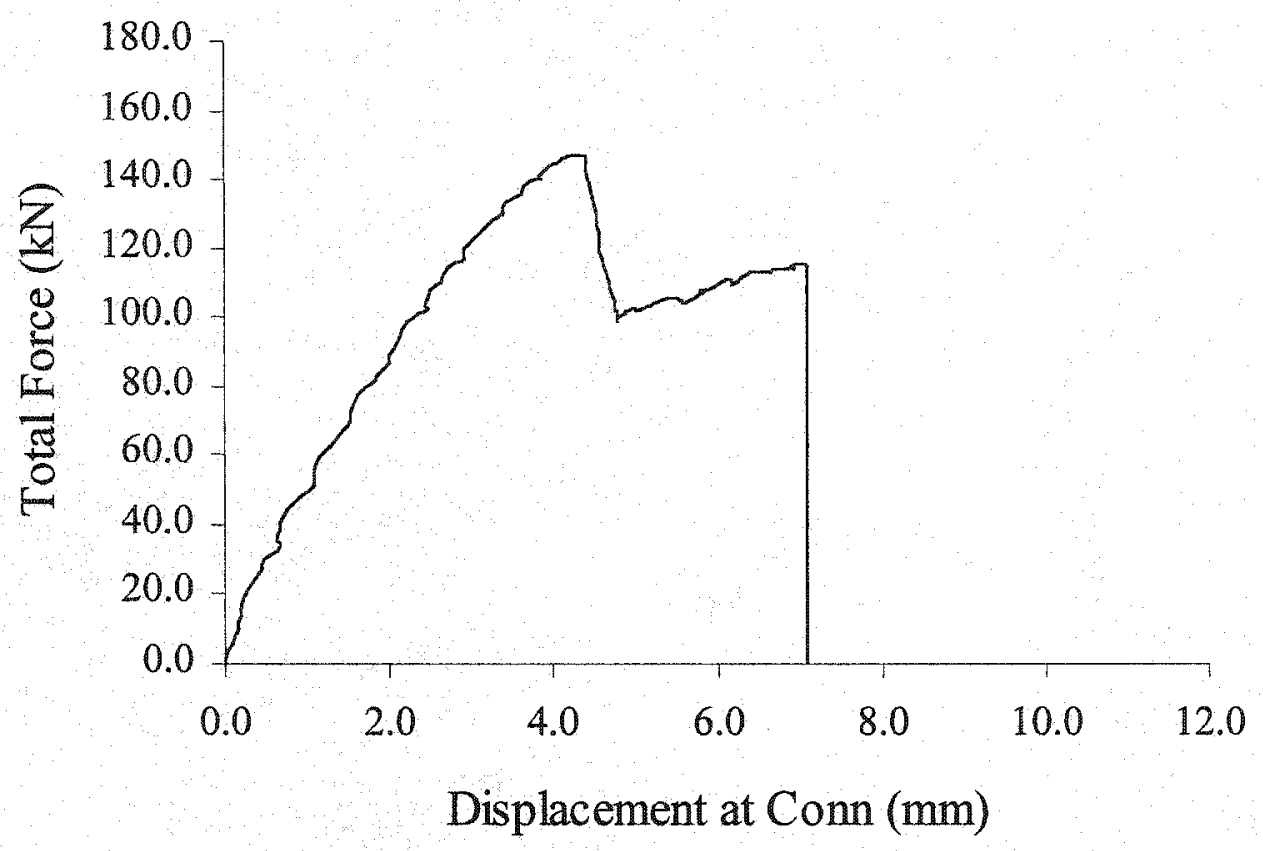

Fig 50. LSC2R Force-Displacement Graph at the Connection

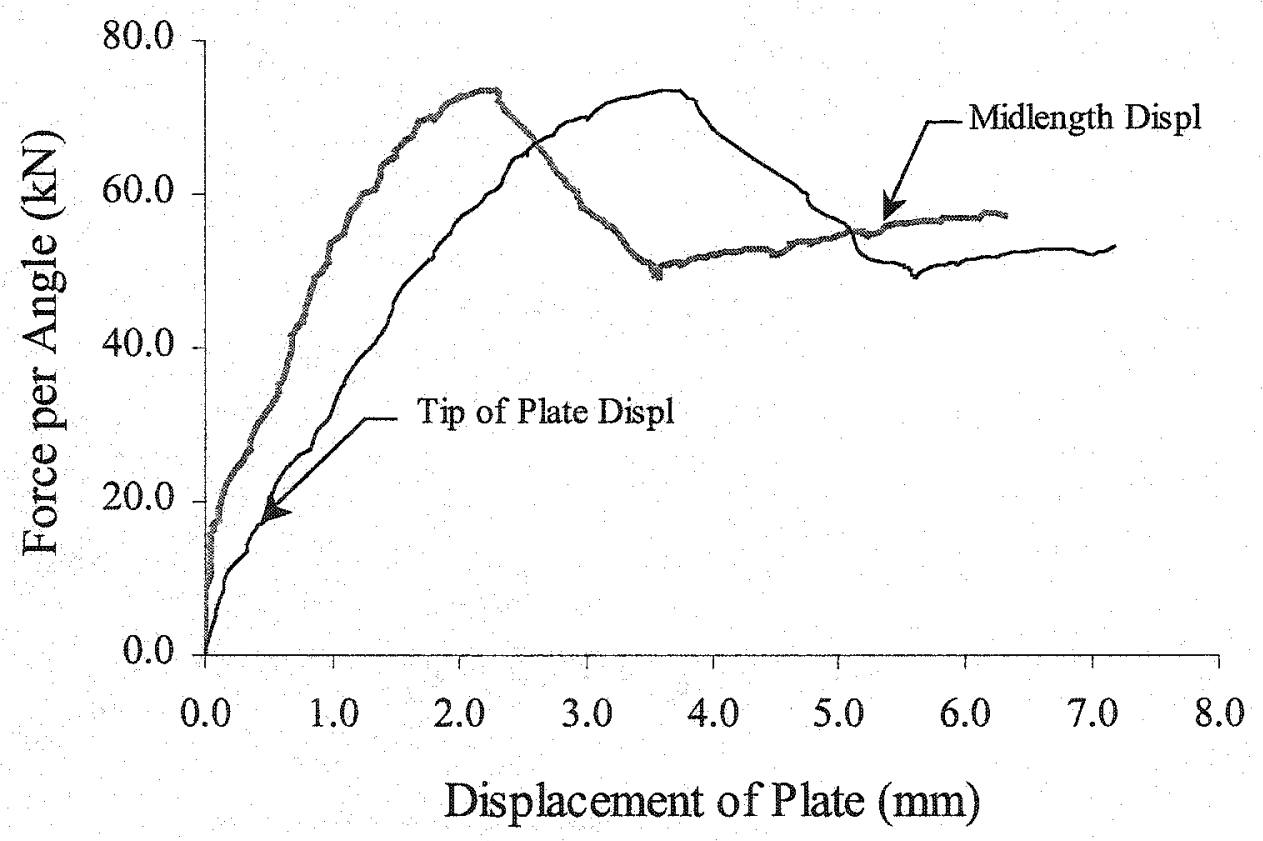

Fig. 51. LSC2R Comparison of Tip and Mid-length Displacement per Angle 


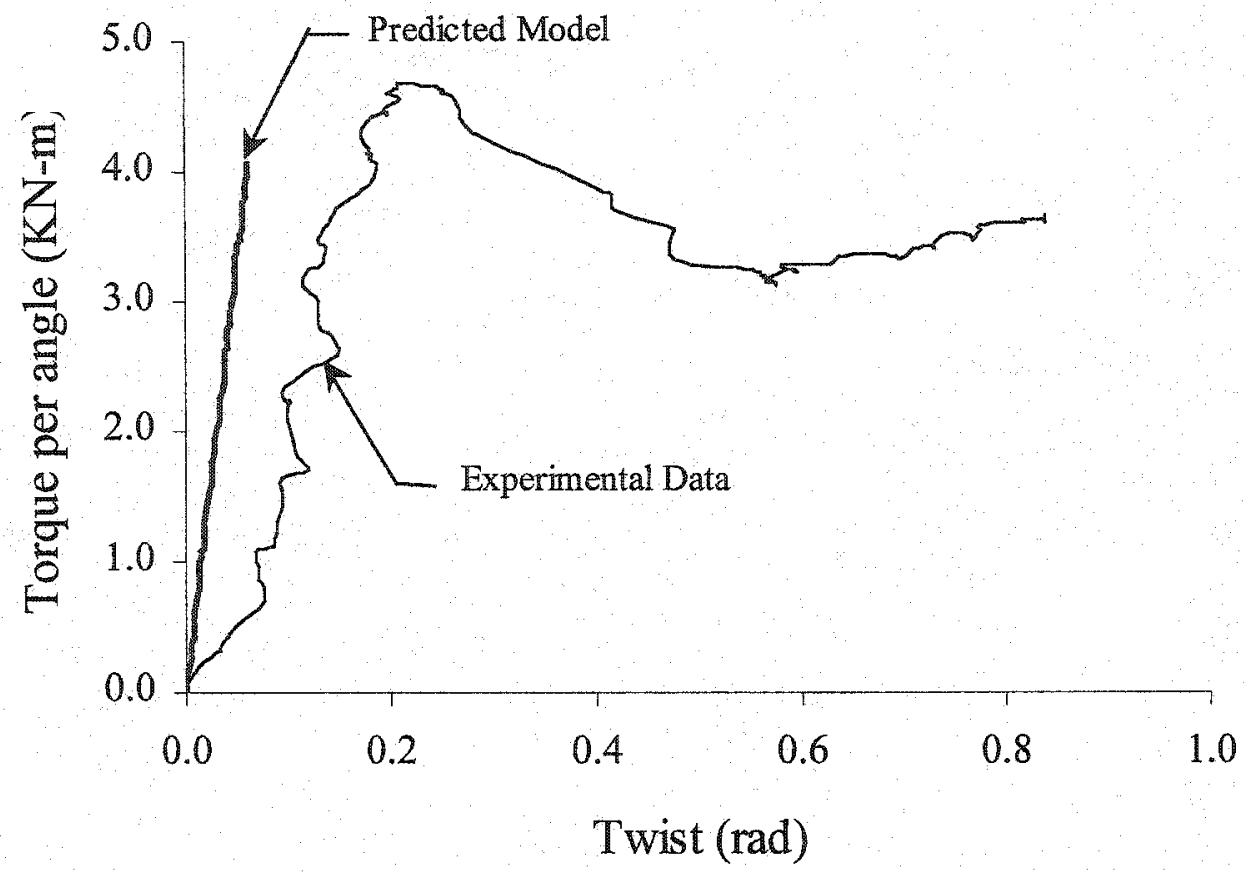

Fig. 52. LSC2R Torque versus Twist at the Tip of the Plate (Side A)

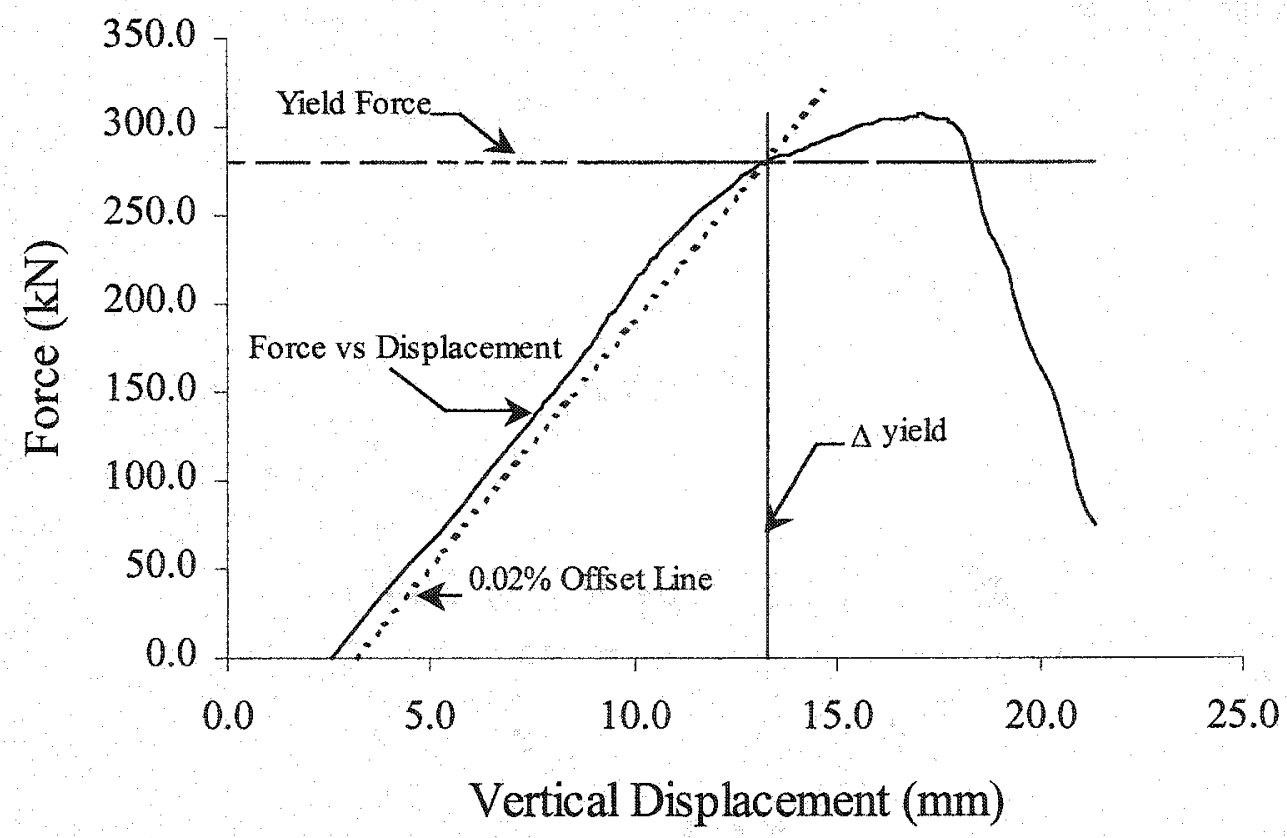

Fig. 53. Procedure for Determining the Offset Yield Displacement 


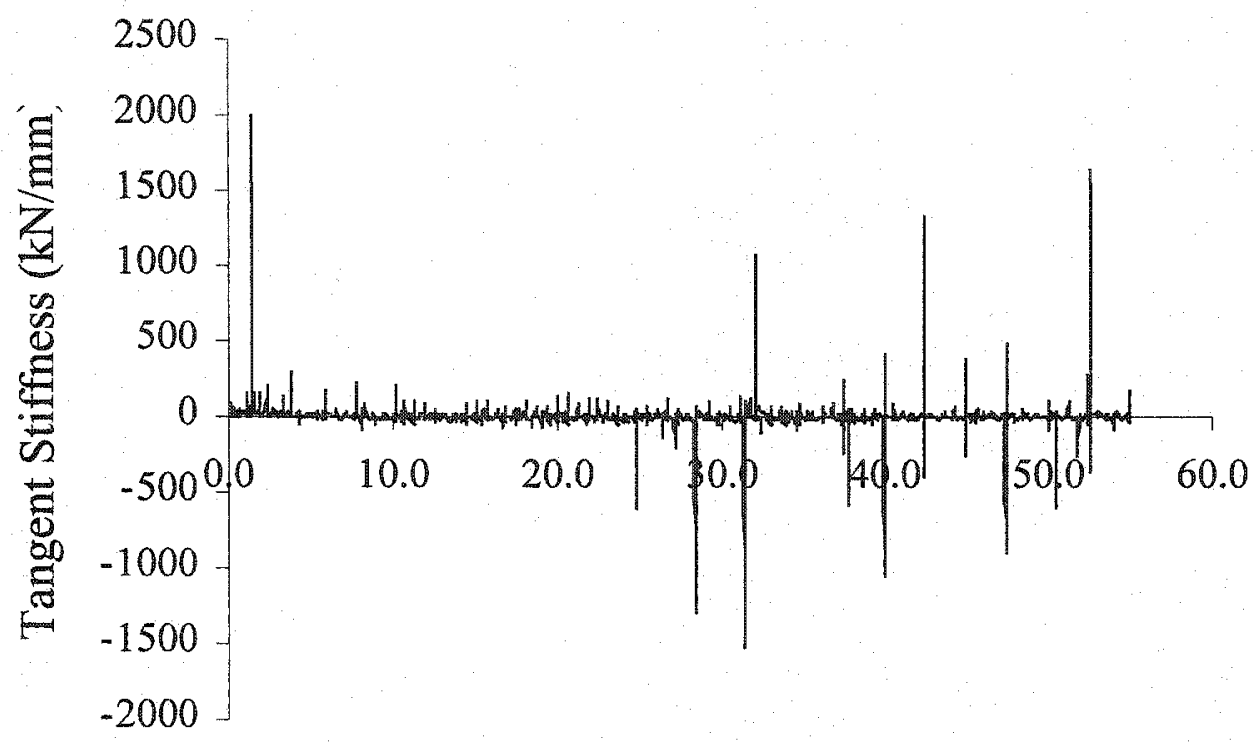

Displacement (mm)

Fig. 54. Illustrates the Original Tangent Stiffness Graph of LPC3

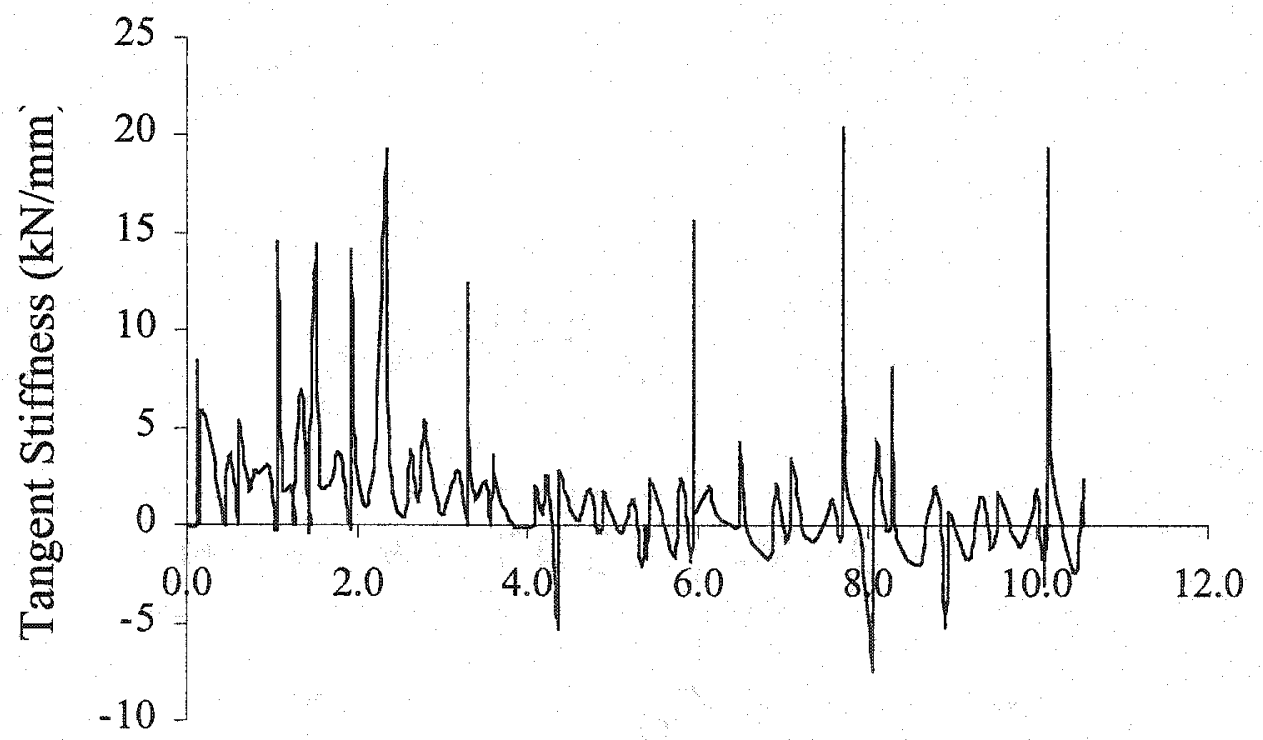

Displacement (mm)

Fig. 55. Tangent Stiffness Curve after Smoothing of LPC3 


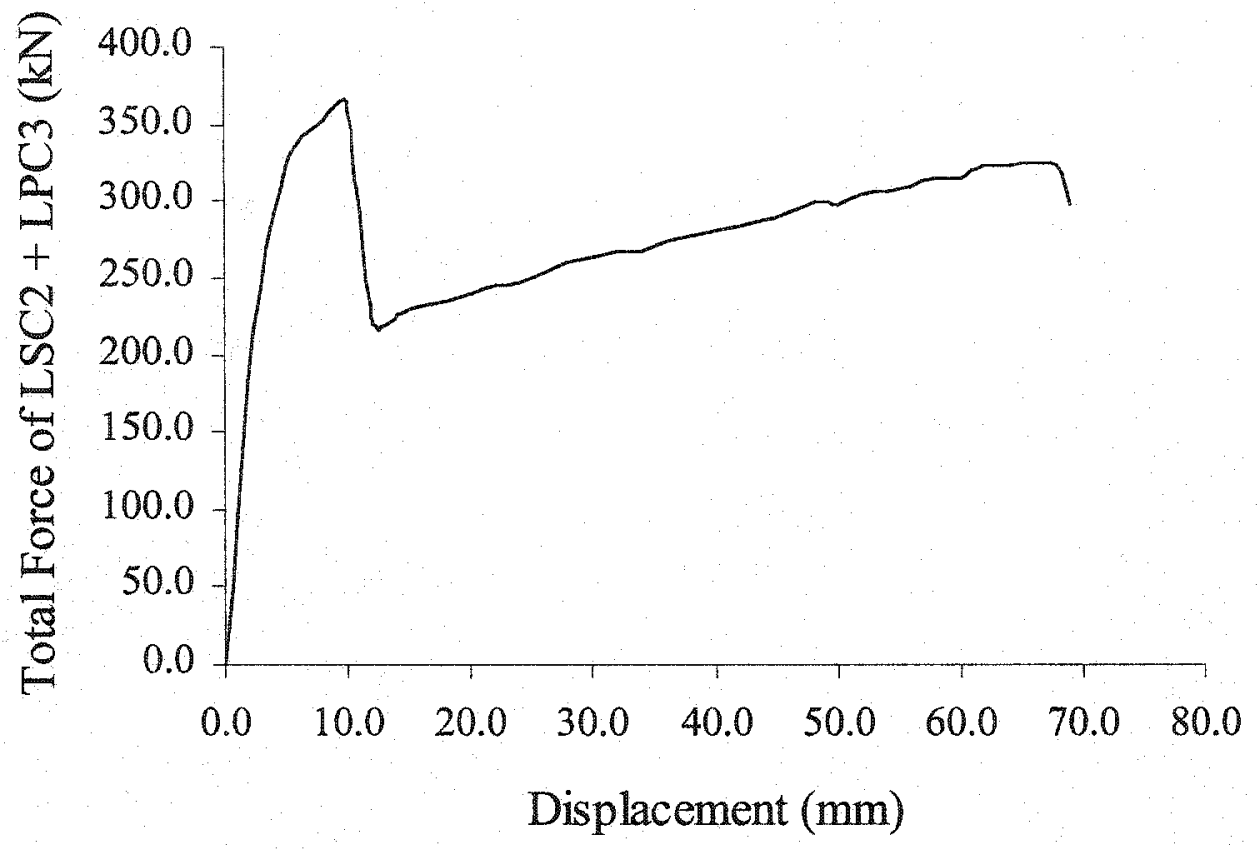

Fig. 56. Total Force of $L S C 2$ and LPC 3 versus Displacement of the Lateral Seismic Connection 


\section{APPENDIX E. TEST SUMMARIES AND MATERIAL TESTS SJSU LATERAL SEISMIC CONNECTION RESEARCH SUMMARY OF EXPERIMENT 1}

OBJECTIVE: Analyze sequence of failure of the plate attached to the angle subjected to tensile forces

TEST DATE: $\quad$ November $4^{\text {th }}, 2002$

CONDUCTED BY: KMM and CC at San Jose State University

SPECIMEN NO: LSC1

PROPERTIES OF TEST SPECIMEN 1:

$\begin{array}{lll}\text { ANGLE: } & \text { L8 } \times 8 \times 1 & \text { Length: } 406 \mathrm{~mm}\left(16^{\prime \prime}\right) \\ \text { PLATE: } & 2-25 \times 127 \mathrm{~mm}\left(1 \times 5^{\prime \prime}\right) & \text { Length: } 685.8 \mathrm{~mm}\left(27^{\prime \prime}\right) \\ \text { WELD SIZE: } & 8 \mathrm{~mm}\left(5 / 16^{\prime \prime}\right) & \text { Length: } 127 \mathrm{~mm}\left(5^{\prime \prime}\right) \\ \text { WELD ELEC: } & \text { E70XX } & \end{array}$

ACTUATOR: $\quad$ Riehle Tension Machine (Rm. 131)

TEST RESULTS:

ULTIMATE SHEAR:307.45kN (69.12kips)

MAXIMUM DISPLACEMENT: $21.3 \mathrm{~mm}$ (0.84in)

FAILURE MODE: Weld cracked on the bottom weld (between plate and angle) COMMENTS:

-At $138 \mathrm{kN}$ (31 kips) the weld return cracked on the top weld of the bottom plate. -At $287 \mathrm{kN}$ (64.5kips) visible yielding and slight bending can be seen from the angle. -At $298 \mathrm{kN}$ (67kips) cracking noise from the weld are heard. Weld material begins to break off from the top of the bottom weld. Peak load of $307.45 \mathrm{kN}$ reached. -At $214 \mathrm{kN}$ (48kips) top of bottom weld cracks $25 \mathrm{~mm}$ (1") from the top down its length. -At $142 \mathrm{kN}$ (32kips) top of bottom weld cracks $50 \mathrm{~mm}$ (2in) from the top down.

-Weld fracture occurred significantly higher than the calculated force.

-Weld fracture resulted in deep penetration, the weld cracked directly in the middle. -After 307kN (69kips) the weld has failed by shear. 


\section{SISU LATERAL SEISMIC CONNECTION RESEARCH SUMMARY OF EXPERIMENT 2}

OBJECTIVE: Analyze sequence of failure of the tube attached to the column plates and W12 column

TEST DATE: February $5^{\text {th }}, 2003$

CONDUCTED BY: KMM and CC at San Jose State University SPECIMEN NO: LPC3

PROPERTIES OF TEST SPECIMEN 2:

TUBE: $\quad$ TS8 $83 \times 3 / 8 \quad$ Length: $864 \mathrm{~mm}\left(34^{\prime \prime}\right)$

WELD SIZE: $\quad 8 \mathrm{~mm}\left(5 / 16^{\prime \prime}\right) \quad$ Length: $\quad 76 \mathrm{~mm}\left(3^{\prime \prime}\right), 165 \mathrm{~mm}$ $\left(6.5^{\prime \prime}\right), 178 \mathrm{~mm}\left(7^{\prime \prime}\right)$

WELD ELEC: E70XX

TYPE OF BOLTS: 2-25mm Dia. Coil Rod Length: 305mm(12") 4-25mm Dia. Coil Nuts Tested:254mm(10") 4-PL Washers PL $1 / 2 \times 4 \times 0-4$ "

LOAD BM: W12 $\quad$ Length: $4.66 \mathrm{~m}\left(183.5^{\prime \prime}\right)$

SUPPORT BM: $\quad 2-W 24 \times 68 \quad$ Length: $1.97 \mathrm{~m}\left(77.75^{\prime \prime}\right)$

ACTUATOR: 2-305mm (12") Dia. Pistons

TEST RESULTS:

ULTIMATE FORCE: $326 \mathrm{kN}$ (73.21kips)

MAXIMUM DISPLACEMENT: $69 \mathrm{~mm}$ (2.72in)

FAILURE MODE: Complete weld fracture at tube and column plate COMMENTS:

-At $220 \mathrm{kN}$ (49.4kips) approximately $10.1 \mathrm{~mm}(0.4 \mathrm{in})$ of vertical rise by the column, the plate washer begins to bend, the washers punching stress force bends the wall of the TS. -At $250 \mathrm{kN}$ (56.2kips) at approximately $20.4 \mathrm{~mm}(0.8 \mathrm{in})$ of deflection side A of the tube (with instrumentation) deflects significantly more than side B. 
-At $276 \mathrm{kN}$ (62.1kips) at approximately $36 \mathrm{~mm}$ (1.4in) of deflection visible bowing of the TS is seen across the column.

-At $282 \mathrm{kN}$ (63.5kips) at approximately $33 \mathrm{~mm}$ (1.3in) of deflection the weld return cracked on side B (whitewashed side) of the column plate and TS.

-At $318 \mathrm{kN}$ (71.5kips) at approximately $53.3 \mathrm{~mm}$ (2.1 in) of deflection of the column, side A developed a weld return crack of $38.1 \mathrm{~mm}$ (1.5in) in length. Crack on side B was $19 \mathrm{~mm}(3 / 4 \mathrm{in})$. There was a $6.35 \mathrm{~mm}(1 / 4 \mathrm{in})$ gap between the column plate and TS at the weld crack region.

-The connection resisted a total force of $326 \mathrm{kN}$ (73.21kips).

-At approximately $300 \mathrm{kN}$ (67.5kips) the connection ultimately failed as welds from both side $A$ and $B$ completely separated.

-Weld fracture resulted in deep penetration, the weld cracked directly in the middle. 


\section{SJSU LATERAL SEISMIC CONNECTION RESEARCH SUMMARY OF EXPERIMENT 3}

OBJECTIVE: Analyze sequence of failure of the plate attached to an angle and W12 column

TEST DATE: $\quad$ February $14^{\text {th }}, 2003$ (LSC2), February $17^{\text {th }}, 2003$ (LSC2R)

CONDUCTED BY: KMM and CC at San Jose State University SPECIMEN NO: $\quad$ LSC2

PROPERTIES OF TEST SPECIMEN 3:

\begin{tabular}{|c|c|c|c|}
\hline ANGLE: & $2-\mathrm{L} 8 \times 8 \times 1$ & Length: & $406 \mathrm{~mm}\left(16^{\prime \prime}\right)$ \\
\hline PLATE: & $25 \times 127 \mathrm{~mm}\left(1 \times 5^{\prime \prime}\right)$ & Length: & $864 \mathrm{~mm}\left(34^{\prime \prime}\right)$ \\
\hline WELD SIZE: & $8 \mathrm{~mm}\left(5 / 16^{\prime \prime}\right)$ & Length: & $127 \mathrm{~mm}\left(5^{\prime \prime}\right)$ \\
\hline WELD ELEC: & E70XX & & \\
\hline LOAD BM: & $\mathrm{W} 12 \times 120$ & Length: & $4.66 \mathrm{~m}(183.5 ”)$ \\
\hline SUPPORT BM: & $2-W 24 \times 68$ & Length: & $1.97 \mathrm{~m}\left(77.75^{\prime \prime}\right)$ \\
\hline ACTUATOR: & $2-305 \mathrm{~mm}\left(12^{\prime \prime}\right) \mathrm{Dia}$ & & \\
\hline
\end{tabular}

TEST RESULTS:

ULTIMATE SHEAR: $154.04 \mathrm{kN}$ (34.63kips)

MAXIMUM DISPLACEMENT: $10 \mathrm{~mm}$ (0.40in)

FAILURE MODE: Weld cracked along the angle and plate COMMENTS:

-At $152 \mathrm{kN}$ (34kips) at $7.62 \mathrm{~mm}(0.30 \mathrm{in})$ visible yielding and slight bending of the plate along side $\mathrm{B}$.

-Maximum force occurred at $154 \mathrm{kN}$ ( $35 \mathrm{kips}$ ) with a $8.75 \mathrm{~mm}$ (0.34in).

-Weld fracture occurred significantly lower than the calculated force.

-Weld fracture resulted in deep penetration, the weld propagated throughout the entire length.

-After $152 \mathrm{kN}$ (34 kips) the weld completely failed by shear and twist. 


\title{
SJSU LATERAL SEISMIC CONNECTION RESEARCH SUMMARY OF EXPERIMENT 3 RETEST
}

\author{
OBJECTIVE: Analyze sequence of failure of the plate attached to an angle and \\ W12 column \\ TEST DATE: $\quad$ February $14^{\text {th }}, 2003$ (LSC2), February $17^{\text {th }}, 2003$ (LSC2R) \\ CONDUCTED BY: KMM and CC at San Jose State University \\ SPECIMEN NO: $\quad$ LSC2R (Re-welded and Retested)
}

PROPERTIES OF TEST SPECIMEN 3R:

$\begin{array}{llll}\text { ANGLE: } & \text { 2-L8 } \times 8 \times 1 & \text { Length: } & 406 \mathrm{~mm}(16 ") \\ \text { PLATE: } & 25 \times 127 \mathrm{~mm}(1 \times 5 ") & \text { Length: } & 864 \mathrm{~mm}(34 ") \\ \text { WELD SIZE: } & 8 \mathrm{~mm}(5 / 16 ") & \text { Length: } & 127 \mathrm{~mm}(5 ") \\ \text { LOAD BM: } & \text { W12 X 120 } & \text { Length: } & 4.66 \mathrm{~m}(183.5 ") \\ \text { SUPPORT BM: } & \text { 2-W24 x } 68 & \text { Length: } & 1.97 \mathrm{~m}\left(77.75^{\prime \prime}\right) \\ \text { ACTUATOR: } & \text { 2-305mm (12") Dia. Pistons } & & \end{array}$

TEST RESULTS:

ULTIMATE FORCE: $147.21 \mathrm{kN}$ (33kips)

MAXIMUM DISPLACEMENT: $7.1 \mathrm{~mm}$ (0.28in)

FAILURE MODE: Weld cracked along the column and plate

\section{COMMENTS:}

-Visible yielding and slight bending of the plate along side $\mathrm{A}$.

-Maximum force occurred at $147 \mathrm{kN}$ (33kips) with a $4.32 \mathrm{~mm}$ (0.17in).

-Weld fracture occurred significantly lower than the calculated force.

-Weld fracture resulted in deep penetration, the weld propagated throughout the entire length.

-After $114 \mathrm{kN}$ ( $25 \mathrm{kips})$ the weld completely failed by torsion. 


\section{Steel Coupon Test Results \\ San Jose State University Structures Laboratory}

Coupon Specimen Number: PL-1

Date of Testing:

March 26, 2003

Testing conducted by:

KMM, PJ, Kevin Chan, Carter Choi

Coupon Type:

Plate-type

Specimen taken from:

$1 \times 5$ inch (2002)

Specimen Size:

8 -inch length

Measurement of specimen dimensions

$\begin{array}{rlr}\text { Width }: \text { Reading } 1=1.508 & \text { Thickness: } & \text { Reading } 1=1.012 \\ \text { Reading } 2=1.507 & \text { Reading } 2=1.012 \\ \text { Reading } 3=1.508 & \text { Reading } 3=1.012 \\ \text { Average }=1.508 & \text { Average }=1.012 \\ \text { Average Cross-Sectional Area }= & 1.53\end{array}$

Test Data

\begin{tabular}{ll} 
Loading Point & Force \\
\hline Upper Yield & $61.62 \mathrm{kips}$ \\
Ultimate & $98.15 \mathrm{kips}$
\end{tabular}

Failure Type: Cup and cone

Percent Elongation Data

Final Length Readings: $\quad 10.43$ in

\section{Final Results}

\begin{tabular}{ll} 
Yield Stress: & $40.27 \mathrm{ksi}$ \\
Ultimate Stress: & $64.15 \mathrm{ksi}$ \\
2\% Elongation: & $41.45 \%$ \\
8\% Elongation: & $30.31 \%$ \\
\hline
\end{tabular}

Notes

1. Testing conducted according to the ASTM E8-96 protocol.

2. All units are kips and inches.

3. Stress-strain data was not recorded during testing. 


\begin{tabular}{|c|c|}
\hline & Steel Coupon Test Results \\
& San Jose State University Structures Laboratory \\
\hline
\end{tabular}

Coupon Specimen Number: PL-2

Date of Testing: March 26, 2003

Testing conducted by: $\quad$ KMM, PJ, Kevin Chan, Carter Choi

Coupon Type: Plate-type

Specimen taken from: $\quad 1 \times 5$ inch (2002)

Specimen Size: $\quad 8$-inch length

Measurement of specimen dimensions

$\begin{array}{rlr}\text { Width } \text { Reading } 1=1.505 & \text { Thickness: } & \text { Reading } 1=1.012 \\ \text { Reading } 2=1.505 & \text { Reading } 2=1.010 \\ \text { Reading } 3=1.505 & \text { Reading } 3=1.011 \\ \text { Average }=1.505 & \text { Average }=1.011 \\ \text { Average Cross-Sectional Area }= & 1.52\end{array}$

Test Data

\begin{tabular}{ll} 
Loading Point & Force \\
\hline Upper Yield & 61.38 kips \\
Ultimate & $98.22 \mathrm{kips}$
\end{tabular}

Failure Type: Cup and cone

Percent Elongation Data

Final Length Readings: $\quad 10.49$ in

\section{Final Results}

Yield Stress: $\quad 40.38 \mathrm{ksi}$

Ultimate Stress: $\quad 64.62 \mathrm{ksi}$

$2 \%$ Elongation: $\quad 57.95 \%$

$8 \%$ Elongation: $\quad 31.13 \%$

\section{Notes}

1. Testing conducted according to the ASTM E8-96 protocol.

2. All units are kips and inches.

3. Stress-strain data was not recorded during testing. 
Coupon Specimen Number: Col PL-1

Date of Testing:

March 26, 2003

Testing conducted by: KMM, PJ, Kevin Chan, Carter Choi

Coupon Type: Plate-type

Specimen taken from: $\quad 1 / 2 \times 16$ inch (2002)

Specimen Size: 8-inch length

Measurement of specimen dimensions

Width: Reading $1=1.502$

Reading $2=1.500$

Thickness: $\quad$ Reading $1=0.512$

Reading $3=1.501$

Average $=1.501$

Average Cross-Sectional Area $=$

Reading $2=0.506$

Reading $3=0.505$

Average $=0.508$

0.763

Test Data

\begin{tabular}{ll} 
Loading Point & Force \\
\hline Upper Yield & $39.79 \mathrm{kips}$ \\
Ultimate & $56.03 \mathrm{kips}$
\end{tabular}

Failure Type: Cup and cone

Percent Elongation Data

Final Length Readings: $\quad 10.19$ in

\section{Final Results}

Yield Stress:

$52.10 \mathrm{ksi}$

Ultimate Stress:

$73.40 \mathrm{ksi}$

$2 \%$ Elongation:

$47.9 \%$

$8 \%$ Elongation:

$27.4 \%$

\section{Notes}

1. Testing conducted according to the ASTM E8-96 protocol.

2. All units are kips and inches.

3. Stress-strain data was not recorded during testing. 


\section{Steel Coupon Test Results}

San Jose State University Structures Laboratory

Coupon Specimen Number:

Date of Testing:

Col PL-2

Testing conducted by:

March 26, 2003

KMM, PJ, Kevin Chan, Carter Choi

Coupon Type: $\quad$ Plate-type

Specimen taken from: $\quad 1 / 2 \times 16$ inch (2002)

Specimen Size: 8-inch length

Measurement of specimen dimensions

Width: Reading $1=1.503$

Reading $2=1.500$

Thickness: $\quad$ Reading $1=0.505$

Reading $3=1.501$

Average $=1.501$

Average Cross-Sectional Area $=$

Reading $2=0.503$

Reading $3=0.504$

Average $=0.504$

0.757

Test Data

\begin{tabular}{ll} 
Loading Point & Force \\
\hline Upper Yield & $40.97 \mathrm{kips}$ \\
Ultimate & $56.71 \mathrm{kips}$
\end{tabular}

Failure Type: Cup and cone

Percent Elongation Data

Final Length Readings: $\quad 10.04$ in

\section{Final Results}

Yield Stress:

$54.10 \mathrm{ksi}$

Ultimate Stress:

$74.9 \mathrm{ksi}$

$2 \%$ Elongation:

$46.0 \%$

$8 \%$ Elongation:

$25.5 \%$

\section{Notes}

1. Testing conducted according to the ASTM E8-96 protocol.

2. All units are kips and inches.

3. Stress-strain data was not recorded during testing. 


\section{Steel Coupon Test Results}

San Jose State University Structures Laboratory

Coupon Specimen Number: ANG-1

Date of Testing:

March 26, 2003

Testing conducted by:

KMM, PJ, Kevin Chan, Carter Choi

Coupon Type: Plate-type

Specimen taken from: $\quad$ L8x8x1 (2002)

Specimen Size: 8-inch length

Measurement of specimen dimensions

$\begin{aligned} & \text { Width }: \text { Reading } 1=1.503 \text { Thickness: } \\ & \text { Reading } 2=1.505 \text { Reading } 1=0.988 \\ & \text { Reading } 3=1.505 \text { Reading } 2=0.990 \\ & \text { Average }=1.504 \text { Reading } 3=0.989 \\ & \text { Average Cross-Sectional Area }= \text { Average }=0.989 \\ & \text { 1.49 }\end{aligned}$

Test Data

\begin{tabular}{ll} 
Loading Point & Force \\
\hline Upper Yield & $62.79 \mathrm{kips}$ \\
Ultimate & $100.11 \mathrm{kips}$
\end{tabular}

Failure Type: Cup and Cone

Percent Elongation Data

Final Length Readings: $\quad 10.49$ in

\section{Final Results}

Yield Stress:

$42.14 \mathrm{ksi}$

Ultimate Stress:

$67.19 \mathrm{ksi}$

$2 \%$ Elongation:

$57.7 \%$

$8 \%$ Elongation:

$31.1 \%$

\section{Notes}

1. Testing conducted according to the ASTM E8-96 protocol.

2. All units are kips and inches.

3. Stress-strain data was not recorded during testing. 
Steel Coupon Test Results

San Jose State University Structures Laboratory

Coupon Specimen Number: ANG-2

Date of Testing:

March 26, 2003

Testing conducted by: $\quad$ KMM, PJ, Kevin Chan, Carter Choi

Coupon Type: $\quad$ Plate-type

Specimen taken from: L8x8x1 (2002)

Specimen Size: 8-inch length

Measurement of specimen dimensions

Width: Reading $1=1.502$

Reading $2=1.501$

Thickness: Reading $1=0.991$

Reading $3=1.502$

Reading $2=0.992$

Average $=1.502$

Reading $3=0.991$

Average Cross-Sectional Area $=$

Average $=0.991$

1.49

Test Data

\begin{tabular}{ll} 
Loading Point & Force \\
\hline Upper Yield & $62.00 \mathrm{kips}$ \\
Ultimate & $101.22 \mathrm{kips}$
\end{tabular}

Failure Type: Cup and Cone

Percent Elongation Data

Final Length Readings: $\quad 10.56$ in

\section{Final Results}

\begin{tabular}{ll} 
Yield Stress: & $41.61 \mathrm{ksi}$ \\
Ultimate Stress: & $67.93 \mathrm{ksi}$ \\
2\% Elongation: & $55.4 \%$ \\
$8 \%$ Elongation: & $32.0 \%$ \\
\hline
\end{tabular}

\section{Notes}

1 Testing conducted according to the ASTM E8-96 protocol.

2. All units are kips and inches.

3 Stress-strain data was not recorded during testing. 


\section{Steel Coupon Test Results}

\section{San Jose State University Structures Laboratory}

Coupon Specimen Number: Tub-1

Date of Testing:

March 26, 2003

Testing conducted by:

KMM, PJ, Kevin Chan, Carter Choi

Coupon Type: $\quad$ Plate-type

Specimen taken from: $\quad$ TS $8 \times 3 \times 3 / 8(2002)$

Specimen Size: $\quad 8$-inch length

Measurement of specimen dimensions

\begin{tabular}{|c|c|c|c|}
\hline Width: Reading $1=$ & 1.500 & Thickness: & Reading $1=$ \\
\hline Reading $2=$ & 1.499 & & Reading $2=$ \\
\hline Reading $3=$ & 1.502 & & Reading $3=$ \\
\hline Average $=$ & 1.500 & & Average $=$ \\
\hline
\end{tabular}

Test Data

\begin{tabular}{ll} 
Loading Point & Force \\
\hline Upper Yield & n/a \\
Ultimate & $32.46 \mathrm{kips}$
\end{tabular}

Failure Type: Cup and Cone

Percent Elongation Data

Final Length Readings: $\quad 10.26$ in

\section{Final Results}

\begin{tabular}{ll} 
Yield Stress: & $\mathrm{n} / \mathrm{a}$ \\
Ultimate Stress: & $62.66 \mathrm{ksi}$ \\
2\% Elongation: & $50.5 \%$ \\
$8 \%$ Elongation: & $28.3 \%$ \\
\hline
\end{tabular}

\section{Notes}

1. Testing conducted according to the ASTM E8-96 protocol.

2. All units are kips and inches.

3. Stress-strain data was not recorded during testing. 
Coupon Specimen Number: Tub-2

Date of Testing: March 26, 2003

Testing conducted by: KMM, PJ, Kevin Chan, Carter Choi

Coupon Type: $\quad$ Plate-type

Specimen taken from: $\quad$ TS $8 \times 3 \times 3 / 8(2002)$

Specimen Size: $\quad 8$-inch length

Measurement of specimen dimensions

Width: Reading $1=1.501$

Reading $2=1.499$

Thickness: $\quad$ Reading $1=0.346$

Reading $3=1.502$

Reading $2=0.344$

Average $=1.501$

Reading $3=0.345$

Average Cross-Sectional Area $=0.518$

Test Data

\begin{tabular}{ll} 
Loading Point & Force \\
\hline Upper Yield & $\mathrm{n} / \mathrm{a}$ \\
Ultimate & $32.68 \mathrm{kips}$
\end{tabular}

Failure Type: Cup and Cone

Percent Elongation Data

Final Length Readings: $\quad 10.16$ in

\section{Final Results}

Yield Stress: $\quad$ n/a

Ultimate Stress: $\quad 63.10 \mathrm{ksi}$

$2 \%$ Elongation: $\quad 46.3 \%$

$8 \%$ Elongation: $\quad 27.0 \%$

\section{Notes}

1. Testing conducted according to the ASTM E8-96 protocol.

2. All units are kips and inches.

3. Stress-strain data was not recorded during testing. 
Coupon Specimen Number: Rod-1

Date of Testing:

March 26, 2003

Testing conducted by: $\quad$ KMM, PJ, Kevin Chan, Carter Choi

Coupon Type: Rod-type

Specimen taken from: $\quad 1$-inch diameter rod $(2002)\left(3^{\text {rd }}\right.$ piece)

Specimen Size: 2.25-inch length

Measurement of specimen dimensions

Diameter: $\quad$ Reading $1=0.500$

Reading $2=0.501$

Reading 3 $=0.502$

Average $=0.501$

Average Cross-Sectional Area $=0.197$

Test Data

\begin{tabular}{ll} 
Loading Point & Force \\
\hline Upper Yield & n/a \\
Ultimate & $17.13 \mathrm{kips}$
\end{tabular}

Failure Type: Cup and Cone

Percent Elongation Data

Final Length Readings: $\quad 2.40$ in

\section{Final Results}

\begin{tabular}{lll} 
Yield Stress: & $69.6 \mathrm{ksi}$ & See Note 4 \\
Ultimate Stress: & $87.0 \mathrm{ksi}$ & \\
$2 \%$ Elongation: & $19.8 \%$ \\
$8 \%$ Elongation: & $\mathrm{n} / \mathrm{a}$ & \\
\hline
\end{tabular}

\section{Notes}

1. Testing conducted according to the ASTM E8-96 protocol.

2. All units are kips and inches.

3. Stress-strain data was not recorded during testing.

4. Ratio of $80 \%$ of ultimate stress was used to estimate yield stress 
Coupon Specimen Number: Rod-2

Date of Testing: $\quad$ March 26, 2003

Testing conducted by: $\quad$ KMM, PJ, Kevin Chan, Carter Choi

Coupon Type: Rod-type

Specimen taken from: $\quad 1$-inch diameter rod (2002) ( $3^{\text {rd }}$ piece)

Specimen Size: 2.25-inch length

Measurement of specimen dimensions

Diameter: $\quad$ Reading $1=0.506$

Reading $2=0.505$

Reading $3=0.505$

Average $=0.505$

Average Cross-Sectional Area $=\quad 0.200$

Test Data

\begin{tabular}{ll} 
Loading Point & Force \\
\hline Upper Yield & $\mathrm{n} / \mathrm{a}$ \\
Ultimate & $17.36 \mathrm{kips}$
\end{tabular}

Failure Type: Cup and Cone

Percent Elongation Data

Final Length Readings: $\quad 2.47$ in

\section{Final Results}

\begin{tabular}{ll} 
Yield Stress: & $69.44 \mathrm{ksi} \quad$ See Note 4 \\
Ultimate Stress: & $86.8 \mathrm{ksi}$ \\
2\% Elongation: & $23.7 \%$ \\
8\% Elongation: & $\mathrm{n} / \mathrm{a}$ \\
\hline
\end{tabular}

\section{Notes}

1. Testing conducted according to the ASTM E8-96 protocol.

2. All units are kips and inches.

3. Stress-strain data was not recorded during testing.

4. Ratio of $80 \%$ of ultimate stress was used to estimate yield stress 


\section{Steel Coupon Test Results \\ San Jose State University Structures Laboratory}

Coupon Specimen Number: Rod-3

Date of Testing:

March 26, 2003

Testing conducted by:

KMM, PJ, Kevin Chan, Carter Choi

Coupon Type: $\quad$ Rod-type

Specimen taken from: $\quad 1$-inch diameter rod (2002) ( $3^{\text {rd }}$ piece)

Specimen Size: 2.25-inch length

Measurement of specimen dimensions

$\begin{array}{ll}\text { Diameter: } & \text { Reading } 1=0.470 \\ & \text { Reading } 2=0.471 \\ & \text { Reading } 3=0.471 \\ & \text { Average }=0.471 \\ & \text { Average Cross-Sectional Area }=\quad 0.174\end{array}$

Test Data

\begin{tabular}{ll} 
Loading Point & Force \\
\hline Upper Yield & $\mathrm{n} / \mathrm{a}$ \\
Ultimate & $15.08 \mathrm{kips}$
\end{tabular}

Failure Type: Cup and Cone

Percent Elongation Data

Final Length Readings: $\quad 2.39$ in

\section{Final Results}

$\begin{array}{ll}\text { Yield Stress: } & 69.36 \mathrm{ksi} \quad \text { See Note } 4 \\ \text { Ultimate Stress: } & 86.7 \mathrm{ksi} \\ \text { 2\% Elongation: } & 19.3 \% \\ 8 \% \text { Elongation: } & \mathrm{n} / \mathrm{a}\end{array}$

\section{Notes}

1. Testing conducted according to the ASTM E8-96 protocol.

2. All units are kips and inches.

3. Stress-strain data was not recorded during testing.

4. Ratio of $80 \%$ of ultimate stress was used to estimate yield stress 


\section{APPENDIX F. CALIBRATION CHARTS OF INSTRUMENTATION}

Load Cell Calibration \#1 (Left)

Serial Number $\quad 46296$

Signal Conditioner E139571

CF (Fluke) 1.2E-05V/lb

$\mathrm{R}^{2} \quad 0.9999$

CF (Indicator) -0.2404

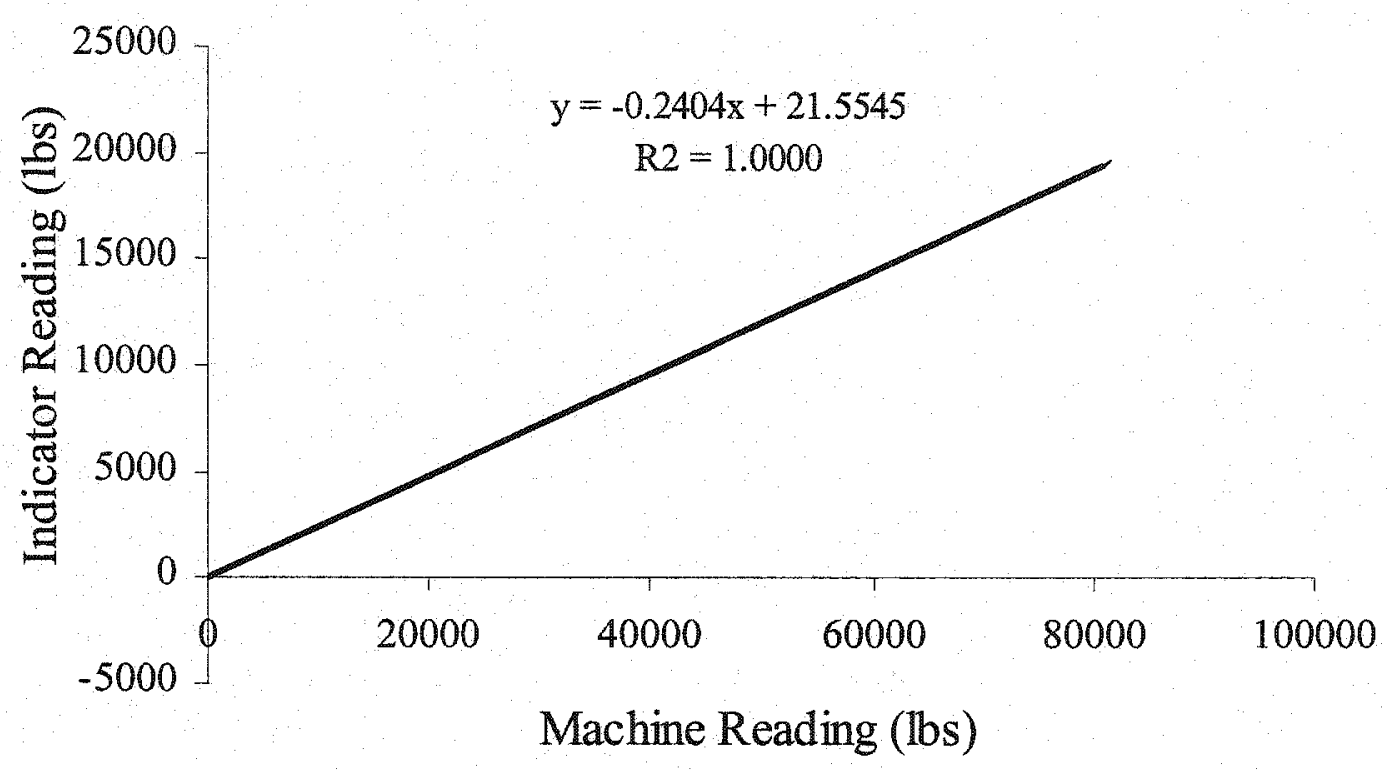

Chart. 1. Load Cell (Left) Force vs. Displacement of the Indicator-Machine 


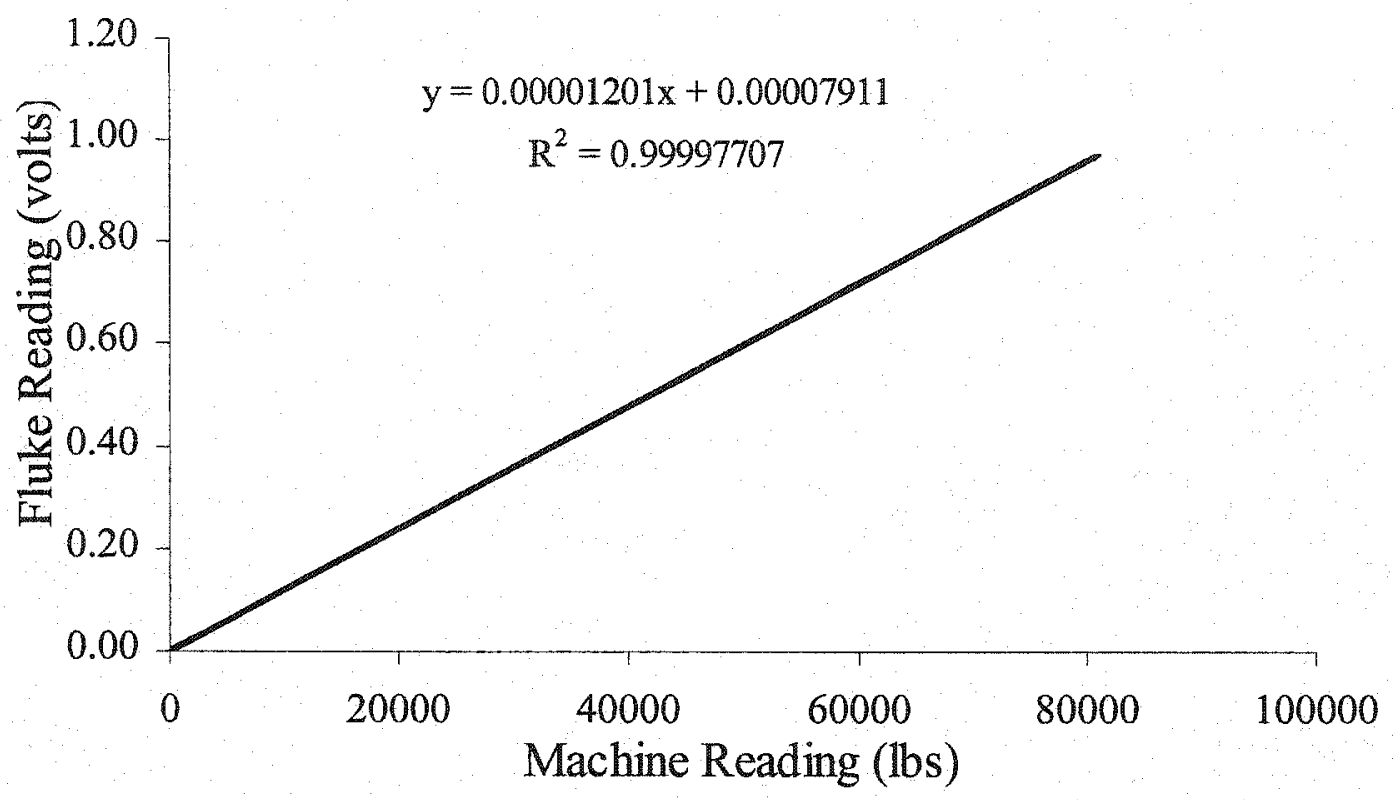

Chart. 2. Load Cell (Left) Force vs. Displacement of the Fluke-Machine

Load Cell Calibration \#2 (Right)

$\begin{array}{llll}\text { Serial Number } & 47161 & \mathrm{CF} \text { (Fluke) } & -9927.81 \mathrm{~b} / \mathrm{V} \\ \text { Signal Conditioner } & \text { E139570 } & \mathrm{R}^{2} & 1 \\ & & \mathrm{CF} \text { (Indicator) } 99.10\end{array}$

Charts 3-6 pertain to Load Cell calibration \#2 


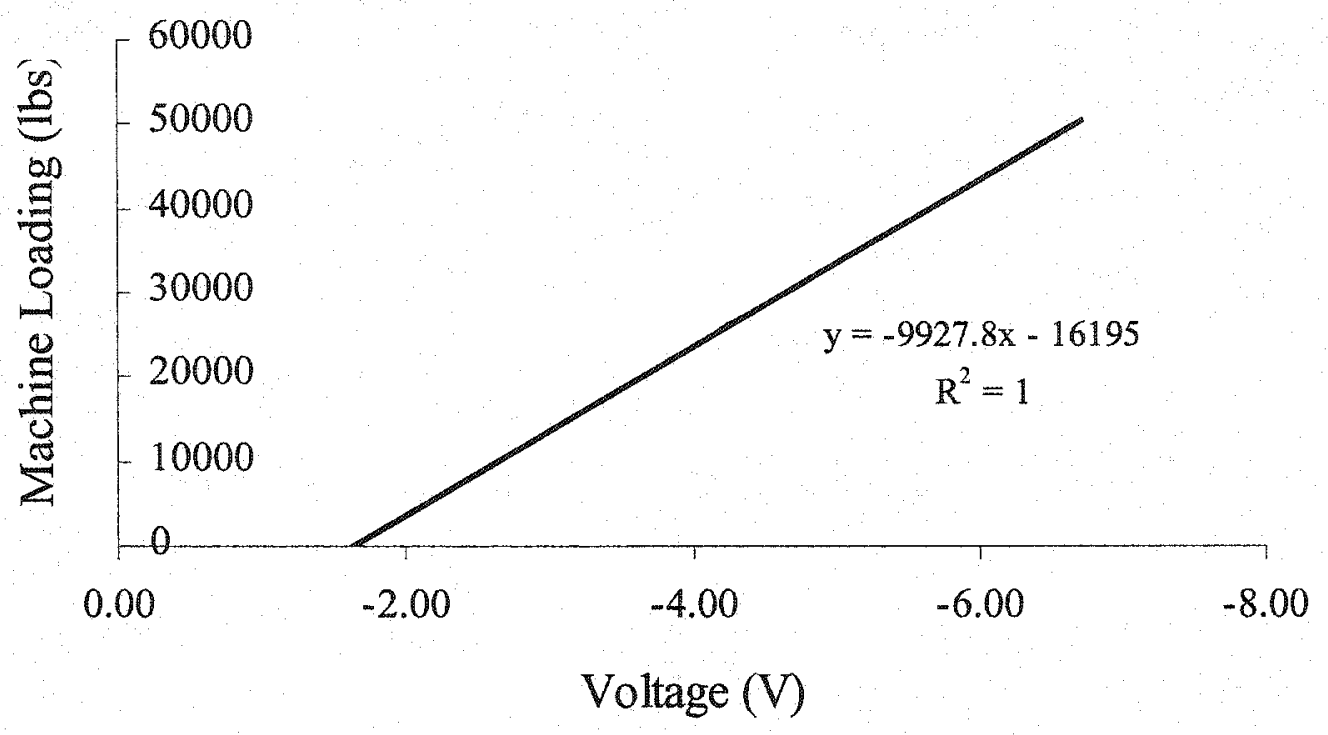

Chart. 3. Load Cell (Right) Force vs. Displacement-Trial 1

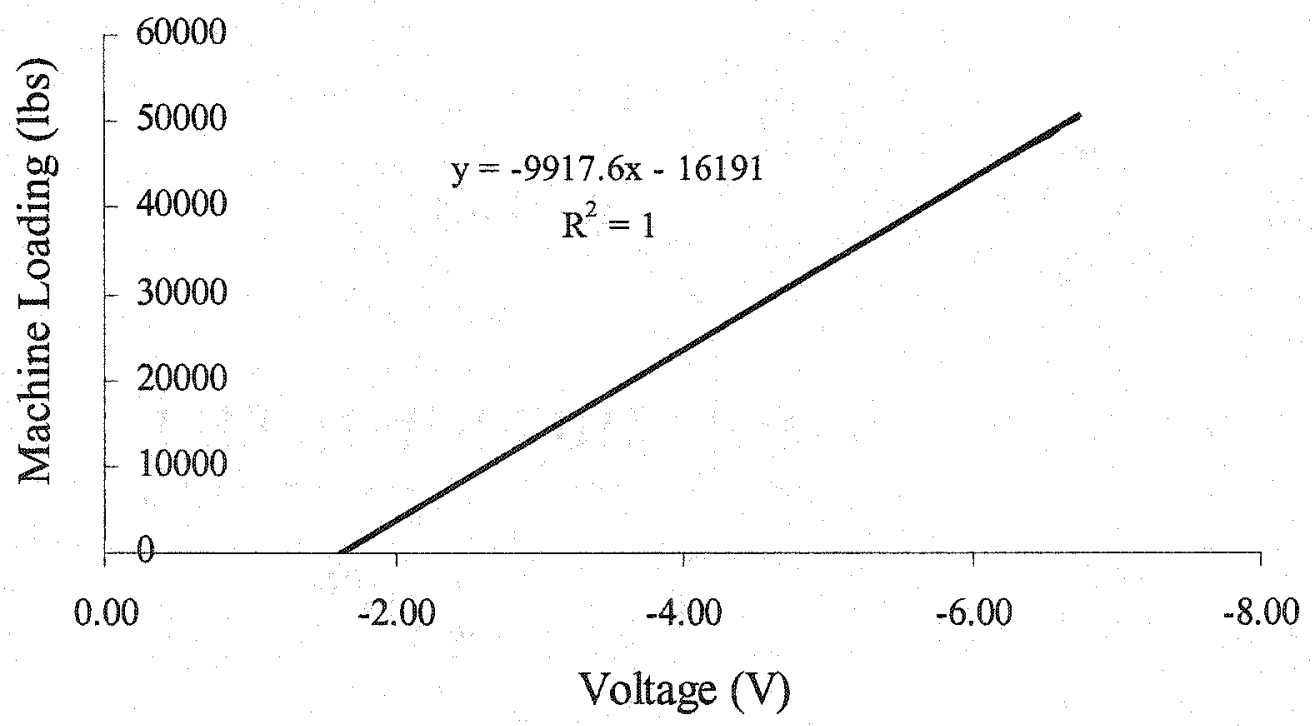

Chart. 4. Load Cell (Right) Force vs. Displacement-Trial 2 


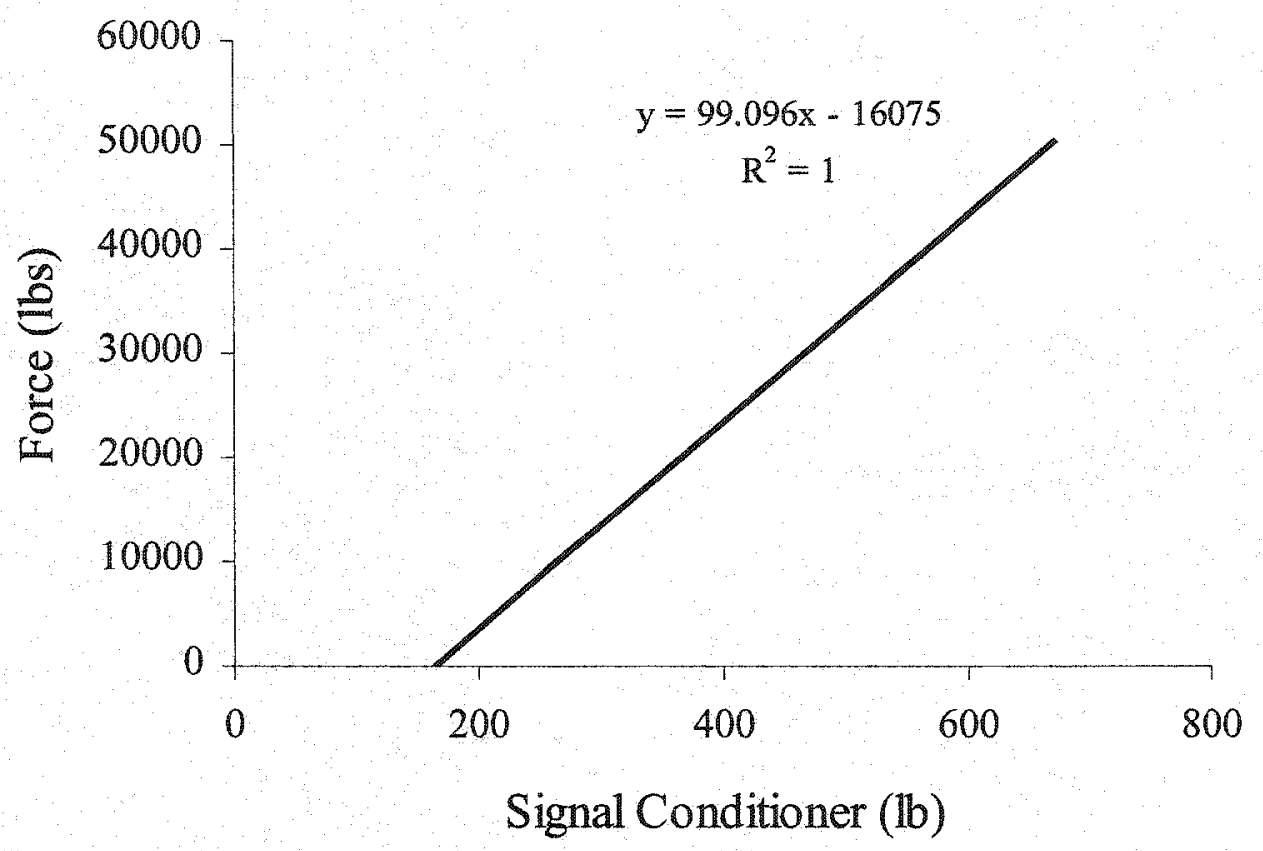

Chart. 5. Load Cell (Right) Signal Conditioner vs. Loading-Trial 1

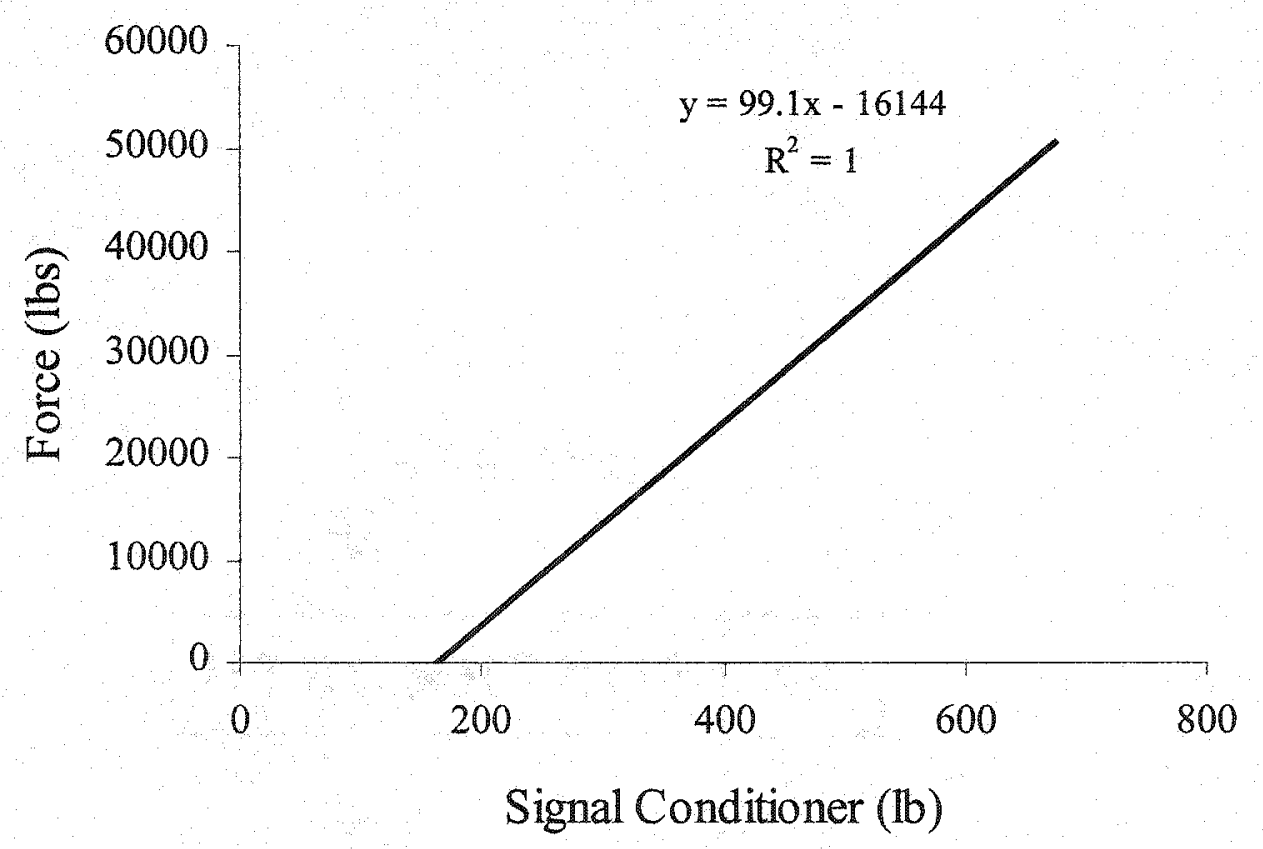

Chart. 6. Load Cell (Right) Signal Conditioner vs. Loading-Trial 2 
LSC2 \& LPC3 Wirepot Calibration

\begin{tabular}{|c|c|c|c|c|c|}
\hline CF (inch/volt) & 1.3406 & 1.3332 & 1.3414 & 2.6752 & 1.3259 \\
\hline Serial No. & B1052679 & C1054469 & B1051980 & C1054518 & C1054470 \\
\hline Data Channel & 2 & 3 & 4 & 5 & 6 \\
\hline No. on wire pot & 4 & 1 & 5 & 3 & 6 \\
\hline Correlation $\left(R^{2}\right)$ & 1 & 0.9974 & 1 & 1 & 1 \\
\hline Distance (in) & \multicolumn{5}{|c|}{ Output Readings (V) } \\
\hline 0 & 1.9765 & 2.5406 & 1.9541 & 1.6550 & 1.3088 \\
\hline 5 & 5.6990 & 6.6110 & 5.6740 & 3.5270 & 5.0710 \\
\hline 10 & 9.4360 & 10.0220 & 9.4090 & 5.3930 & 8.8510 \\
\hline
\end{tabular}

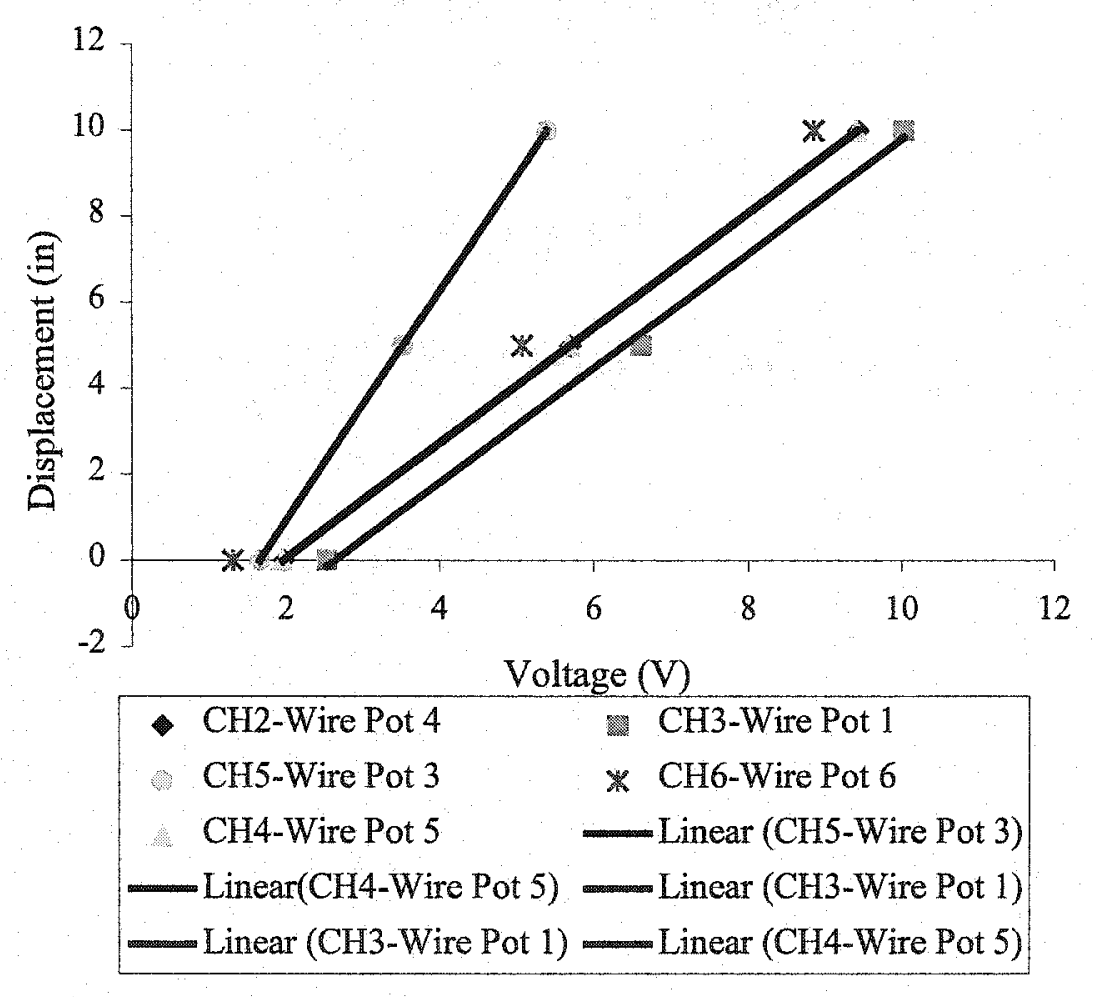

Chart. 7. Calibration Chart for WP, $\mathrm{CH} 2-6$ 


\section{APPENDIX G. \\ SUPPORTING CALCULATIONS}

Supporting Design Calculations:

LSC1: Weld fracture due to Shear

$$
\begin{aligned}
& \phi \mathrm{Rnw}=0.75 \mathrm{te}(0.60)\left(\mathrm{F}_{\text {exx }}\right) \\
& \text { te }=\text { effective throat dimension } \\
& \mathrm{F}_{\text {exx }}=\text { tensile strength of electrode material } \\
& \begin{aligned}
0.75 & =\text { safety factor }
\end{aligned} \\
& \begin{aligned}
\phi \mathrm{Rnw} & =0.75(0.707)\left(5 / 16^{\prime \prime}\right)(0.60)(70 \mathrm{ksi}) \\
& =6.97 \mathrm{kip} / \mathrm{in} \\
& =6.97 \mathrm{kip} / \mathrm{in}(5 \mathrm{in})=34.85 \mathrm{kip}
\end{aligned} \\
& \begin{aligned}
\mathrm{LBV} & =\phi \mathrm{Rnw}=34.85 \mathrm{kip} \quad=155 \mathrm{kN} \\
\mathrm{MEAN} & =\mathrm{Rnw}=46.46 \mathrm{kip} \quad=207 \mathrm{kN} \\
\mathrm{UBV} & =\quad=58.07 \mathrm{kip} \quad=258 \mathrm{kN}
\end{aligned}
\end{aligned}
$$

LSC1: Weld fracture due to eccentrically loaded weld groups

$$
\phi R n=C_{1} D_{-}
$$$$
\mathrm{C}=\text { Coefficient tabulated below includes } \phi=0.75 \text { (function of } \mathrm{a}, \mathrm{k} \text { ) }
$$$$
\mathrm{C}_{1}=\text { Electrode strength coefficient from table 8-37 (1.0 for E70XX Electrodes) }
$$$$
\mathrm{D}=\text { No. of sixteenth-of-an inch in the fillet weld size }
$$$$
\mathrm{L}_{\mathrm{w}}=\text { characteristic length of weld group, in }
$$$$
\mathrm{ex}=\text { horizontal component of eccentricity of } \mathrm{Pu} \text { with respect to centroid of weld }
$$
group, in.

$$
\begin{aligned}
& \phi R n=1.72(1.0)(5)\left(5^{\prime \prime}\right) \\
& \\
& \mathrm{LBV}=\phi \mathrm{Rn}=43 \mathrm{kip} \quad=191 \mathrm{kN} \\
& \mathrm{MEAN}=\mathrm{Rn}=57.33 \mathrm{kip}=255 \mathrm{kN} \\
& \mathrm{UBV}=\quad=71.66 \mathrm{kip}=318 \mathrm{kN}
\end{aligned}
$$

LSC1: Plate Yielding at tapered section 


$$
\begin{aligned}
& \mathrm{Pn}=\text { FyAg } \\
& \text { Fy }=\text { yield stress, assumed } 36 \mathrm{ksi} \\
& \mathrm{Ag}=\text { Gross area } \\
& \begin{aligned}
\mathrm{Pn} & =(36 \mathrm{ksi})\left(1^{\prime \prime} \times 3.5^{\prime \prime}\right) \\
& =126 \mathrm{kip}
\end{aligned} \\
& \mathrm{LBV}=\phi \mathrm{Pn}=113.4 \mathrm{kip}=505 \mathrm{kN} \\
& \mathrm{MEAN}=\mathrm{Pn}=126 \mathrm{kip}=560 \mathrm{kN} \\
& \mathrm{UBV}=\quad=138.6 \mathrm{kip}=614 \mathrm{kN}
\end{aligned}
$$

LSC1: Plate Yielding

$$
\begin{aligned}
& \mathrm{Pn}_{\mathrm{n}}=\mathrm{FyAg} \\
& \mathrm{Pn}=(36 \mathrm{ksi})\left(1 " x 5^{\prime \prime}\right) \\
& =180 \mathrm{kip} \\
& \mathrm{LBV}=\phi \mathrm{Pn}=162 \mathrm{kip} \quad=721 \mathrm{kN} \\
& \mathrm{MEAN}=\mathrm{Pn}=180 \mathrm{kip} \quad=801 \mathrm{kN} \\
& \mathrm{UBV}=\quad=198 \mathrm{kip} \quad=881 \mathrm{kN}
\end{aligned}
$$

LSC1: Angle bending

$$
\begin{aligned}
& \mathrm{My}=\mathrm{Fy}(\mathrm{a}) \\
& \begin{aligned}
\mathrm{a}=\mathrm{y}_{\mathrm{x}}=2.37 \mathrm{in}(\text { for } \mathrm{L} 8 \times 8 \times 1) \\
\mathrm{I}=\text { length of angle }
\end{aligned} \\
& \begin{aligned}
\phi \mathrm{My} & =0.90(36 \mathrm{ksi})(2.37 \mathrm{in})(16 \mathrm{in}) \\
& =1228.61 \mathrm{kip}
\end{aligned} \\
& \begin{aligned}
& \mathrm{LBV}=\phi \mathrm{My}=1228.6 \mathrm{kip}=5465 \mathrm{kN} \\
& \mathrm{MEAN}=\mathrm{My}=1365.1 \mathrm{kip}=6072 \mathrm{kN} \\
& \mathrm{UBV}=\quad=1501.6 \mathrm{kip}=6679 \mathrm{kN}
\end{aligned}
\end{aligned}
$$

LSC1: As-built Strength of Weld fracture due to shear

$$
\phi R n w=0.75 \operatorname{te}(0.60)\left(\mathrm{F}_{\text {exx }}\right)
$$

te $=$ effective throat dimension, actual: 0.411 in 
$\mathrm{F}_{\mathrm{exx}}=$ tensile strength of electrode material

$0.75=$ safety factor

$$
\begin{aligned}
\phi R n w & =0.75(0.707)\left(0.411^{\prime \prime}\right)(0.60)(70 \mathrm{ksi}) \\
& =9.15 \mathrm{kip} / \mathrm{in} \\
& =9.15 \mathrm{kip} / \mathrm{in}(5.692 \mathrm{in})=52.01 \mathrm{kip}
\end{aligned}
$$

$$
\begin{aligned}
& \mathrm{LBV}=\phi \mathrm{Rnw}=52.01 \mathrm{kip} \quad=231.34 \mathrm{kN} \\
& \mathrm{MEAN}=\mathrm{Rnw}=69.34 \mathrm{kip} \quad=308.42 \mathrm{kN} \\
& \mathrm{UBV}=\quad=86.67 \mathrm{kip} \quad=385.51 \mathrm{kN}
\end{aligned}
$$

LSC1: Predicted Model for a designed loading of $207 \mathrm{kN}$

Assumed axially loaded connection of the two-plates

$$
\begin{aligned}
& \Delta=\mathrm{PL} / \mathrm{AE} \\
& \mathrm{P}=\text { load }=207 \mathrm{kN}=46.53 \mathrm{kip} \\
& \mathrm{L}=\text { length }=27+27 \mathrm{in}=54 \mathrm{in} \\
& \mathrm{A}=\text { cross-sectional area of plate }=5 \mathrm{in}^{2} \\
& \mathrm{E}=\text { modulus of Elasticity of steel }=29,000 \mathrm{ksi} \\
& \begin{aligned}
\Delta & =(46.53 \mathrm{kip})(54 \mathrm{in}) /\left(5 \mathrm{in}^{2}\right)(29000 \mathrm{ksi}) \\
& =0.017 \mathrm{in}=0.44 \mathrm{~mm}
\end{aligned}
\end{aligned}
$$

LSC1: Ductility calculation

Ultimate Ductility

$\Delta_{\text {ult }} / \Delta_{\text {yield }}=0.572 \mathrm{in} / 0.43 \mathrm{in}=1.35$

Maximum Ductility

$\Delta_{\max } / \Delta_{\text {yield }}=0.662 \mathrm{in} / 0.43 \mathrm{in}=1.56$

Energy Ductility

$\mathrm{E}_{\text {total }} / 1 / 2 \mathrm{~F}_{\mathrm{y}} \Delta_{\text {yield }}=1.9$ 
LSC2: Weld in tension (Weld fracture at W12 column and 25mm Plate)

Design strength based on tension or compression parallel to axis of weld.

$$
\begin{aligned}
& \phi \mathrm{Rn} \\
& \text { te }=\text { effective throat dimension } \\
& \mathrm{Fy}=\text { yield stress of the base metal } \\
& 0.90=\text { safety factor } \\
& \begin{aligned}
\phi \mathrm{Rn} & =0.90(0.707)\left(5 / 16^{\prime \prime}\right)(36 \mathrm{ksi}) \\
& =7.16 \mathrm{kip} / \mathrm{in} \\
& =7.16 \mathrm{kip} / \mathrm{in}(5 \mathrm{in})
\end{aligned}
\end{aligned}
$$

$$
\begin{array}{rlr}
\mathrm{LBV}=\phi \mathrm{Rn} & =35.8 \mathrm{kip} & =159 \mathrm{kN} \\
\mathrm{MEAN}=\mathrm{Rn} & =39.78 \mathrm{kip} & =177 \mathrm{kN} \\
\mathrm{UBV}= & =43.76 \mathrm{kip} & =195 \mathrm{kN}
\end{array}
$$

LSC2: Weld fracture due to eccentrically loaded weld groups

$$
\begin{aligned}
& \phi \mathrm{Rn}=\mathrm{CC}_{1} \mathrm{Dl} \\
& \phi \mathrm{Rn}=1.72(1.0)(5)\left(5^{9}\right) \\
& \\
& \mathrm{LBV}=\phi \mathrm{Rn}=43 \mathrm{kip} \quad=191 \mathrm{kN} \\
& \mathrm{MEAN}=\mathrm{Rn}=57.33 \mathrm{kip} \quad=255 \mathrm{kN} \\
& \mathrm{UBV}=\quad=71.66 \mathrm{kip} \quad=318 \mathrm{kN}
\end{aligned}
$$

LSC2: Predicted Model for a designed loading of $255 \mathrm{kN}$

Assumed cantilever beam-concentrated load at any point

$\Delta_{\max }=\mathrm{Pb}^{3} / 3 \mathrm{EI}$

$\mathrm{P}=1 \mathrm{load}=255 \mathrm{kN}=57.3 \mathrm{kip}$

$\mathrm{b}=$ longer length dimension $=4$ in

$\mathrm{E}=$ modulus of Elasticity of steel $=29,000 \mathrm{ksi}$

$\mathrm{I}_{\mathrm{y}}=$ moment of inertia about $\mathrm{Y}$-axis $=0.417 \mathrm{in}^{4}$

$$
\Delta_{\max }=(57.3 \mathrm{kip})(4 \mathrm{in})^{3} / 3(29000 \mathrm{ksi})\left(0.417 \mathrm{in}^{4}\right)=0.10 \mathrm{in}=2.57 \mathrm{~mm}
$$


LSC2: Ductility calculation

Ultimate Ductility

$\Delta_{\text {ult }} / \Delta_{\text {yield }}=8.75 \mathrm{~mm} / 4.5 \mathrm{~mm}=2.0$

Maximum Ductility

$\Delta_{\max } / \Delta_{\text {yield }}=10 \mathrm{~mm} / 4.5 \mathrm{~mm}=2.22$

Energy Ductility

$\mathrm{E}_{\text {total }} / 1 / 2 \mathrm{~F}_{\mathrm{y}} \Delta_{\text {yield }}=1352.65 \mathrm{kN}$-mm/ $(0.5 * 142.4 \mathrm{kN} * 4.5)$

LSC2: As-built Strength of weld fracture

Weld fracture due to eccentrically loaded weld groups

$\phi R n=C_{1} D_{w}$

$\phi \mathrm{Rn}=1.72(1.0)(5)(5.04 ")$

$\mathrm{LBV}=\phi \mathrm{Rn} \quad=43.34 \mathrm{kip} \quad=193 \mathrm{kN}$

$\mathrm{MEAN}=\mathrm{Rn}=57.79 \mathrm{kip} \quad=257 \mathrm{kN}$

$\mathrm{UBV}=\quad=72.24 \mathrm{kip}=321 \mathrm{kN}$

LSC2: Predicted twist at $20 \mathrm{kN}$

$\phi=\Sigma(\mathrm{Tz}) /(\mathrm{GJ})$

$\mathrm{T}=$ Torque

$\mathrm{G}=$ Shear Modulus of elasticity of steel $(11200 \mathrm{ksi})$

$\mathrm{J}=$ Torsional constant $=\mathrm{bt}^{3} / 3=\left((5 \mathrm{in})(0.5 \mathrm{in})^{3}\right) / 3=0.21 \mathrm{in}^{4}$

$\mathrm{z}=$ distance of the specimen subjected to torque

$\mathrm{T}=(20 \mathrm{kN})(2.5 \mathrm{in})(25.4 \mathrm{~mm} / 1 \mathrm{in})(1 \mathrm{~m} / 1000 \mathrm{~mm})=11.24 \mathrm{kip}-\mathrm{in}=1.27 \mathrm{kN}-\mathrm{m}$

$\phi=\Sigma(\mathrm{Tz}) /(\mathrm{GJ})=(11.24 \mathrm{kip}$-in $)(4 \mathrm{in}) /(11200 \mathrm{kips} / \mathrm{in} 2)(0.21 \mathrm{in} 4)=0.019 \mathrm{rad}$

LSC2R: As-built strength based on tension or compression parallel to axis of weld.

Weld in tension (Weld fracture at W12 column and 25mm Plate)

$\phi R n=0.90 \mathrm{teFy}$

te $=$ effective throat dimension $=0.354$ in

$\mathrm{Fy}=$ yield stress of the base metal $=41.87 \mathrm{ksi}$

$0.90=$ safety factor 


$$
\begin{aligned}
& \mathrm{L}=5.34 \text { in (actual) } \\
& \phi \mathrm{Rn}=0.90(0.707)\left(0.354^{\prime \prime}\right)(41.87 \mathrm{ksi}) \\
& =9.43 \mathrm{kip} / \mathrm{in} \\
& =9.43 \mathrm{kip} / \mathrm{in}(5.34 \mathrm{in}) \\
& \mathrm{LBV}=\phi \mathrm{Rn} \quad=50.36 \mathrm{kip} \quad=224 \mathrm{kN} \\
& \mathrm{MEAN}=\mathrm{Rn}=55.96 \mathrm{kip} \quad=248 \mathrm{kN} \\
& \mathrm{UBV}=\quad=61.56 \mathrm{kip} \quad=274 \mathrm{kN}
\end{aligned}
$$

LSC2R: Ductility calculation

Ultimate Ductility

$\Delta_{\text {ult }} / \Delta_{\text {yield }}=4.32 \mathrm{~mm} / 4 \mathrm{~mm}=1.1$

Maximum Ductility

$\Delta_{\max } / \Delta_{\text {yield }}=7.1 \mathrm{~mm} / 4 \mathrm{~mm}=1.8$

Energy Ductility

$\mathrm{E}_{\text {total }} / 1 / 2 \mathrm{~F}_{\mathrm{y}} \Delta_{\text {yield }}=879.99 \mathrm{kN}-\mathrm{mm} /(0.5 * 143.90 \mathrm{kN} * 4 \mathrm{~mm})=3.1$

LPC3: Rod Failure, Bolt strength of one-1 in diameter bolt

$$
\begin{aligned}
& \mathrm{Rn}=\phi \mathrm{FuA} \\
& A=0.785 \times\left(d_{b}-(0.9743 / n)\right)^{2} \\
& \mathrm{~d}_{\mathrm{b}}=\text { diameter of bolt, } 1 \text { in } \\
& \mathrm{n}=\text { no of threads within 1in length of bolt, } 3 \text { threads } \\
& A=0.785 \times(1 \text { in }-(0.9743 / 3))^{2} \\
& =0.358 \mathrm{in}^{2} \\
& \mathrm{Rn}=\phi \mathrm{FuA} \\
& =0.75(58 \mathrm{ksi})\left(0.358 \mathrm{in}^{2}\right) \\
& =15.57 \mathrm{kip} \\
& \mathrm{LBV}=\phi \mathrm{Rn} \quad=15.57 \mathrm{kip} \quad=69.3 \mathrm{kN} \\
& \mathrm{MEAN}=\mathrm{Rn}=20.76 \mathrm{kip} \quad=92.3 \mathrm{kN}
\end{aligned}
$$


$\mathrm{UBV}=\quad=25.95 \mathrm{kip} \quad=115.4 \mathrm{kN}$

LPC3: Weld fracture at tube, double fillet 3" weld

Design strength due to shear

$\phi R n w=0.75 \operatorname{te}(0.60)\left(F_{\text {exx }}\right)$

te $=$ effective throat dimension

$\mathrm{F}_{\mathrm{exx}}=$ tensile strength of electrode material

$0.75=$ safety factor

$\phi R n w=0.75(0.707)\left(5 / 16^{\prime \prime}\right)(0.60)(70 \mathrm{ksi})$

$=6.97 \mathrm{kip} / \mathrm{in}$

$=6.97 \mathrm{kip} / \mathrm{in}(3 \mathrm{in} \times 2 \mathrm{sides})=41.82 \mathrm{kip}$

$\mathrm{LBV}=\phi \mathrm{Rnw}=41.82 \mathrm{kip} \quad=186 \mathrm{kN}$

$\mathrm{MEAN}=\mathrm{Rnw}=55.76 \mathrm{kip} \quad=248 \mathrm{kN}$

UBV $=\quad=69.7 \mathrm{kip} \quad=310 \mathrm{kN}$

LPC3: Weld fracture at tube and W12 column, 7" long weld.

Design strength based on tension or compression parallel to axis of weld.

$\phi R n=0.90 \mathrm{teFy}$

te $=$ effective throat dimension $=5 / 16 "$

Fy $=$ yield stress of the weld $=$ assume $36 \mathrm{ksi}$

$0.90=$ safety factor

$$
\begin{aligned}
\phi \mathrm{Rn} & =0.90(0.707)\left(5 / 16^{\prime \prime}\right)(36 \mathrm{ksi}) \\
& =7.16 \mathrm{kip} / \mathrm{in} \\
& =7.16 \mathrm{kip} / \mathrm{in}(7 \mathrm{in})
\end{aligned}
$$

$$
\begin{array}{lll}
\mathrm{LBV}=\phi \mathrm{Rn} & =50.1 \mathrm{kip} & =222.8 \mathrm{kN} \\
\mathrm{MEAN}=\mathrm{Rn} & =55.7 \mathrm{kip} & =248 \mathrm{kN} \\
\mathrm{UBV}= & =61.3 \mathrm{kip} & =273 \mathrm{kN}
\end{array}
$$


LPC3: Weld fracture at column plate, 6-1/2in long welds.

Design strength based on shear stress

$\phi R n w=0.75 \operatorname{te}(0.60)\left(F_{e x x}\right)$

te = effective throat dimension

$\mathrm{F}_{\mathrm{exx}}=$ tensile strength of electrode material

$0.75=$ safety factor

$$
\begin{aligned}
\phi R n w & =0.75(0.707)\left(5 / 16^{\prime \prime}\right)(0.60)(70 \mathrm{ksi}) \\
& =6.97 \mathrm{kip} / \mathrm{in}=6.97 \mathrm{kip} / \mathrm{in}(6.5 \mathrm{in} \times 2 \text { sides })=90.61 \mathrm{kip}
\end{aligned}
$$

$$
\begin{aligned}
& \mathrm{LBV}=\phi \mathrm{Rnw}=90.61 \mathrm{kip} \quad=403 \mathrm{kN} \\
& \mathrm{MEAN}=\mathrm{Rnw}=120.81 \mathrm{kip}=537 \mathrm{kN} \\
& \mathrm{UBV}=\quad=151.01 \mathrm{kip}=671 \mathrm{kN}
\end{aligned}
$$

LPC3: Predicted Model for a designed loading of $248 \mathrm{kN}$

Assumed cantilever beam-concentrated load at any point

$$
\begin{aligned}
& \Delta_{\max }=\mathrm{Pb}^{3} / 3 \mathrm{EI} \\
& \mathrm{P}=\text { load }=248 \mathrm{kN}=55.75 \mathrm{kip} \\
& \mathrm{b}=\text { longer length dimension }=6.68 \mathrm{in} \\
& \mathrm{E}=\text { modulus of Elasticity of steel }(29,000 \mathrm{ksi}) \\
& \mathrm{I}_{\mathrm{y}}=\text { moment of inertia about } \mathrm{Y} \text {-axis }=10.4 \mathrm{in}^{2}
\end{aligned}
$$

$$
\Delta_{\max }=(55.75 \mathrm{kip})(6.68 \mathrm{in})^{3} / 3(29000 \mathrm{ksi})(10.4 \mathrm{in} 4)=0.018 \mathrm{in}=0.47 \mathrm{~mm}
$$

LPC3: As-built strength of weld fracture at tube, double fillet 3" weld

Design strength based on shear stress

$$
\begin{aligned}
& \phi R \text { Rw }=0.75 \text { te }(0.60)\left(F_{\text {exx }}\right) \\
& \text { te }=\text { effective throat dimension }=0.3145 \mathrm{in} \\
& F_{\text {exx }}=\text { tensile strength of electrode material }=70 \\
& \begin{aligned}
0.75 & =\text { safety factor } \\
\phi R n w & =0.75(0.707)\left(0.3145^{\prime \prime}\right)(0.60)(70 \mathrm{ksi}) \\
& =7.00 \mathrm{kip} / \mathrm{in}=7.00 \mathrm{kip} / \mathrm{in}(2.49 \mathrm{in} \times 2 \mathrm{sides})=34.86 \mathrm{kip}
\end{aligned}
\end{aligned}
$$




$$
\begin{aligned}
\mathrm{LBV}=\phi \mathrm{Rnw} & =34.86 \mathrm{kip} & =155 \mathrm{kN} \\
\mathrm{MEAN}=\mathrm{Rnw} & =46.48 \mathrm{kip} & =206.74 \mathrm{kN} \\
\mathrm{UBV}=\quad & =58.1 \mathrm{kip} & =258.4 \mathrm{kN}
\end{aligned}
$$

LPC3: As-built weld fracture strength at tube and W12 column, 7" long weld.

Design strength based on tension or compression parallel to axis of weld.

$$
\begin{aligned}
& \phi R n=0.90 \text { teFy } \\
& \text { te }=\text { effective throat dimension }=0.3145^{\prime}, \\
& \text { Fy }=\text { yield stress of the weld }=53.1 \mathrm{ksi} \text { (coupon test) } \\
& 0.90=\text { safety factor } \\
& 1=6.47 \mathrm{in} \\
& \phi \mathrm{Rn}=0.90(0.707)\left(0.3145^{\prime \prime}\right)(53.1 \mathrm{ksi}) \\
& \quad=10.63 \mathrm{kip} / \mathrm{in} \\
& \quad=10.63 \mathrm{kip} / \mathrm{in}(6.47 \mathrm{in}) \\
& \mathrm{LBV}=\phi \mathrm{Rn}=68.8 \mathrm{kip} \quad=305.8 \mathrm{kN} \\
& \mathrm{MEAN}=\mathrm{Rn}=76.4 \mathrm{kip} \quad=340 \mathrm{kN} \\
& \mathrm{UBV}=\quad=84.1 \mathrm{kip} \quad=374 \mathrm{kN}
\end{aligned}
$$

LPC3: Combined weld fracture at tube and column plate (Forces of $3 \& 7$ in long weld)

$\mathrm{MEAN}=206.74+340 \mathrm{kN}=546.74 \mathrm{kN}=122.88 \mathrm{kip}$

LPC3: Ductility calculation

Ultimate Ductility

$\Delta_{\text {ult }} / \Delta_{\text {yield }}=66.97 \mathrm{~mm} / 5 \mathrm{~mm}=13.39$

Maximum Ductility

$\Delta_{\text {max }} / \Delta_{\text {yield }}=68.88 \mathrm{~mm} / 5 \mathrm{~mm}=13.77$

Energy Ductility

$\mathrm{E}_{\text {total }} / 1 / 2 \mathrm{~F}_{\mathrm{y}} \Delta_{\text {yield }}=18289 \mathrm{kN}-\mathrm{mm} /(0.5 * 177.53 \mathrm{kN} * 5 \mathrm{~mm})=41.21$ 